\title{
Towards Spectacular Nationality: \\ Media Production of Korean Nationality through the 2002 World Cup
}

By Sun-ha Hong

A thesis submitted to the Victoria University of Wellington in fulfilment of the requirements for the degree of Master of Arts in Media Studies

Victoria University of Wellington 
This paper explores the role of the media in the production of Korean nationality during the 2002 World Cup. It suggests that the media coverage helped organise a spectacle of consumption, which became the primary means by which Korean nationality was articulated and understood. This study brings together research in media and Korean studies and aims to contribute to a timely understanding of nationality that recognises both its intimate connection with media and consumer culture and its normative and taxonomic function.

The study elaborates a hybrid theoretical framework of a 'system of signs', which draws from Michel Foucault's analysis of power and normalisation and the ideas of spectacle and simulacrum by Guy Debord and Jean Baudrillard. The study examines two key cases of nationality production. Firstly, the 'Red Devils' and millions of street supporters that celebrated Korean victories were appropriated by the media to produce internally oriented affirmations of Korean identity and values that doubled as an entertainment spectacle. Secondly, the cult of admiration around the foreign manager Hiddink demonstrated how discourses of globalisation contribute to a social imaginary of global nationalities that compelled Koreans to judge their own nationality against the standards of the sŏnjin'guk ('advanced nations').

Keywords: spectacle, nationality, sport, normativity 


\section{Contents}

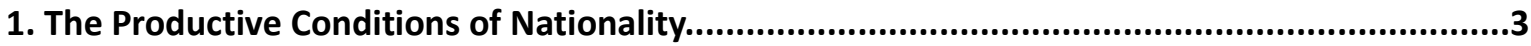

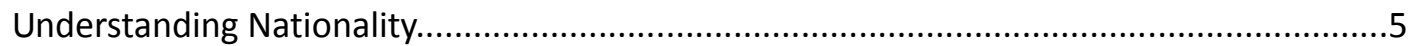

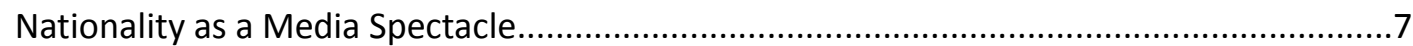

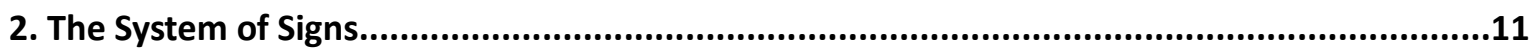

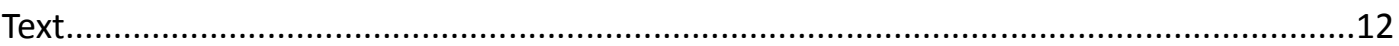

Discourse

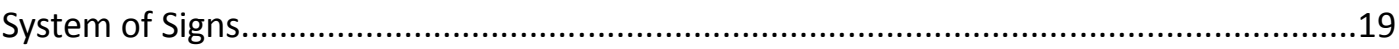

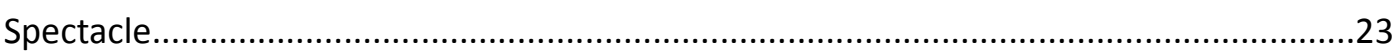

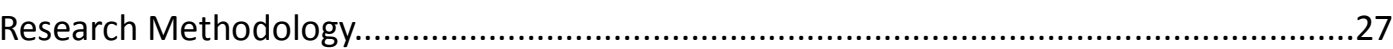

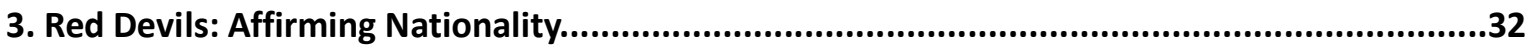

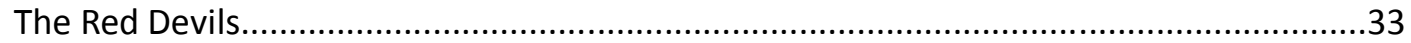

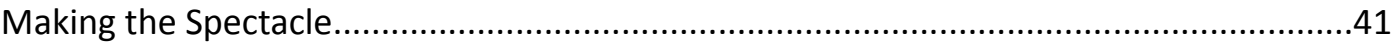

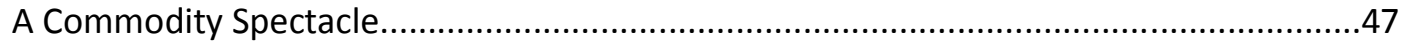

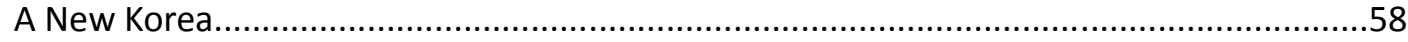

4. The Global: Nationality and the Double-Sided Gaze...............................................................67

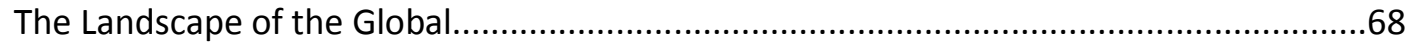

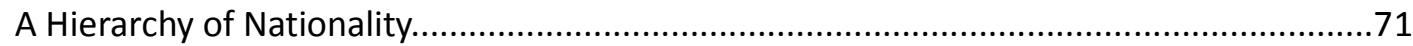

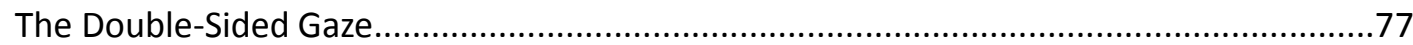

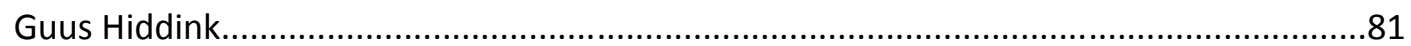

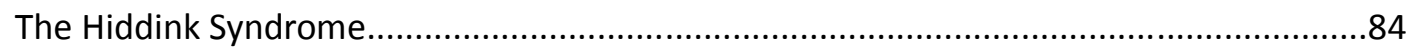

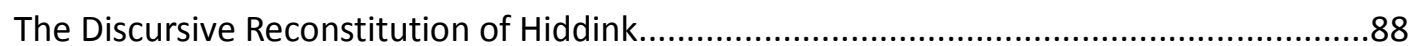

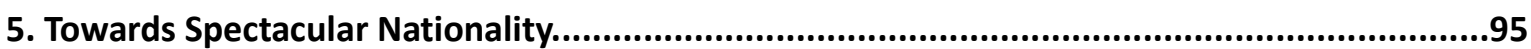

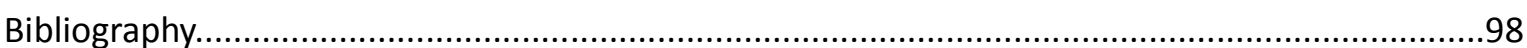




\section{The Productive Conditions of Nationality}

On the 2nd of July, 2002, over one hundred and fifty thousand Koreans took to the streets in celebration. The 2002 World Cup, jointly hosted by South Korea and Japan, had just concluded. The unprecedented success of the Korean football team in the tournament, as well as the remarkable level of enthusiasm demonstrated by the public, had helped create a general impression of a highly successful tournament. In response, the Korean government had declared a one-off public holiday, and its World Cup and football bodies had hosted nationwide festivities to celebrate the successful hosting of the mega-event. In an unusual maneuver, the three major Korean broadcasters, both publicly and privately owned, collaborated to offer joint coverage of the parades and shows around the country. It was the final hurrah of a pervasive environment of national celebration that had dominated the public sphere for at least the past month.

The participants of this festival were densely packed into a crowded mob. An overwhelming number sported 'Be the Reds' t-shirts, a football supporter's kit that had quickly become a visual signifier of Korean nationality. Many had turned up hours earlier to guarantee a good view of the proceedings, but it was implicitly recognised that the 'ideal' way to experience this festival was not so much to watch the various celebrations as to simply be present, to declare one's passionate attachment to Korean nationality, and witness its collective manifestation through the crowd. Such an attitude had been cultivated through a newly emergent practice of 'street support', where millions of Koreans had formed crowds such as this one to watch and celebrate the seven football matches played by the Korean team during the World Cup. Emboldened by the media's active endorsement of street support as a patriotic activity and an evolution of Korean nationality, many had come to understand their participation in such celebrations as a productive activity that would contribute to a positive transformation of themselves as Koreans and the nation as a whole. The cheering mass of red on the 2 nd of July was the visible manifestation of powerful discourses of national pride and transformation, discourses that had owed much of their pervasiveness and influence to the media.

Throughout the day, this crowd was treated to a series of shows and performances that both entertained them and contributed to this national feeling. Flanked by traditional Korean sculptures, the Korean football team emerged in suits to greet the crowd and kick signed balls already placed at their feet. An orderly procession of selected supporters laid elaborate wreaths on the players, 
who were then guided into decorated open cars and paraded through the waiting crowd. At the same time, crowds elsewhere were entertained by musical and dance performances, split between the most popular pop artists of the day and performing troupes for traditional Korean song and dance. When the parade reached the kwanghwamun, a gate with an iconic status as a symbol of Korean history and culture, they were announced by a series of traditional Korean artistic performances and several giant Korean flags. As day passed into night, Kim Dae-Jung, the president of Korea, made an appearance to present each player with a medal and badge of honour, and give a short speech on the positive impact the World Cup would have on Korea's 'national development'. Finally, all the guests of the day took to the stage amidst fireworks and chants of tae-han-min-guk ${ }^{1}$ : the President, the players in their suits, the traditional performers with their colourful traditional dress and instruments, the pop artists in their revealing outfits. Every stage of the day-long festival was designed to combine the appeal of the festival as an entertaining spectacle with the discourses and symbols of national pride and transformation. The experience of the festival as a whole was in the form of an environment of spectacle, wherein the visual signifiers of Korean nationality and discourses of national celebration were presented and consumed through familiar commodities of celebrity exposure, concerts and, for those watching from home, media texts.

Yet this government-sponsored festival was not the apex of public enthusiasm and national celebration during this period; rather, it was an echo of a month-long festival during the World Cup, which had occurred nearly entirely without state intervention. The number of participants and the level of public enthusiasm on the $2^{\text {nd }}$ of July, while substantial, paled in comparison to the millions of frenzied 'street supporters' that had dominated the headlines during the World Cup. In fact, during the tournament itself, government-sponsored events and festivals had been consistently ignored by the public in favour of street supporting, 'spontaneous' gatherings encouraged by the media. ${ }^{2}$ It was through the allure of an impressive array of high profile pop stars and the Korean football team that the $2^{\text {nd }}$ of July festival became attractive. Far from taking a leading role in using this mega-event to focus on and promote Korean nationality, as it had intended before the tournament ${ }^{3}$, the government was relegated to a position where they had to do their best to align themselves with newly emerging practices of national celebration and discourses of nationality. The kungmindaech'ukche ('big national festival'), as it was called, had shown that it was the media who took on this leading role. The operations of the Korean media

\footnotetext{
${ }^{1}$ Literally translating to "The Great Nation of Korean Peoples", it is the full and official name of South Korea, though a shortened version ('han'guk') is often used. The use of the term in the chant signified, generally speaking, an empowering proclamation of national glory and patriotism.

${ }^{2}$ G. H. Joo (2002) p182

${ }^{3}$ Y. G. Ha (2002) p3, 47 and J. Horne \& W. Manzenreiter (2002) pp11-13
} 
during the 2002 World Cup were central to the outburst of positive and all-encompassing discourses of Korean nationality that has since come to define the event for Koreans. Looking back at this event, we can identify an important characteristic of nationality in contemporary society: its subjection, to a lesser or greater extent, to the laws and logics of the commodity spectacle.

The festival of the $2^{\text {nd }}$ of July and the events surrounding the 2002 World Cup illustrate the emergence of a new set of conditions for the production of nationality in recent years. This is closely tied to the advent of globalisation, widely recognised as one of the leading transformative factors in contemporary society. The rapid increase in the mobility of peoples, media, technology, money and ideas ${ }^{4}$ across national and geographical boundaries has now reached a point where much of the world lives with a persistent awareness of global flows. As a corollary, however, uncertainty now dominates attempts to understand the meaning of nationality, and its functions and forms of operation in the contemporary world. ${ }^{5}$ It is now generally accepted that globalisation will not mean the end of the nation-state, but the exact parameters of its ongoing development are far from clear. This thesis considers the logics that now drive the production and operation of nationality, and to some extent determine its form and effect. The purpose of such an inquiry is to understand not so much manifestations of nationality, but how they are being produced - if nationality is changing, what is happening to the ways in which it is produced? Understanding nationality at its operative roots is key to realising the roles it can and should play for globalising societies. Through a case study of Korean media coverage during the 2002 World Cup, this thesis will analyse the terms and conditions that dictate the discursive production of contemporary nationality through the media.

\section{Understanding Nationality}

What exactly is meant by 'nationality'? To think of a nation, and to identify things and people with a nation, does not just involve the geographical or administrative demarcation of a particular set of objects, but a constellation of ideas, symbols, norms and truths. Collectively held understandings of nationalities draw from a huge variety of sources, from the collective memory of historical events, such as the Korean recollection of Japanese rule, to aesthetic and ideological archetypes such as 'football-loving Brazilians' and 'short and hot-tempered Italians'. In other words, a nationality is a collective imaginary of characteristics that is continually shaped and

\footnotetext{
${ }^{4}$ A. Appadurai (2006) p589, J. Xavier Inda \& R. Rosaldo (2008) pp4-5.

${ }^{5}$ See: M. Sasaki (2006) p272
} 
reshaped through discourse.

Nationality implies a pervasive system of symbolic attribution - a rather different mode of conceptualisation from oft-used terms such as nationalism and national identity. ${ }^{6}$ The former carries political connotations, particularly reactionary ones, while the latter is often used in a more specific manner regarding the identities of individuals and groups in relation to a nation.

Nationality is a broader term that recognises specific ideas such as national history, identity and pride as part of a constellation of signifiers and discourses. This concept allows an investigation into the productive processes of nationality as a whole.

Nationality continues to be an extremely prominent and deep-seated force: it still constitutes a key area on which the social subjectivity of individuals is founded. This thesis considers two key functions that nationality performs in contemporary society. Firstly, nationality provides a taxonomic system by which categories and classifications can be made: it is a generally identifiable grid by which various elements can be sorted, defined and associated. ${ }^{7}$ Secondly, nationality is a site that conditions the production and dissemination of templates of normativity ${ }^{8}$, by which the Self and the Other can be identified. These functions can be understood through the deployment of Michel Foucault's model of power relations. This enables an understanding of nationality's productive role in formulating regimes of truths and norms, its disciplinary aspect in training citizens that internalise those regimes, and the crucial role discourse plays in enacting these power relations.

These core characteristics have long been a feature of modern (post-Westphalian) nationality, and the phenomenon of globalisation has not fundamentally altered them. The change globalisation has precipitated lies in the ways in which nationality is now produced. Specifically, I suggest that as "our daily lives become more and more interwoven with, and penetrated by, influences and experiences that have their origins far away" ${ }^{\prime \prime}$, the media has become the primary site for the production of nationality. Individuals, especially in the developed world, are now connected to a bewildering number of nationalities - in the form of peoples, ideas, consumer products, institutions and so forth - despite the fact that they may have no personal experience of them. In such a context, many people now operate through a combination of personal understandings of a few nationalities, and mediated impressions of a larger variety of nationalities. The media provide anecdotes, symbolic signifiers, statistics, 'expert' opinions and other elements that purport to

\footnotetext{
${ }^{6}$ H. J. Lee \& Y. H. Cho (2009) pp2-3

${ }^{7}$ A similar definition is made in R. Giulianotti (1999) p32 regarding nationality in sport.

${ }^{8}$ See: M. Foucault (1975 [1979]) pp178-180, M. Foucault (1973, 1974 [2006]) pp53-4

${ }^{9}$ A. Tomlinson in M. Sasaki (2006) p279. Also see: A. Giddens in J. Xavier Inda \& R. Rosaldo (2006) p11.
} 
offer a more 'complete' picture of the scenes and contexts in which 'the national' is played out. In short, we inevitably rely on the media to aid in understanding that which is too big for us to see for ourselves: taking Anderson's idea of the imagined nation to its extreme, the landscape of nationalities has become Baudrillard's simulacrum, a collectively imagined and mediated sphere where media images seem more real and identifiable than reality itself. ${ }^{10}$ Even as nationality retains a 'sacred' allure, the media claims an ever greater hold on the conditions of its production.

\section{Nationality as a Media Spectacle}

If the media is now the central site for the discursive production of contemporary nationality, it stands to reason that the characteristics of media industries and media production will have a significant impact on the type of nationalities that are produced. One of the key consequences of this relationship between media and nationality is that we are now witnessing the production of spectacular nationality, or nationality that is structured and presented as an entertaining and commodified spectacle.

This thesis conceptualises the spectacle as a pervasive environment of consumption in contemporary society, appropriating Guy Debord's works on the society of the spectacle and Jean Baudrillard's analysis of the image and simulacra in post-industrial societies. The spectacle is thus understood as "not a collection of images... [but] a social relationship between peoples that is mediated by images". ${ }^{11}$ In other words, the spectacle is not to be defined by the images and commodities that constitute its material manifestations: it must be understood as a pervasive and totalising logic that privileges exchange value and seeks to extend the processes of commodification onto every arena of social activity, in turn establishing consumption of the image as the primary form of social existence. ${ }^{12}$ The logic of the spectacle reorganises and appropriates its subject material for the purposes of formulating aestheticised and fetishistic commodities. More generally, such processes are part of totalising structures wherein commodification and consumption of all things becomes rationalised and naturalised. It is by now well documented that the media have played a key role in the development of the spectacle, and that the commodity logic of the latter governs the production of the former. ${ }^{13}$ Therefore, it must be recognised that as nationality has become more and more intertwined with the media, it has become more and

\footnotetext{
10 J. Baudrillard (2001) pp148-9, p169-170, p179 and B. Anderson (1991) pp5-7.

${ }^{11}$ G. Debord (1994) p12

${ }^{12}$ G. Debord (1994) pp35-7, p46 and G. Debord (1988 [1990]) p9

${ }^{13}$ G. Debord (1994) p12 and D. Kellner (2003) pp1-2
} 
more spectacular. We can now trace the outward manifestations of nationality in media discourse - be it articulations of stereotypes, or the framing of events through a national narrative - to a commodifying and spectacular logic. "Images chosen and constructed by someone else have everywhere become the individual's principal connection to the world he formerly observed for himself ${ }^{\prime 14}$; it is the mediated image of nationality that now performs the social functions of nationality. At the same time, the productive conditions of such an image demand that it perform the functions of a spectacular commodity, bringing together the spectacle and nationality in a single manifestation.

At this point we return to the events of the $2^{\text {nd }}$ of July, and the Korean media coverage of the 2002 World Cup as a whole. As discussed above, the 'big national festival' on that day was not the crown jewel of a government-led, official celebration of Korea through the tournament, but an imitative echo of the media-led, spectacular festivals of consumption that the government sought to appropriate for its own purposes. Involving millions of 'street supporters', corporate advertisements and proclamations of national transformation, the 2002 World Cup was the site of a highly focused and explicit form of spectacular nationality that rearticulated 'Korea' through media discourse. This thesis will use the media production of Korean nationality during the 2002 World Cup as a case study in order to investigate the operation of spectacular nationality.

Such a case study follows on from a long-held recognition of sport's significance as a cultural field in which a great deal of political and national interests is invested. ${ }^{15}$ The World Cup, as one of the most important contemporary global events, puts the relationship between sport and nationality into even sharper relief: it is an arena where discourses of nationality, and the mechanisms of nationality production, are unusually explicit and prominent. National teams continue to be seen as a microcosm of their nation, and the World Cup a proving ground for nationalities. ${ }^{16}$ Sport has also developed an extremely close relationship with the media, to the extent that the logic of the spectacle has directly influenced the rules by which sport is played, kinds of socio-cultural functions it has taken on, and the financial infrastructure that supports the field. ${ }^{17}$ In particular, Korea in 2002 presents a unique mix of a highly developed and sophisticated media industry, and a social climate in which unusually explicit forms of social engineering and ideological discourse became acceptable when regarding the question of nationality.

To this end, this thesis takes the media discourses of nationality as its primary object of study. As

\footnotetext{
${ }^{14}$ G. Debord (1988 [1990]) p27

${ }^{15}$ T. Schirato (2009) pp112-5

${ }^{16}$ M. Roche (2000) p6, S. Perera (2001) p521

${ }^{17}$ See: T. Schirato (2009) pp89-90, G. Crawford (2004) p81, J. Horne (2006) p42,
} 
Foucault asserted, power is always at its most explicit, and most vulnerable, when it is enacted and brought into being: the use of discourse in media texts is the point at which the underlying logic of the spectacle is made manifest. ${ }^{18}$ The examination of discourse enables an analysis of nationality that does not concentrate on the current meaning of nationality, but rather how this meaning is continuously produced and reproduced. For this purpose, this thesis will undertake a case study of the Korean media coverage during the 2002 World Cup. The 2002 World Cup was an event that brought forth a highly explicit, deliberate and focused form of nationalistic discourse: it greatly exceeded the boundaries of its status as a sporting event, and became a site in which the media articulated what Korean nationality was and what it should strive to become. Furthermore, members of the Korean media simultaneously, and through the same discourse and texts, produced spectacular narratives and signifiers in order to capitalise on the commodity potential of the event. ${ }^{19}$ The media discourse involved a "simultaneous production of a communal identity and/as a commodity", wherein Korean nationality was "simultaneously both inalienable culture and a commodity" ${ }^{20}$ and thus demonstrated the relationship between media, spectacle and contemporary nationality. This thesis analyses print and broadcast media in Korea between May and July 2002, and the media's role as a productive mechanism of spectacular nationality.

Chapter 2, 'The System of Signs', will introduce the theoretical framework of such an analysis. I use the model of the 'system of signs' to chart the process by which discourse manifests, challenges and reconsolidates relations of power through the medium of texts, producing sets of signs that are meaningful not only in their own signification, but through their relative positioning to other signs and the system as a whole. The systems of signs, of which nationality is but one, then present a normative taxonomy which subjectivises its audience to the same rules that constitute its own being. This general model of media power and discourse is then integrated with an adaptation of Guy Debord's theories of the spectacle. This framework will then be applied to two specific media phenomena during the 2002 World Cup. Chapter 3 will examine the 'Red Devils' and the phenomenon of 'street support', which saw millions of Koreans take to the streets in a collective experience of spectatorship and solidarity. This was discursively produced as not only a defining image of the mega-event, but a means by which Korean nationality could be positively redefined, validated, and inculcated. Chapter 4 will investigate the extraordinary level of idolisation of the Korean national team manager, Guus Hiddink. The specific characteristics of this 'Hiddink Syndrome' were symptomatic of a discursive relationship between Korean nationality and other, 'global' nationalities; this relationship was in turn demonstrative of the crucial role that the

\footnotetext{
${ }^{18}$ See: M. Foucault (1976 [1988]) p101, M. Foucault (1972 [1980]) p119.

${ }^{19}$ See: J. Horne \& W. Manzenreiter (2004) pp194-5, "consumer nationalism".

${ }^{20}$ T. Schirato (2007) p2
} 
the Other plays in the shaping of Korean nationality, whose subjects are made to adopt a 'doublesided gaze' that constantly refers back to its own imaginary of the Other. Taken together, the two phenomena provide an understanding of the discursive conditions under which Korean nationality was produced at the time, and the forms through which the logic of the spectacle influenced the process. The case studies suggest the means by which an understanding of contemporary nationality can recognise the role of a spectacular and commoditised media industry in the age of globalisation. 


\section{The System of Signs}

The nature of the question posed in this thesis demands perspectives that do not sit easily within either traditional investigations of national identity, or debates regarding globalisation. These approaches often focus on the interaction between nationality and another object, such as national subjects or global influences, rather than the mechanisms that characterise and constitute manifestations of nationality. An examination of nationality's influences and interactions is necessarily predicated on the idea of a nationality as an identifiable and stable referent, and leads to assumptions about its unity. On the other hand, rethinking nationality as a spectacular affair requires a critical analysis of its mechanical operations, such as the way it produces a sense of the sacred and solidarity. It also means that nationality should not be considered in an abstracted, 'ideal' form, or in terms of decline or distortion in the face of globalisation. In short, nationality needs to be analysed as a series of discursive regimes, sites and practices oriented towards an interpellative ideal.

To this end, this thesis conceptualises nationality as a 'system of signs', best understood as an architectural constellation of signifiers that are produced through discourse, and operate to establish taxonomies of knowledge/truths that create social norms and subjects. This concept models the process where elements in media text invoke and mobilise discourses; these discourses have a productive and significative function, and in turn, formulate generalised systems of ideas and beliefs. It is a necessary demarcation of what is in reality a fluid and overlapping process of signification and meaning-making. Within such a framework, discourse is identified as the primary object of analysis where the ideas, signs and value systems that constitute nationality are produced. This means nationality can be understood not in terms of how 'real' or artificial it is, or why it might have occurred, but in terms of how it is working and what it is producing. This approach involves an adaptation of Michel Foucault's models of power in the context of contemporary media, wherein power is recognised as an impersonal and compelling force, and discourse a key mechanism by which power is enacted. This theoretical basis is supplemented by the theories of the spectacle. Adapted from Guy Debord's notion of the 'society of the spectacle', and integrating Jean Baudrillard's discussions of signification and simulation, the spectacle is here understood as a 'general logic' that pervades the productive processes of the system of signs. Nationality is not analysed as a self-contained and inherent aspect that is then imposed on fields and texts to varying degrees of fidelity, but inversely, as a product of these discursive manifestations. 
The primary objective of this model is to identify not so much the visual artefacts of texts or their eventual social consequence, but the processes and the mechanisms of textual production as a means of naturalising and deploying meanings. The specific content of Korean World Cup coverage, or the resulting ideas of Korean nationality, matter only insofar as they illuminate the patterns and techniques that are employed in the process. Ultimately, this perspective will enable an analysis of the normalising and subjectivising forces that are the gears and cogs of the visible phenomena of nationality.

$\underline{\text { Text }}$

The integrity of the text and the author is a concept that has long been problematised. Since Roland Barthes wrote of the 'death of the author', theories of media audiences and fandom, especially in the internet age, have coined terms such as 'prosumers' and 'active audiences' to explain the ways in which the meaning of a text is increasingly determined by the audience and the contexts of production, as much as the intention of the creator. Yet true to the original point of Barthes' argument, the death of the author does not mean the dissolution of the text: in the relocation of meaning-making from the author to the process of communication itself, the 'realness' of the text becomes ever more important. The text, as a static, material artefact with visibly identifiable components, serves as a site for meaning-making and a common referent. Moreover, the mass media text, with its wide distribution network and high production values, still possesses a strong sense of legitimacy that sets it apart as a focal point for publicly influential discourse. The newspaper article, the television show, and prime time news - they are sites where the implicit workings of power are articulated and made possible. ${ }^{21}$ The text is where knowledge and power, or in fact knowledge as defined and shaped by power, ${ }^{22}$ is both visible and brought into being.

The media text is therefore a site of the communication and production of knowledge. It is where things, whether a singular object (a person, an image, a word) or a composite element (a relationship, a structure, a format), are made into or renegotiated as signs in a way that imbues them with meaning. Of course, rarely, if ever, are things merely 'things' without any form of signification; it is the status, meaning and position of a thing in the symbolic order that determines the terms of its social existence. The text is a place for producing and reifying signs whose origins are never quite as certain as their current manifestation, and they come together to form a

\footnotetext{
${ }^{21}$ M. Foucault (1988 [1976]), pp92-3

${ }^{22}$ ibid., p119
} 
general landscape of signification.

During the 2002 World Cup, the Korean media performed this function actively and deliberately, flooding the country with textual content that was remarkable in its variety, quantity, intensity and prominence. Newspapers used serial features to build up anticipation before the event, ${ }^{23}$ and when the tournament began, they raised the bar by allowing every section of the publications to be dominated by World Cup stories, from sport and lifestyle to politics. The three major broadcasters were just as enthusiastic, dedicating a staggering 34 per cent of their schedule to World Cup content during the tournament. ${ }^{24}$ On days of Korean victories, prime time news programs opened with dramatic announcements of triumph, pushing all non-World Cup news aside to the last ten minutes. Each of these media texts communicated ideas, impressions and perspectives about the World Cup, Korean performance as a host and football team in the tournament, and Korean nationality as a whole. Moreover, these ideas were not simply pushed out as disparate, fractured pieces, but came together to form the aforementioned pattern of signification. There was a significant level of coordination and planning behind the World Cup coverage: broadcasters convened with each other and the government to formulate general strategies towards promoting Korean nationality, and individually moved to educate staff in football journalism and invest in overseas correspondents. ${ }^{25}$ By no means was there a singular and centralised will driving the coverage, but narratives, ideas and impressions across texts complemented each other and were consumed with regard to each other. Indeed, the stories in print and broadcast media at the time tended to have strong similarities across genres and publishers. ${ }^{26}$ When a celebrity program tracked down a Korean footballer at home and depicted him as an innocent, hard-working hero, that act of signification was consumed in relation to a pundit's commentary on his performance during a World Cup match or a newspaper column's discussions about Korean mentality in general. I suggest that the flood of Korean media coverage during the 2002 World Cup can be considered an amalgam of independent, but connected and complementary media texts whose singular and composite elements are produced as signs and imbued with meaning. These elements consist of the objects, structures, narratives and contexts of any given media text.

\footnotetext{
${ }^{23}$ The Chosun-Illbo ran its 'gŭllobŏl etiket sidae' (The Global Etiquette Age) series from 9 December 1998 to 31 May 2002, where they identified areas in which Korean citizens needed to improve their manners. The Donga-llbo ran serial features ' $t$ 'aegukjŏnsa' (Taeguk Warrior) and '12pŏntchae sŏnsuga ttwinda' (The $12^{\text {th }}$ Player Runs) in April and May 2002, profiling the players in the Korean national team and the supporter cultures of other participating nations, respectively.

${ }^{24}$ Y. G. Ha (2002), p75, 89, 90

${ }^{25}$ ibid., pp63-4

${ }^{26}$ C. M. Kang (2006), p247.
} 
Objects are verbal or visual units that act as conduits for the association and production of impressions and emotions. In the case of Korea this could be the case with the colour red, both as one of the national colours and a symbol of the communist threat; reference to a shared memory, such as the military dictatorships between the 1950's and 1980's; the particular choice of language or accent; or the similarities to traditional Korean art in advertisement graphics. These objects are all iconic to varying extents, in that they are the most explicit and obvious form of meaning production. Crucially, objects are not units of self-contained meaning that are simply selected and arranged in texts, but fluid vessels that are able to be mobilised for a wide variety of possible significations, depending on the context and method of their representation. The media coverage of the 2002 World Cup showed how reports of the Red Devils and other supporters helped detach the colour red of its pre-existing connotations of communism and the word devil from its strong ties to Christianity. These objects were unmoored from their original contexts and reinvested into the symbolic order with new meanings and connotations, becoming symbols of a new generation of modern, democratic, individualistic and expressive Koreans. In this way, every appearance of an object in media text involves a redefining of its symbolic connotations, whether it reinforces existing meanings, subverts them or creates new ones.

Narratives articulate and establish relationships between objects. They are often chronological, but not always so. Narratives therefore have the potential to position object-signs in relation to one another, producing associations, perspectives and familiarities. This positioning often involves variations of general types, which van Dijk calls 'scripts' and 'models': templates of syntax, situations and relationships that can be adapted to specific events and stories to produce narratives that we are familiar with and understand in particular, pre-set ways. ${ }^{27}$ The Korean media appeared to rely on such templates frequently during the World Cup period in order to deal with the journalistic challenges presented by the event. For instance, the introduction of the large number of participating countries was handled by employing familiar and generalised narratives, involving the reduction of specific nationalities into easily identifiable caricatures. The success of the Senegalese team was fitted into a familiar narrative of underdog triumphs, not strongly differentiated from coverage of other over-performing nations, or even from similar templates in fictional texts. This script also mobilised their French opponents into the role of the Goliath, completing the retelling of a familiar narrative in terms of real events. Narratives in Korean media texts were crucial for understanding the ways in which particular ideas or objects are positioned in relation to certain regimes of truth and normativity.

Structures of the medium or genre as a whole can also be distinguished from structures of specific

${ }^{27}$ T. van Dijk (1988) pp21-2 
narratives. These range from the ways in which close-ups are used to stitch together mininarratives in sport coverage, to the organisation of daily newspapers into sections that predispose certain types of stories each day. These structures themselves are imposed on the text through discourse that signals their appearance. Print news media, for instance, has developed its own syntax for headlines that immediately identify the text and position the reader: in English, the inverted declarative sentence structure is very frequently used to privilege the event or claim at hand over the veracity or source of that claim. ${ }^{28}$ While the Korean media makes use of similar techniques, a more pervasive convention is the use of compact, stylised 'slogans' that often employ poetic and/or conversational language. A Korean story about the Italian anger at the refereeing of a World Cup match was titled "sŭngri dodukmatatda' dŭlkkŭlnŭn italia" ('We've been robbed'... rages Italy), while an article on fashion during the World Cup ran under the headline "kaesŏngmanjŏm' wŏldŭk'ŏp paeshŏn" ('Full marks for individuality' - World Cup fashion). In both cases, the compact slogans set the tone and perspective of the story using strong and direct language. Meanwhile, in television, the generic conventions governing program intros fulfil this role, such as the fast-paced, distinct visual style of sports program intros pioneered by Roone Arledge in his programs like Monday Night Football. Like narratives, it is their function to position objects in relation to each other and derive meaning from the constellation of objectsigns as a whole.

Finally, it is necessary to consider the context within which each text is produced. In other words, media texts invoke existing structural, symbolic and narrative elements from different texts and fields by identifying points of similarity or cross-reference. For instance, a football match between England and Germany can readily employ references to and the discourses of World War II, and leverage the pre-existing relationships of enmity to produce excitement. ${ }^{29}$ It was not uncommon for Korean newspapers to borrow from history to make sense of each nation's performance in the World Cup, or appropriate the language and narratives of fields like war and celebrity culture to expand their range of stories. The effect was that the media coverage of the World Cup was not limited to the tournament as a sporting competition, but produced a collective imaginary of nationalities - a rich and expansive landscape that draw upon a huge variety of different contexts. The production of French nationality involved their startling failure on the football field as well as their love of wine and a general impression of sophistication. ${ }^{30}$ Dramatic documentaries drew upon evidence of civic responsibility and hospitality as well as personal stories of Korean football

\footnotetext{
${ }^{28}$ Ibid., p10

${ }^{29}$ R. Brookes (2002), p95

${ }^{30}$ See: "atŭsakŏ ssŭrŏjida" (The fall of art soccer), Donga Ilbo, 12 June 2002. General section.

Also see: "ch'ukkuyŏljŏng, segyerŭl chŏngbokhada" (Football passion conquers the world), Seoul: KBS, July 2002.
} 
players to flesh out narratives of Korean triumph and identify positive traits in Korean nationality. The mobilisation of contexts in this way allowed media texts to be both simple and complex: easy to grasp through various references, but containing a huge variety of implicitly communicated ideas and values.

These four elements - objects, narratives, structures, context - are intimately connected aspects that reside in any media text. Their function is to present, or make manifest, stories, arguments and ideas in communicable form; at the same time, and inseparably, they work to produce structures of meaning that direct ways of understanding. This is where discourse comes into play, as the mechanism involved in the productive process of text.

\section{Discourse}

In media texts, speech and image are deployed in a regulated and normative manner to achieve the production of structures of meaning. Discourse refers to this process of how systems of value, norms and categories are embedded into the signs we recognise and the meanings we interpret. This production of the material, in terms of regimes of signification, occurs within a discursive matrix that derives value, legitimacy, truth and identity through the relative positioning of signs. ${ }^{31}$ In short, discourse is the technique and the means by which production occurs.

How does such a technique operate, and what characteristics does it possess? Above all, discourse is a regulated and public performance. The deployment of discourse is a public act intended to establish symbolic associations, whether it be identity with individual, signifier with signified, or a value or lack of value with an idea or ideology. The text acts as the material conduit and public site of this performance. The public nature of discourse gives it the capacity to affirm and legitimise the truths and power relations it expresses - at once both a declaration and a definition. This public and performative quality of discourse can be identified by the way it constantly addresses an imagined audience. Korean media are arguably more explicit in this than their Western counterparts; they frequently refer to the audience as 'sichŏngja yŏrŏbun' (literally, "all you viewers"), excusing their behaviour or presuming certain responses on the viewers' behalf. Frequently, the audience is also inclusively interpellated as part of 'urinara' and 'urinara saramdŭl' ("our country" and "people of our country"). These techniques construct and position the imagined audience in such a way that a particular mode of reception is naturalised. Finally, while

\footnotetext{
${ }^{31}$ Similar to Bourdieu's 'market of linguistic exchange': see P. Bourdieu (2006 [1999]), pp480-2.
} 
discursive performance may at times appear theatrical or contrived, this does not always detract from its efficacy or legitimacy: within the context of mass media, there is an implicit understanding between producer and consumer that while the mode of expression is theatrical, the values and ideas underneath retain their truth value.

Discursive performances are also codified and regulated: the spontaneous elements of speech are organised according to predefined expectations of what is said and how it is said ${ }^{32}$, taking the form of familiar rituals that reinforce both the aforementioned symbolic associations and the legitimacy of the discursive templates they invoke. ${ }^{33}$ This regularity means that discursive performances are constructed, maintained and perpetuated through a system of cumulative anticipation. Discourse is rarely random, but refers to social norms, categories and values, just as it redraws and perpetuates them. Therefore, they follow a regulated matrix that governs what to say, and when and how to say it - one of the primary functions of Foucaltian power and Bourdieu's habitus. ${ }^{34}$ In effect, one always anticipates: there is an expectation for certain discursive performances, and appropriate responses or outcomes. ${ }^{35}$ It is this anticipation that can prompt formulaic responses, foreclosure of ideas, indignance at seemingly transgressive performances, and even confusion (or delight) at a violation of expectations. There is a matrix of discursive performances that governs how to 'say/show' and how to 'listen/see'.

The full extent of the regulations that govern discursive performance, and its legitimising and normalising function, is often masked from both the performer and the addressed. It is relatively easy to understand what is expected of one in a given situation, as this is already a part of the subject's habitus. However, the question of what that knowledge legitimises and what power relations it affirms is much more obscure, since it is theoretically foreclosed. Thus it is through "this opacity of discourse... [that] people can be legitimising (or delegitimising) particular power relations without being conscious of doing so". ${ }^{36}$ The media discourse during the 2002 World Cup, and ideas of Korea and Korean nationality it produced, were not so much the result of careful and conscious choreography on the part of media producers, but seemingly 'natural' consequences of the codified discourses they mobilised for media texts.

Finally, discourse, despite its codified nature, is fluid and flexible in its manifestation. The

\footnotetext{
${ }^{32}$ P. Bourdieu (2006 [1999]), p483, 485

${ }^{33}$ Also see N. Fairclough (2001 [1989]) p23; T. van Dijk (1988) pp21-2

${ }^{34}$ P. Bourdieu (2006 [1999]) p485; M.Foucault (1988 [1976]) pp55-6, 101; M. Foucault (2007 [1977, 1978])

p3

${ }^{35}$ P. Bourdieu (2006 [1999]) pp483-4

${ }^{36}$ P. Bourdieu in N. Fairclough (2001 [1989]) p33
} 
challenge in understanding the productive capacity of discourse is the ever-present potential for slippage. Regulating, foreclosing and legitimising discourse may be, but its public and explicit nature renders it contestable. Each utterance - a slip of the tongue, a faux pas, an inadequate performance - can expose these 'rules of discourse ${ }^{37}$ and the power relations immanent in them. ${ }^{38}$ What happens to the discourse of 'quintessential' British values of hard work and honesty, if the players on the screen then engage in foul play? Discourse derives its efficacy from its ability to adapt to such occasions. When the Korean team, managed by Guus Hiddink, succumbed to humiliating defeats in two high-profile matches, this did not erode the underlying belief that Korea possessed a strong football team and could achieve great things on the world stage (in football as well as in other areas). The defeat and reasons for the defeat were isolated into specific maladies in this case, Hiddink's management policies and his lack of knowledge of Korean players. By attacking Hiddink for his supposed failures and depicting him as a villain, the media avoided a direct challenge to that underlying discourse of Korean greatness. Later, when the same Korean team achieved an unprecedented semi-final finish in the World Cup, Hiddink's management policies were quickly rearticulated as factors which helped Korean players maximise their inherent potential. Discourse, therefore, should be considered not a public exertion of coercive force, but a fluid and constantly negotiated site of Foucaultian power.

Discourse is, therefore, a performative act; a public, regulated and negotiated act of communication which operates on the textual elements described above to produce meaning. However, this meaning does not exist in the form of a series of laws or declarations, such as 'Americans are xenophobic' or 'Africa is primitive'. As the example of Guus Hiddink demonstrates, discourse disposes one towards an ideal rather than imposing a definition. Thus, following Foucault, power does not explicitly define truth, but rather disciplines and disposes subjects to interpret things in particular, regulated ways to produce an effect of 'truth'. ${ }^{39}$ When the Korean media covered the Korea-Italy match in the 2002 World Cup, they were not making explicit declarations of Italian perfidy and Korean heroism. Rather, they positioned the audience to empathise with the Korean team, producing Korean athletes as committed and hard-working underdogs and the coach as canny and intelligent, and the Italians as petty, weak and cowardly (when the Koreans could easily have been depicted as violent and unscrupulous, and the Italians technically gifted victims of that physicality). This consistent performance of discourse trained the Korean audiences to appreciate hard Korean tackles as heroic acts of valour and regard Italian

\footnotetext{
${ }^{37}$ N. Fairclough (2001 [1989]) pp24-25

${ }^{38}$ M. Foucault (1988 [1976] p101

${ }^{39}$ M. Foucault (1980 [1972]) p119, 131, 133
} 
ones as dangerous assaults, ultimately vilifying the entire Italian nation, if only for a time. ${ }^{40}$ Furthermore, this Korean heroism was recognised not only in its own right, but also in contrast to the antithetical villainy of the Italian players: thus emerged a composite and relational understanding of nationality that was defined by both what they were and what they were not. ${ }^{41}$ In such ways, the media texts disposed the audience to derive particular meanings and interpretations from their viewing experience, through a discourse that was consistently oriented towards a nationalistic ideal.

In summary, two key points can be made about discourse. Firstly, it is a performative act that produces meaning from textual elements. Secondly, it employs regulated and structured frameworks of interpretation to do so, thus producing an 'architecture' of meaning, a system of ways of thinking about the text. It is this systemic, structural organisation of meaning that is the system of signs.

\section{System of Signs}

A system of signs can be considered an organised collection of frameworks of interpretation defined, articulated, employed and affirmed through discourse; it encompasses systems of categorisation, normativity and valuation. While the system has no consolidated form, its operation can be verified through moments in which its relations of power are enacted - in this case, the discourse of media texts.

The system of signs is an architecture rather than merely a collection, series or landscape. The structural arrangement of signs and their relationships are just as important as the signs themselves in determining meaning and how one derives meaning. Thus, this architecture has a taxonomic function: it discursively categorises things, charts them against ideal norms and delimits abnormality, and assigns matrices of value to their positions within the taxonomy (in relation to other things and the normative trajectory). The primary modes of structural organisation in the system of signs are categories, norms and value systems - the three frameworks of interpretation by which we understand things as signs.

Categories organise ideas, objects, people and emotions into particular types, which govern how one interprets and reacts to them. An individual that plays football professionally, for instance, is

\footnotetext{
${ }^{40}$ See: “ikyŏngkyuga kanda” (Lee Kyung-Kyu is coming). Seoul: KBS, July 2002.

${ }^{41}$ See J. Butler (1997) pp24-5
} 
discursively located within the category of athlete, which establishes a Butlerian 'passionate attachment' of that player to the 'sporting ethos'. ${ }^{42}$ One is then compelled to interpret that individual (now made intelligible as a subject) in relation to previously understood ideals of sportsmanship, a certain type of bodily aesthetic and the like, while alternative readings of that individual are foreclosed. Nationality, indeed, is used as a category in and of itself. It is a pervasive taxonomy that can demarcate a vast number of objects, from individual human characteristics such as laziness or honesty to colours, sounds and musical styles. By way of historical and anecdotal examples, such qualities can be attached to a national category, and qualities within the same national category can then be associated in the symbolic order, forming composite impressions of that nationality. This composite nature of nationality makes it a powerful and influential category that is able to draw upon a huge range of narratives and signs. As a recent example, the Romanian government found out how enduring and powerful these categories can be in 2009 , when its attempts to redefine the country as a vibrant and colourful tourist destination met with embarrassing failure. ${ }^{43} \mathrm{~A}$ composite impression of Romania as primitive, mystical, dark and foreboding had emerged around the legend of Count Dracula over several decades; far from dispelling or subverting it, the government's advertising campaigns simply could not compete with it as an enduring, collective imaginary.

Norms and normativity refer to the ways in which discursive enactment of power establishes an ideal norm, and then positions all other things within that category in relation to that norm, mapping out a graduated field of the normal and abnormal. ${ }^{44}$ Normativity operates in two levels with regards to nationality. There is first a normative trajectory that defines the 'normal' of that nationality - the theoretical spectre of the ideal Korean - and gradations of normality and abnormality in relation to it. ${ }^{45}$ At a more basic level, there is then a normative expectation of one's relationship to one's nationality, which includes the vernacular idea of patriotism. In such a system, the aberrations to the norm are also mapped in a way that allows for their existence and, by way of negative example, affirms the normal. The Korean that is not 'Korean' becomes an example of the importance of being a 'proper' Korean, and a foreigner that loves Korea or exhibits 'Korean' values is appropriated as an affirmation of Korean nationality. In such ways, contradictions or violations of normative Korean-ness are isolated and positioned in such a way that they enforce the validity of what they oppose or contradict. ${ }^{46}$

\footnotetext{
${ }^{42}$ See J. Butler (1997) p7, 10, 20

${ }^{43}$ A. Imre and A. Bardan, "Branding Romania II, or, the End of Choice", FlowTV 11, no.13 (2010), http://flowtv.org/2010/05/branding-romania-ii-or-the-end-of-choice-aniko-imre-and-alice-bardanuniversity-of-southern-california/ (accessed 2 June 2010)

44 J. Butler (1997) pp23-4, M. Foucault (1979 [1975]) pp179-182

45 J. Butler (1997) p21

${ }^{46}$ See J. Butler (1997) p27, M. Foucault $(2007$ [1977, 1978]) pp8-9
} 
Systems of value enable and compel comparative judgments of quality, validity and social capital. Pierre Bourdieu asserts that all linguistic communication occurs within a market of such value, an economic exchange predicated on relationships of symbolic power. ${ }^{47}$ That is to say, discursive performances are the mechanisms for the attribution or accreditation of value for all parties involved - the performer, the addressed, and the discourse itself. When a mayor gives a speech to the citizen body, his or her social standing and the legitimacy of the employed discourse is at stake ${ }^{48}$ : he or she would be aiming to establish an authoritative position through the appropriate discourse of government and civic patronage, enabling him or her to declare 'truths' on relevant matters of policy. ${ }^{49}$ The systems of categorisation and normativity are intimately connected to this process, and provide the standards and expectations by which both the mayor as performer and the accompanying utterances as discourse can be evaluated and given value. In the case of nationality, the normative trajectory of Korean-ness would be employed for the attribution of various values, such as social capital, individual preference, moral right, quality and excellence, depending on the context. Finally, "any discourse or practice implies conventional types of discourse or practice" ${ }^{\prime 50}$ : while each discursive performance is judged against an existing matrix of value, it also works to re-negotiate and re-affirm the said frameworks.

As a whole, these systems contribute to ideas and ideology that are normative, taxonomic and finally subjectivating, in the sense that they cultivate subjects who are founded on these ideas and will willingly employ and advocate them. ${ }^{51}$ Within this model, subjectivity can be understood as the conditions of social existence - a process by which individuals recognise and internalise generalised regimes of truth and knowledge, a 'grid of intelligibility' mapped out through the discursive enactment of Foucauldian power. ${ }^{52}$ Nationality as a system of signs is a mechanism of subjection because it is that taxonomic architecture which imbricates in individuals a naturalised understanding of not only what nationality is, but what its social significance is. In this sense, the system of signs serves as a reference point and source of identities (of people as well as of nations and other impersonal objects). Here, identity is understood as the material product of subjection that is an ensemble of performances disposed towards an ideal. An identity consists of habitus, markers of identification and social status that is performative and internalised, ${ }^{53}$ manifest in the

\footnotetext{
${ }^{47}$ P. Bourdieu (2006 [1999]) p480

${ }^{48}$ ibid., p483

${ }^{49}$ See the 'mayor of Béarnais' in P. Bourdieu (2006 [1999]) pp481-2.

${ }^{50} \mathrm{~N}$. Fairclough (2001 [1989]) p23

51 J. Butler (1997) p9, also echoed in G. Debord (1990 [1988]) p29

${ }^{52}$ See: A. Brady \& T. Schirato (2011) pp5-6, 24

${ }^{53}$ Also see P. Bourdieu (2000) pp143-144
} 
action, speech and thought of the subject. ${ }^{54}$ Thus, the discursive performance of nationalistic identities contributes to reifying and producing the system of signs.

The system of signs, and nationality as a system of signs, is very much a mechanical apparatus. It originates from and operates through neither the manipulations of a singular and centralised will, or from 'natural' and inherent qualities of social life, but through public discourses that produce categories, norms and values by which thought is governed. Therefore, understanding nationality as a system of signs means recognising that it is not primarily a sacred force or an innate demographic quality. This allows us to consider nationality not by beginning from the idea of a 'pure' nationality, and then examining the ways in which it is distorted or misrepresented, but accepting that it has always been 'artificial', and then critiquing the reality of that artificial nationality. The things about nationality that seem the most important and central - national identity, pride, patriotism, visual symbols - in fact form only the surface manifestations of this deeper mechanism.

The productive process in question, then, is as follows. 'Text' is the material site of production, which contains textual elements (object, structure, narrative, context) that are the material components for meaning-making; 'discourse' is a performative process that reifies, produces and also contests that meaning. Finally, the 'system of signs' is the structured, regulated end result of that process, composed of frameworks of interpretation that guide subjects' understanding of the text. Together, these concepts describe a process whereby symbolic meaning is produced as a set of structured, regulated ways of thinking, and an enactment of Foucauldian power-implicit, subjectivating, normalising, and disciplinary.

\section{Spectacle}

The model of the system of signs recognises that nationality is a constructed system of thought, and that discourse is a key technique in its production. However, it does not explain what kinds of nationality are produced through media texts, or their characteristics and styles. I suggest that the media industry operates primarily around the logic of the spectacle, and that this logic is irrevocably intertwined with the production of nationality.

Spectacle is characterised by its commodity logic and its normative, subjectivising function,

54 J. Butler (1997) p16, M. Foucault (1979 [1975]) pp184-6, 206 
derived from Guy Debord's notion of a pervasive, commoditising and normalising 'society of the spectacle'. Debord's focus on the political dimension of the spectacle and his polemical debates on totalitarianism, however, are less relevant for this study; instead, the spectacle is here conceived as an indulgent phantasmagoria. It is a tantalising, theatrical performance of media images that dispose the audience to desire it in both consumptive and subjective modes, demanding more of the spectacular image and willingly becoming subjects of the spectacular logic. ${ }^{55}$

Spectacle, in the Debordian sense, is predicated on the notion of 'integration', or total appropriation. According to Debord, this totality of the spectacle means that the spectacular way of presenting reality, performing identity and standard of exchange value has replaced any preceding 'Real', forming an entire social logic that is able to operate autonomously. ${ }^{56}$ Thus "all that was once directly lived has become mere representation" ${ }^{\prime 57}$. Such a totality is compatible with Baudrillard's concept of the simulacrum, in that one's perception of the world comes entirely from a collection of images produced by the logic of the commodity. ${ }^{58}$ Together, it can be argued that the imaginary spectacle replaces the Real completely, and its images mediate all social relationships. ${ }^{59}$ Consequently, the consumption of symbolic goods has become the only way to understand social reality; it sets the 'domains of conceivability'. ${ }^{60}$

This is the totality of the commodity, or the total domination of exchange value. Debord wrote that the logic of the commodity has now pervaded the entirety of lived experience. ${ }^{61}$ In other words, every person, object and situation potentially can be judged by his or her potential exchange value on the market. ${ }^{62}$ Together with the idea of integration, this means that various fields that were previously held as sacred from the market have now been appropriated by the spectacle. This includes art, national heritage (and indeed, nationality itself), journalism and news, the family (private familial events and processes) and more. But this appropriation is rarely so complete as to eliminate that sense of sanctity and the ideology that was held sacred; in fact, the spectacle prefers to maintain the illusion that these fields are still sacred, in order to leverage that sanctity for additional value. For media texts that make spectacles of national events, nationality remains a sacred ideology: it is discursively produced as a power that brings people together and gives a sense of belonging, sacred in theory and spectacular in practice. In fact, such an ideology

\footnotetext{
${ }^{55}$ See G. Debord (1990 [1988]) p27: "images chosen and constructed by someone else have everywhere become the individual's principal connection to the world he formerly observed for himself".

${ }^{56}$ G. Debord (1990 [1988]) p9

${ }^{57}$ G. Debord (1994 [1967]) p12

${ }^{58} \mathrm{~J}$. Baudrillard (2001) p47, 139

${ }^{59}$ Ibid., p24

${ }^{60}$ G. Debord (1990 [1988]) p34

${ }^{61}$ G. Debord (1994 [1967])) 41, 42

${ }^{62}$ Ibid., p46
} 
operates as a Lacanian 'universal Lie' ${ }^{63}$, a disavowed belief that says, 'we all know this is a spectacle for consumption and profit, and that it does not operate fully in terms of this nationalistic ideal, but we will act and speak as if it does anyway. ${ }^{64}$ It is a simulacrum that is coterminous with the field itself, real in function if not in definition.

A number of qualities are generally valued throughout sites of spectacular production, and many of them can be found in the Korean media coverage of the 2002 World Cup. Of these, perhaps the most relevant for the idea of nationality is that of authenticity. Despite, or perhaps because of, the contrived nature of a spectacle, one of its greatest selling points is the idea that the meaning and experience derived from the spectacle are experienced as real, and not simply manufactured for the consumer's indulgence. The spectacle also promises strange, new and exciting authenticities. The spectacle's logic of the commodity constructs exotic, yet consumable difference decontextualised sets of aesthetic tropes calculated to entice the viewers. ${ }^{65}$ It is a fetish of the exotic and, more generally, of novelty; a discursive stratagem for the cultivation of audiences who are led to desire the newest (and, by implication, the best) product on the market. ${ }^{66}$

Another characteristic of the spectacle is the transformation of expertise. Institutionally qualified experts become the sole source of authority and opinion, and the invocation of this institutional authority endows discourse with legitimacy. Football coverage is now run through pundits that explain and judge players and events before, during and after matches. Scientists, whose white lab-coats function as almost ceremonial signifiers of knowledge and power, are utilised in every kind of story to provide institutionally approved statistics and explanations to 'how things really work', and the truth of what we are seeing. During the 2002 World Cup, academics were in high demand by current affairs, lifestyle and documentary programs, which would ask psychology professors about the street supporters' motivations, or management professors about Hiddink's coaching techniques. Opinions of an individual supporter, in comparison, were treated with less respect, considered in terms of the expert's arguments, or simply isolated as anecdotal evidence and dismissed. This meant that, ironically, the discourse of a new and individualistic Korea was produced through the authority of government institutions and reputable universities. Debord claimed that in all kinds of stories, statistics and explanations, the spectacle claims the sole right to expertise and to the regime of truth. ${ }^{67}$ The respectful use of institutional expertise was one of the key ways in which media discourse acquired legitimacy and authority.

\footnotetext{
${ }^{63}$ S. Zizek (1997) p130

${ }^{64}$ S. Turkle in S. Zizek (1997) p137

${ }^{65}$ G. Debord (1990 [1988]) pp16-7

${ }^{66}$ Ibid., p7

${ }^{67}$ Ibid., pp16-7
} 
The spectacle is also, necessarily, a drama. While not explicitly identified by Debord, his discussions make clear that there is a dramatic quality to spectacular commodities and a fetishistic demand for it, which is of particular relevance to a study of media sport. This is not unique to the contemporary spectacle: Baudrillard, for instance, mentions the key role dramatised, public spectacles at the church and court played in the demonstration of imperial power in medieval Europe. ${ }^{68}$ What is new is the unprecedented level of control the mass media now exerts over the representation of reality. In other words, so much of a 'real event' is now subject to technical manipulation, and so strong is the desire for consumable drama, that the result is reality reappropriated and manufactured to the service of dramatised spectacle. ${ }^{69}$ This has strong relevance for the systems of categorisation that we derive from the media, as they will often tend towards familiar relationships and conflicts to produce drama in every situation. ${ }^{70}$

All these systems of spectacular society maintain their dominance through the voluntary cooptation of its subjects. Following the logic of the integrated spectacle, the internalisation and reproduction of spectacular images has become the only way to produce socially acceptable identities. ${ }^{71}$ The spectacle subjectivates individuals in a voluntary manner; "the spectators want to be just as illogical as the spectacle". ${ }^{72}$ Even resistant and alternative world views or identities must obey the logic of the spectacle, since the media has become the only way to be recognised, and avoid 'social death'. ${ }^{73}$ This is in fact compatible with Foucault's model of power and subjectivity. As Crary has shown, the Foucauldian surveillance that encourages prisoners to voluntarily adopt the identity of the prisoner is akin to the spectacle that cultivates consumers to voluntarily reproduce the spectacle they see and consume; the spectacle is now the site of that grid of intelligibility through which subjects locate their social significance. ${ }^{74}$

In short, the spectacle is a general logic that pervades society, and the system of nationality is a specific network of signs that has been produced through texts. The spectacle is a logic that deals with interest and process - an interest in commodification and all its related functions, such as profitability, audience capture, branding, and the process of commoditising, including the tendency towards the visual, the immediate, the dramatic, the novel and exotic. It is a general

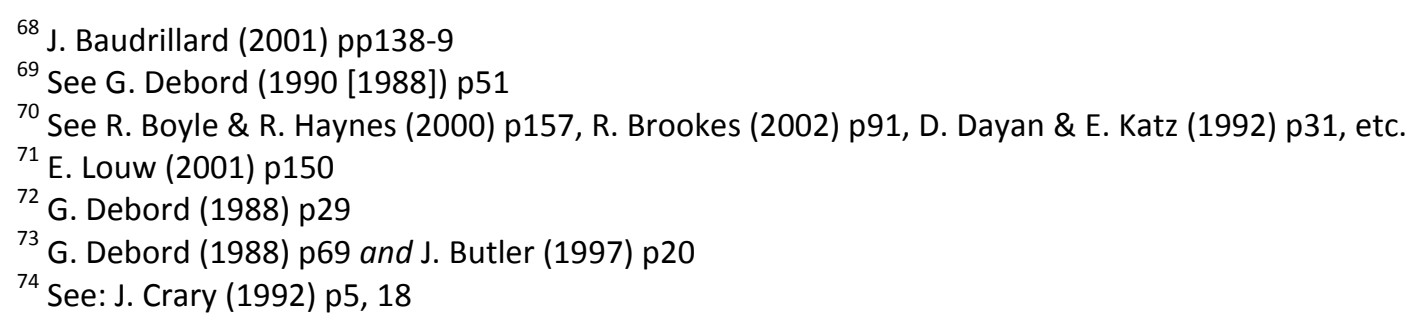


logic that has to do with what we consider to be viable and advantageous, and how to produce those qualities in a consumable form. It is a shell or template for spectacular production that obeys the logic of the commodity. On the other hand, the system of signs is concerned with meaning and identity - affixing meaning to things and identifying norms and value. It is a general logic that considers what the world is, which fits in that spectacular template and is produced in a spectacular manner. Thus there is a hierarchical relationship between spectacle and nationality: nationality is one of the specific, material forms that the general logic of the spectacle affects, one example of a realm of thought, behaviour, speech and signification that has been reappropriated by the logic of the spectacle. In short, nationality as a system of signs is now a spectacular nationality.

The spectacle, then, is a template for the production of meaning in a way that especially privileges commercial viability, dramatic entertainment and visual attraction. It has, in contemporary society, reached such a level of pervasive normality that it can be considered a general and dominant logic, especially for the production of media texts. This spectacular nature of media sport plays an important part in determining how nationality is produced through that media.

\section{Research Methodology}

Operating from the position that nationality is a system of signs, and that the conditions of its production are governed by the logic of the spectacle, the Korean media coverage of the 2002 World Cup was qualitatively analysed to provide a case study of spectacular nationality at work. A significant sample of press and broadcast media from the period before, during and after the 2002 World Cup was complemented by academic and popular literature from both Korean and Western sources. The wide and varied range of the sampled data allowed for the preservation of the contexts in which the discourses of nationality were produced, adequately reflecting the flood of media coverage that engulfed Korea at the time. This media-centric sample also focuses on the types of discourses that are employed by the media individually and as a whole over time, allowing a comprehensive examination of the techniques of nationality production.

Print media constituted a significant portion of the media sample. Despite the global panic over the 'end times' of newspapers in 2008-9, symbolised by the financial troubles of the New York Times, print media remains a cornerstone of mass media and the news in Korea and worldwide. Although Korea in 2002 was already boasting unusually high levels of internet penetration and usage, internet 'news portals' such as Naver and Daum, who now dominate the news industry, 
were still in their infancy. In practical terms, the absence of reliable archives has prevented the gathering of a comprehensive sample from internet media. As such, this case study primarily examines articles from the two most prominent newspapers in Korea at the time-Chosun Ilbo and Donga Ilbo.

Largely due to the influence of the military dictatorships until the 1980's, most major Korean newspapers range from mildly to extremely conservative, and are openly recognised as such. Chosun Ilbo, the most widely read newspaper in the country, is seen as moderately conservative ${ }^{75}$, while Donga Ilbo, another prominent newspaper, is considered strongly conservative. While the Han'gyŏrae represents a more liberal viewpoint, its archives were not available for research. Every article published by the two newspapers from 9 May 2002 to 15 July 2002, including the tournament schedule of 1 June to 1 July, was examined for discussions on the World Cup or related phenomena. Of these, a total of 931 articles discussed ideas relevant to spectacular nationality. They were coded into a quantitative tagged index (Table A), and individually analysed for textual elements and their use of discourses on nationality.

Table A: Media Data Tags (Inclusive)

\begin{tabular}{|l|l|l|}
\hline General & General & All miscellaneous articles \\
\hline Branding & Civic Training & $\begin{array}{l}\text { Improving manners and public order in the Korean citizen } \\
\text { body }\end{array}$ \\
\cline { 2 - 3 } & Economy & Korea's brand image and economic consequences \\
\cline { 2 - 3 } & Hospitality & Providing hospitality for foreign guests \\
\hline 'Celebrity Athletes' & Ahn Jung-Hwan & Depiction of Ahn, one of the players in the Korean team \\
\cline { 2 - 3 } & Lee Chun-Soo & Depiction of Lee, one of the players in the Korean team \\
\cline { 2 - 3 } & Park Ji-Sung & Depiction of Park, one of the players in the Korean team \\
\cline { 2 - 3 } & Veteran Players & $\begin{array}{l}\text { Depiction of Hong Myung-Bo and/or Hwang Sun-Hong, } \\
\text { two of the players in the Korean team }\end{array}$ \\
\cline { 2 - 3 } & Other & Depiction of other players in the Korean team \\
\hline 'Foreigners' & Guus Hiddink Cult & $\begin{array}{l}\text { Depiction of Guus Hiddink and the cult of adoration } \\
\text { around him }\end{array}$ \\
\hline
\end{tabular}

\footnotetext{
${ }^{75}$ See: "sinmun hogamdo chosŏnilbo irwi--- yŏnghyangnyŏgdo apdojŏk" (Chosun Ilbo most favoured newspaper--- dominant in influence as well), 2009. Chosun Ilbo.

http://news.chosun.com/site/data/html dir/2009/03/04/2009030402212.html?Dep0=chosunnews\&Dep1=rel ated\&Dep2=related all (Last Accessed 3 June 2010)

See: "potal, yŏnghyangnyŏg/silloedo 'chosŏn' apjirŭda" (Portal races past Chosun [llbo] in influence / reader trust), 2009, Naver.com.

http://news.naver.com $/ \mathrm{main} / \mathrm{read}$. nhn?mode $=$ LSD\&mid=sec\&sid1 $=001 \&$ oid $=006 \&$ aid $=0000030645 \&$ (Last Accessed 3 June 2010)
} 


\begin{tabular}{|l|l|l|}
\hline \multirow{4}{*}{ Nationality } & Other & Other articles in the category \\
\cline { 2 - 3 } & Foreign Judgment & $\begin{array}{l}\text { Use of foreign sources or invoking foreigners to evaluate } \\
\text { Korea }\end{array}$ \\
\cline { 2 - 3 } & Pride, Identity & Discussions of national pride, patriotism and identity \\
\cline { 2 - 3 } & Other & Other articles in the category \\
\hline 'Red Devils' & Citizen Supporters & Discussion of ordinary Koreans supporting in the streets \\
\cline { 2 - 3 } & Commodification & Discussion of merchandise and other commodities \\
\cline { 2 - 3 } & Red Devils & $\begin{array}{l}\text { Discussion of actual Red Devils members and/or } \\
\text { organisation }\end{array}$ \\
\cline { 2 - 3 } & Other & Other articles in the category \\
\hline
\end{tabular}

By encompassing the entirety of the published material from the two newspapers in the selected period, the print media data was able to track both day-to-day changes and longer term trends in the publications. In broad terms, both newspapers showed an overriding interest in promoting the World Cup in three ways: as a 'global festival' of cultures and peoples that are brought together in a utopian vision of globalisation; as a test of Korea's hospitality and civic order for the world to judge; and as an adventure of the Korean national football team as underdogs. All three of these grand narratives both enforced and accepted an implicit understanding of the World Cup as a desirable occurrence and opportunity. These optimistic depictions were deployed in a surprisingly consistent and uniform manner across newspapers, time periods and genres. Explicit discussions of Korean nationality were commonplace in every issue, often instructing or exhorting the readers to take part in and accelerate the economic, mental and societal evolution of Korea through the World Cup. Historical, anecdotal, statistical and philosophical evidence was frequently used in every kind of article to support this argument. On the other hand, issues in the field of 'entertainment', such as merchandise and celebrity involvement, were significantly less prominent, not fitting easily into existing expectations of conservative newspapers and their content structure. The only exception was 'pure' sports coverage, where discussions were firmly grounded in the field of sport and its familiar topics and languages. While media sport is not separate from discourses of nationality, they retained a degree of autonomy as discourses of sport.

Broadcast media involved a more selective sample: I have made use of the most prominent and visible media texts in Korean television during the same period. In this period, Korean television was dominated by three media broadcasters - the government-owned but independently run KBS, and privately owned MBC and the relatively young SBS. SBS, being smaller and with less of a focus on sports content, was unable to compete with the other two, however, and chose not to pursue 
World Cup related coverage as aggressively. ${ }^{76}$ On the other hand, KBS and MBC were extremely active in maximising the quantity and variety of World Cup related programs, which were so highly prioritised as to push news programs and high-rating dramas out of their time slots. The Korean matches were shown live, as well as in several full replays, while important moments were played in dozens of other programs to achieve what must have been an almost total level of exposure. ${ }^{77}$ Television played an extremely prominent role as gatekeeper and narrator during this period: the most popular World Cup-related programs achieved audience ratings of 20 to 30 per cent, while MBC's prime time news program achieved a 30 per cent spike in audience ratings by packing its schedule of some seventy World Cup related bulletins. ${ }^{78}$

For research purposes, 29 programs from KBS and MBC were selected based on their audience ratings. When these were not available, the prominence of the program (deducible by elements such as time slots, promotional blurbs and choice of hosts) was used. The programs included prime time news, special features made to celebrate and review the World Cup and normal programs which had adopted World Cup as a visual and topical theme, such as breakfast programs and current affairs debates. The coverage of Korea's seven World Cup matches from the two broadcasters was also analysed. These broadcast items were indexed according to the same tags as print media (Table A), and independently and comparatively examined for the discursive production of Korean nationality.

The data from the broadcast media provided further evidence as to the remarkable symmetry across mediums, genres and publications in the way the World Cup was reported in Korea. The same limited types of stories, framing and narratives were exhaustively and repeatedly produced across the analysed programs, to the point that the footage, and the way in which they were used, were interchangeable. Endless shots of nameless supporters coalesced together to form an imagined totality of celebration, while the same highlight reel of Korean goals in the tournament was played in almost every program (and often multiple times in each program), becoming established as the pre-eminent, iconic image of Korean success. This uniformity persisted in the symbolic order. A small number of immediately recognisable and familiar conventions in television texts were employed at every opportunity to produce the same kind of emotional responses. Sounds of the 'tae-han-min-guk' chants and the 'o- $p^{\prime} i l s u$ ng K'oria' song ${ }^{79}$ were combined with quick montages of supporters to convey the aforementioned idea of a totality of Korean

\footnotetext{
${ }^{76}$ Y. G. Ha (2002), pp65-6

77 ibid., pp77-8

78 ibid., p91

${ }^{79}$ For the meaning of 'tae-han-min-guk' see Chapter 1, Footnote 1. 'O-p'ilsŭng K'oria', roughly meaning 'certain victory or ultimate victory for Korea', was a familiar refrain and supporting chant turned into song.
} 
celebration, while epic orchestral music and slow-motion shots amplified the sense of triumph in moments of success. Conventions from Korean soap dramas were often borrowed for profiles of individual athletes and coach Guus Hiddink, such as familiar narrative themes of family and hardship set against reflective, piano-based instrumental music, to produce the football stars in terms of immediately identifiable signifiers. During the 2002 World Cup, Korean television played an important role in not only determining the key stories of the day and the terms in which they would be understood, but also in providing these stories, figures and events with 'personalities', encouraging emotional and personal connections with them.

In the following chapters, the findings from this research of academic texts, print media and broadcast media will be examined in order to analyse and consider what kind of Korean nationality was being produced by the media coverage, and how this was carried out. I suggest that a spectacular Korean nationality was being produced in this period both internally, through positive affirmations of the validity and viability of the Self, and externally, through the construction of a foreign gaze that would be used to define and affirm Korean nationality. 


\section{Red Devils: Affirming Nationality}

"Cries of joy. A united voice and red passion. Streets filled with happy faces that had not been there before. In June 2002, twenty-two million people took to the streets in Korea. We discovered a new 'us', and the world paid tribute to our passion." ${ }^{80}$

"Men and women, young and old all shout with one voice: tae-han-min-guk. The cries of the supporters are still ringing in my ears. From the passionate cheering worthy of a football sŏnjin'guk to the voluntary cleaning up afterwards, right now the entire world is taking note of our advanced supporting culture." ${ }^{81}$

The 2002 World Cup was a remarkable event for the South Korean nation not only in terms of its success on the football pitch, but also because the surreal phenomenon of 'street supporters' millions of Koreans who took to the streets to support their team and celebrate that success. What made this even more remarkable was the apparent lack of any centralised agency organising or regulating these street supporters. The Korean media, government and academia hurried to proclaim this phenomenon as both evidence of and catalyst for an evolution and revitalisation of Korean society and mentality, an interpretation that was presented with almost no dissent or counter-argument in the public sphere.

In this section, the phenomenon of the street supporters is examined from its origins in a small group of football fans, the Red Devils, to its eventual life as a collective imaginary in the mass media, composed of general, abstracted national narratives on one hand and readily consumable spectacles of fashion and performative identities on the other. I suggest that the largely spontaneous phenomenon of the street supporters was quickly identified and appropriated by the mass media in order to create easily understood, memorable and consumable signs of Korean nationality. In doing so, the media enacted a transformation of a lived experience of spontaneous supporting activity into a mediated and collective imaginary of Korean-ness, drawing back on and extending existing narratives and discourses of Korean nationality. Not only did the media produce a particular interpretation of the phenomenon and a particular understanding of Korean

\footnotetext{
${ }^{80}$ MBC sŭpeshŏl - pulgŭnangma, hanbandorŭl ch'ukcheŭi jangŭro (MBC special - The Red Devils, and Korea a land of festival). Seoul: MBC, July 2002.

${ }^{81}$ welkŏm 2002 wŏldŭkŏp - sinhwachangjo taehanmin'guk - ŭngwon wŏldŭkŏp (Welcome 2002 World Cup

- taehanmin'guk, A New Legend - A Supporters' World Cup). Seoul: KBS, June 2002.
} 
nationality; it also produced a type of nationality that is performed in spectacular ways and through the consumption of spectacular entertainment.

\section{The Red Devils}

The term 'Red Devils' originally referred to a supporters' group for the Korean national football team, a grassroots movement founded in 1997. In previous years, Korea's appearances in the World Cup finals had helped build enthusiasm for football, as had the upgrading of the domestic league into a fully professional outfit. The founding members of the Red Devils came from a background of dedicated football fandom, and were primarily inspired by the highly developed, well-organised and popular supporter culture in European nations such as England and Italy. ${ }^{82}$ At the core, the Red Devils were therefore concerned with development and progress in the field of football as a sport. Their primary objective was to help build in Korea the kind of 'advanced' supporter culture that they had witnessed in Europe. The original members of the Red Devils also tended to be strongly patriotic: ideas of promoting Korean nationality and developing uniquely 'Korean' forms of support factored prominently in their early discussions. ${ }^{83}$ Elements of traditional Korean culture, such as samullori, a traditional percussion and dance arrangement, were adopted into chants, insignia and movements in a bid to create a Korean supporter culture, though this was modelled after European precedents. The Red Devils hoped to create an immediately identifiable and memorable visual performance of Korean nationality, and thus promote football to Koreans and Korea to the world. Finally, the Red Devils placed a strong emphasis on staying true to their roots. The group pursued this principle almost obsessively, depriving any single member or committee of complete control, refusing almost every form of corporate sponsorship and refusing to leverage their later popularity for political purposes. ${ }^{84}$

The Red Devils, in their original form, thus consisted of a complex web of motivations and values. While their stated objectives are as much about national pride as their love of football, the Red Devils were first and foremost a football-oriented group, and firmly located in the field of sport. Despite efforts to create 'Korean' forms of support, European supporter culture was firmly held as the ideal model to aspire to, and the group wasted no effort in instructing both members and nonmembers in 'correct' forms of support. For the Red Devils up to 2002, the act of supporting was

\footnotetext{
${ }^{82}$ S. Y. Lee (2004) pp5-7, 11-13

83 ibid., p9

${ }^{84}$ ibid., p10, 181.

Also See: Red Devils. "Introduction”. http://www.reddevil.or.kr/reddevil/introduction.asp (accessed 16 August 2010).
} 
not centred on the festive atmosphere and enjoyment, but intimately connected with knowledge of football and a series of dynamic reactions to events in the match with a view to influencing its progress. The following record of a Red Devils executive meeting illustrates this perspective:

"The Red Devils executives identified a number of problems with the growing Red Devils [in early 2000's]. One issue was that of supporters who were so focused on cheering they were apathetic about the rest of the match. The argument was that supporters who were obsessed with cheering and making waves even when the team was losing were counterproductive to the original purpose of live spectatorship. Because the outward elements developed before the purposes of spectator culture were not adequately communicated, the role of a proper supporter's group could not be fulfilled..." ${ }^{185}$

Throughout the 1998 World Cup and other appearances by the Korean national football team, the Red Devils continued to develop as a supporters' club, well known to fans of football but virtually unknown to the population at large.

All this changed with the 2002 World Cup. The explosion of the 'street supporters' phenomenon during the tournament effected an almost complete transformation of the ways in which Koreans watched football, and the role the Red Devils as a group played. For the first time, the World Cup was not thousands of miles away for Koreans, but highly accessible; and for the first time, the Korean team was winning matches. The Red Devils, who had become used to a membership base of a few thousand, and perhaps a peak of a hundred thousand during major tournaments, were bombarded with up to 7 million registrations. ${ }^{86}$ While football fans had always cheered and watched the game from outside the stadium, or in public places when they could not acquire tickets, the sheer scale of these 'street supporters' gave a new complexion to the phenomenon. The mass media had considered the Red Devils a minority fan group, and had paid them little attention; but eventually they adopted the group's aural and visual elements as the centrepiece of World Cup coverage. Indeed, by the end of the tournament, the term 'Red Devils' had come to refer to the millions of street supporters, or even the Korean nation as a whole. In this thesis, the 'Red Devils' will refer to this official organisation of supporters, and the term 'street supporters' the millions of casual supporters, unless otherwise specified.

The phenomenon of street supporters was composed of several key characteristics. Above all, its

\footnotetext{
${ }^{85}$ S. Y. Lee (2004) p25

${ }^{86}$ ibid., p2
} 
defining quality was the aforementioned inclusiveness: it seemed as if literally everybody in Korea was participating. The natural difficulty in gathering accurate numbers on such an 'unorganised' and fluid gathering was seemingly forgotten, with the media reporting figures in the millions. Later, the Seoul Metropolitan Council reported that $53.1 \%$ of those surveyed had participated in street support. ${ }^{87}$ The Korean media frequently reported on the sheer demographic variety of participants, suggesting that every social category was participating in the celebrations with equal enthusiasm and in the same way. The most exotic examples, from monks to cruise ship passengers to the disabled, were mobilised to show how even the fringes of Korean society were participating in the festival.

"The long-awaited knockout stages. The cries of joy are shaking the walls of Chogye temple. As the final whistle sounds, both the monks and the faithful rise as one to celebrate. The match is over, but emotions are slow to fade. The monks, too, have laid aside their normally solemn demeanour.

The monks, who had prayed and prayed for Buddha to lend his power to our World Cup bid. Shouting and cheering all throughout the match, truly, they too were 'Red Devils., ${ }^{\prime \prime 8}$

This juxtaposition of the grey-robed monks and the 'regular' supporters in red (Photo A) ${ }^{89}$ was symptomatic of the way in which media coverage highlighted difference in order to establish uniformity. The coverage demarcated the monks from normal Koreans, and then reported on their participation in street support, suggesting that Koreans had united through this phenomenon. The street support phenomenon was clearly very widespread and visible, and had become far more attractive to the media than the dedicated efforts of the Red Devils in years past.

The expansion of the target audience also meant a diluting of sporting discourses and the language of sport. In the media's attempt to cater to viewers who are not regular

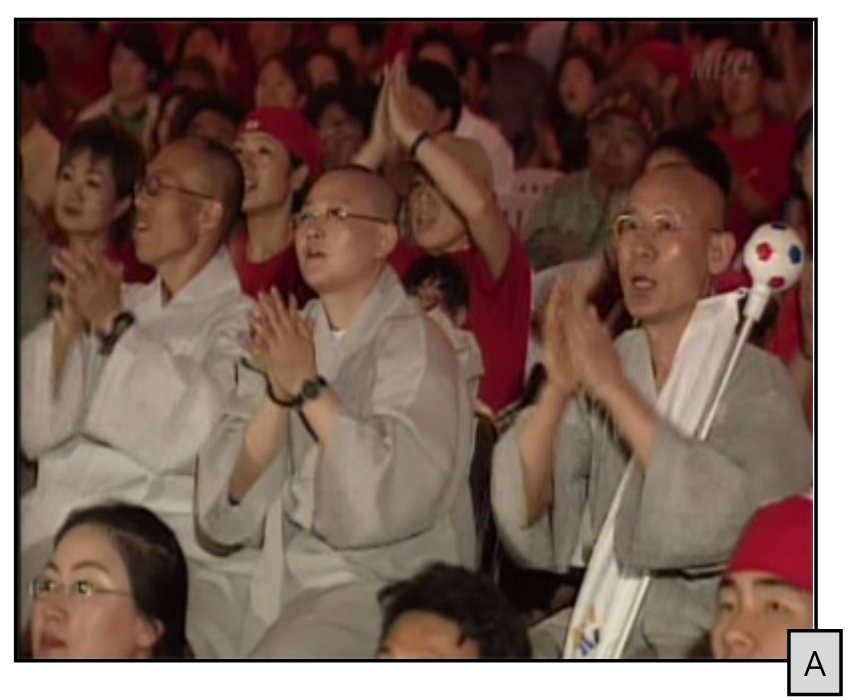

\footnotetext{
87 "A report on the 2002 FIFA World Cup Korea/Japan in Seoul". Seoul: Seoul Metropolitan Council, 2003.

${ }^{88}$ Newsdesk. Seoul:MBC, June 2002.

89 ibid.
} 
consumers of media sport, extraneous types of narratives and framing, such as human interest stories, celebrity stories and features on exotic cultures and historical details, expanded to produce a more varied media landscape. ${ }^{90}$ This contributed to the eventual production of a mediated interpretation of the World Cup that would reach far beyond the confines of sporting discourse.

Street support grew into an enormous phenomenon with the help of government, corporate and media institutions. They had provided infrastructure and organised promotions in anticipation of the World Cup, and once the scale of street support began to overtake their wildest predictions, hastily responded in whatever way they could. Companies sponsored large-scale screens or information stations in public venues, anticipating return of investment in the form of brand exposure. ${ }^{91}$ The media took on an even more active role, producing explicit instructive articles and programs which guided the audience on the 'right' way to spectate and support.

"Ten rules to keep in mind when watching the World Cup:

1.Let's do light stretches before and after a match to release tension

2.Let's drink water frequently to wet the vocal cords

$\ldots$

6.Let's take care of the children - they may exhibit signs of anxiety after a match

7.Let's not become too obsessed with the match, but enjoy it"992

This typical health advisory in the daily newspaper was in fact an amalgam of advice and instruction in the fields of medicine, family and even individual psychology, in an effort to reassert regulations and rules with regard to a new and unpredictable activity. The repeated use of 'Let's' was part of a general and common use of the pronoun 'we', through which a specific and inclusive form of exhortation was achieved. These paternalistic guidelines were accompanied by media coverage of scenes of support around the country. These would, by way of example, establish what methods of support were acceptable, fashionable and preferable. In one such program, the hosts reviewed coverage of supporters in various locations from a previous Korean match, and then mapped out the 'right' place of support for each demographic.

"There is the mecca of support, the city hall, and also the Han river park, but also, the younger supporters mostly congregate around Taehangno ('University Road') - and

\footnotetext{
${ }^{90}$ See: P. Bourdieu (1991) p364

91 "yahu K'oria, kyŏngijŏngbo chegong kilgŏri saibŏ k'ap'e sŏlch'i”" (Yahoo Korea installs a 'street cyber cafe' to provide match information), Chosun Ilbo, 23 May 2002, Sports section

92 "tarŏpshi wŏldŭk'ŏp ŭngwŏnhagi 10dae such'ik" (Ten rules to keep in mind when watching the World Cup), Chosun Ilbo, 18 June 2002, Society section.
} 
there are rumours that you can also fix up some on-the-spot blind dates! Working adults gather at Samsung Station, and there is the Seoul Equestrian Park and Chamshil baseball stadium for those who might need a sit-down to last the match. ${ }^{193}$

Finally, as corporate and media attention grew, the street support phenomenon quickly evolved beyond the 'core' activity of spectatorship and cheering. The millions of supporter-spectators formed a new and attractive market of a highly concentrated audience disposed to spend. Street vendors, shops, mass media, celebrities, and large corporations all gravitated to this market. While the media coverage focused on and iconised the visual image of the supporters, all around them an active market of fashion, music, entertainment and small goods had emerged. By far the most popular item was the 'Be the Reds' shirt, originally designed and distributed by the Red Devils free of charge. ${ }^{94}$ However, demand quickly surpassed their production and distribution capacity, and soon 'Be the Reds' shirts were on sale everywhere: street vendors sported the shirts on their picnic mats, while many clothing stores suspended their regular catalogue to make the most of the World Cup fever. ${ }^{95}$ Larger corporations such as Samsung also distributed shirts for promotional purposes, even delivering 'Be the Reds' shirts to other countries such as the Netherlands - emblazoned with the Samsung logo. ${ }^{96}$ The vast majority of these shirts were produced and sold without the permission of the copyright holder, the Red Devils, but such concerns were submerged under an atmosphere of national celebration that supported this environment of consumption. The shirts were complemented by scarves, flags, cushions, and even on-the-spot face-painting services, ${ }^{97}$ all of which helped create a regime of practice - the achievement and performance of nationality through consumption of small goods.

Such a market was closely intertwined with the emergence of what the Korean media called the 't'aegŭkki fashion'. While the Red Devils had long made use of the t'aegŭkki, the Korean flag, and other visual signifiers of the Korean nation, they were primarily a way of identifying themselves as Korean supporters in the stadium. The street supporters now exceeded the original signification of the t'aegŭkki, both as a national flag and as the Red Devils' visual icon, and manipulated its visual elements to create various fashion items, ranging from capes and headwear to accessories. While such fashionable and spectacular appropriations of national imagery are commonplace in megaevents such as the World Cup, the street supporters did so with regard to a signifier whose use had

\footnotetext{
93 “Aju tŭkpyŏrhan ach'im" (A very special breakfast). Seoul: MBC, June 2002.

${ }^{94}$ S. Y. Lee (2004) p148

${ }^{95}$ See: "wŏldŭk'ŏp sindŭrom yŏlp'ung... pulgŭnangma shŏch'ŭ upsŏsŏ motp'ara ('World Cup Syndrome' takes the country by storm... Red Devils shirts sold out), Donga Ilbo, 30 May 2002. Society section.

96 “Aju tŭkpyŏrhan ach'im" (A very special breakfast). Seoul: MBC, June 2002.

${ }^{97}$ ibid.
} 
been tightly regulated until the late 1980's and tied Korean nationality to the sovereignty of the state. The t'aegŭkki fashion was also notable in the ways it spilled outside the boundaries of the football stadium and the field of football. The following extracts from the Korean media coverage show how t'aegŭkki fashion quickly evolved from a simple donning of a red shirt to a comprehensive performance through consumption.

"The World Cup begins! Today the party has started. Let's change to our party clothes. The dress code for the party that will last from today to the $30^{\text {th }}$ of June is as follows. The World Cup [Korean] national football team uniform, football shoes, thick socks that come up to your knees... other than this 'official' dress code, tracksuits with strips down the sides, shirts with a large number printed on the front or back, trainers and wrist-bands are also good choices." ${ }^{\prime 98}$

"The t'aegŭkki is the most popular fashion instrument. Women participate in street support wearing skirts, trousers or even belly shirts made out of the t'aegŭkki. Zealous men paint their entire upper body in red, and pen the name and number of their favourite player on the back." ${ }^{\prime 99}$

"More than once, I have been surprised and awed by the free and imaginative ways in which the t'aegŭkki has been used. Capes, bandanas and skirts wrapped around the waist are already 'ordinary'. You'll need at least tank-tops or miniskirts to get more than a quick glance from passers-by."100

In the first extract, published just before the World Cup, the 'World Cup fashion' consisted of blending everyday clothes with football-related items: by the end of the tournament, t'aegŭkki fashion involved a total transformation of the individual's body with various appropriations of national imagery, which would simultaneously locate that individual within the category of Korean subjectivity and allow him/her to flaunt the body according to the logic of fashion and sexuality. (Photo $B)^{101}$ The government, media and academia joined in the praise and celebration of this provocative new fashion, perhaps because they deemed it a surprising and welcome demonstration of national pride. This is highly unusual when viewed in the context of Korea's

\footnotetext{
98 "ja! onŭl... wŏldŭk'ŏp p’aeshŏnŭro karaipja” (Today, let's change into World Cup fashion), Chosun Ilbo, 31 May 2002. Supplements section.

99 "ŭngwon p'aeshŏn taedamhaejyŏtda" (Supporting fashion becomes bold and daring), Donga Ilbo, 22 June 2002. Society section.

100 "'kaesŏngmanjŏm' wŏldŭk'ŏp p'aeshŏn" ('Full marks for individuality' - World Cup fashion), Chosun Ilbo, 22 June 2002. Supplements section.

101 “Aju tŭkpyŏrhan ach'im” (A very special breakfast). Seoul: MBC, June 2002.
} 

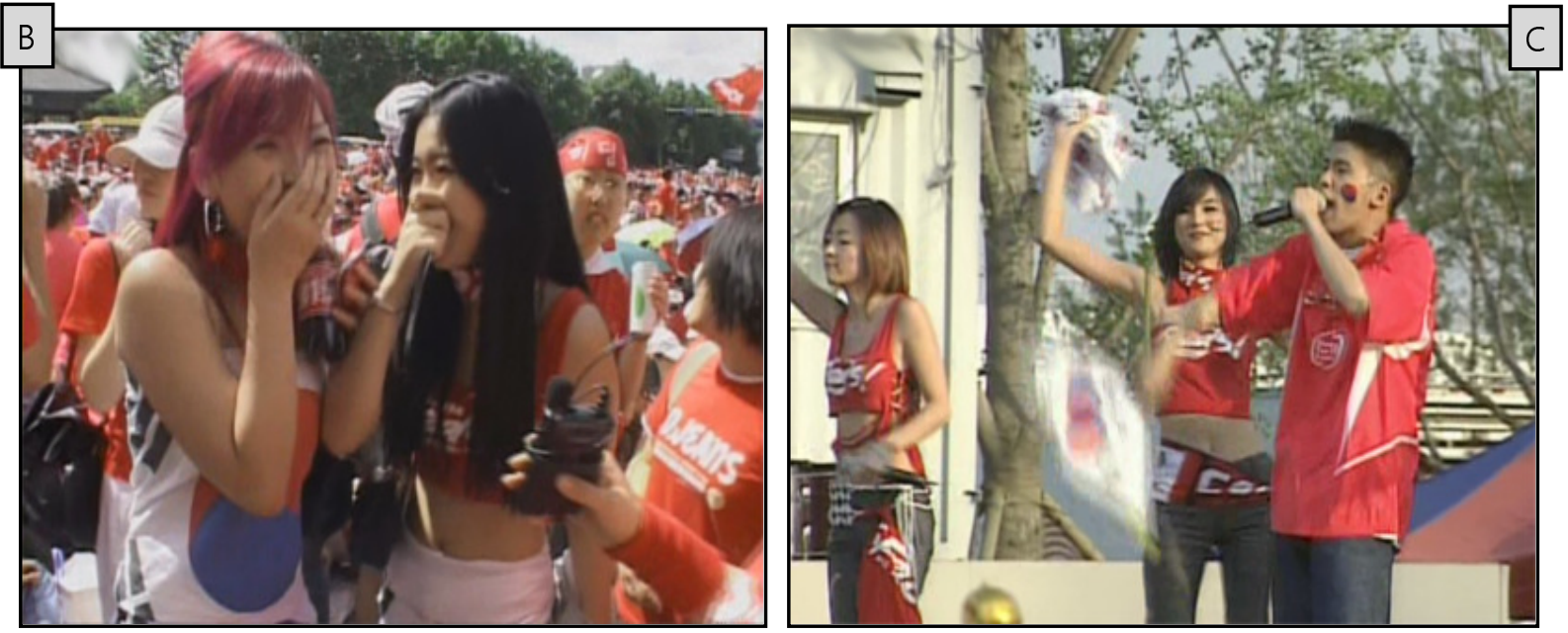

dedication to traditional Confucian values: only a few years prior to the World Cup, the Korean media had banned celebrities with dyed hair on television and hotly debated the merits of banning belly shirts. Yet the discourse surrounding the t'aegŭkki fashion in 2002 involved a fetishism of 'kabyŏum' (lightness, shallowness); they celebrated the flag's divestment of its gravitas as a form of emancipation and liberation, rather than one of moral decline. ${ }^{102}$ This discourse supported the development of the t'aegŭkki fashion into another form of spectacle, involving a performative use of the body as a site of commodification. One example of this was Mina. As a supporter during the 2002 World Cup, she flaunted her revealing and eye-catching t'aegŭkki fashion to attract the television cameras, and as a result of this exposure was recruited by a celebrity agency. This was repeated with Han Chang-Hŭi after the 2006 World Cup: the two women, and their scores of imitators, had identified the t'aegŭkki fashion not simply as a trend, but a market through which individual value and fame could be earned.

Those who were already celebrities were also acutely aware of the opportunities street support provided. Because of the unprecedented levels of attention the World Cup commanded, and because of the extraordinarily positive ways in which support of Korea was regarded, an astute celebrity's public image and popularity could - and did - skyrocket. Celebrities knew that their participation, or non-participation, in the festivities would be closely monitored by the media and their fans. Many adopted the t'aegŭkki fashion, attended matches, and screamed chants for the cameras in an attempt to build empathy and assert their pride in the Korean nation. ${ }^{103}$ Yun DoHyŏn, the leader of a little-known niche rock band (Yun Do-Hyŏn Band), became a household name by lending his voice to a single song, 'o- p'ilsŭng K'oria', which began as an advertisement theme and was quickly adopted by millions of street supporters. Lee Kyŏng-Kyu, arguably the most popular comedian in Korean television in the 1990's, ran a parody commentary program of Korean matches throughout the tournament, enjoying excellent audience ratings and bolstering his iconic

\footnotetext{
${ }^{102}$ G.H. Joo (2002) pp116-7

${ }^{103}$ See: “seksyŏn TV yŏnyet’ongsin” (Section TV Celebrity Correspondence). Seoul: MBC, June 2002.
} 
status. The extensive involvement of celebrities in street support had an important effect on street supporters as well, by introducing yet another element into the lived experience of street support. Musicians and comedians held or participated in concerts and shows in popular street support sites before matches, often with quickly composed World Cup songs based around simple and catchy pop tunes. (Photo $\mathrm{C})^{104}$ Watching a football match became just one of a variety of experiences on offer for the prospective street supporter. Indeed, the festive atmosphere created by the people, the media attention, the t'aegŭkki fashion and the celebrity presence was cited as the chief reason for attendance above football spectatorship or national pride. ${ }^{105}$

The relationship between the Red Devils as a supporters' group and the 'Red Devils' street supporters was complex. It is undeniable that the 2002 World Cup represented an explosion of popularity for the Red Devils: they received a substantial amount of media exposure, operational funds in the form of member contributions and corporate donations, and millions of new members, though most of these predictably faded away after the tournament. The Red Devils, lending their experience and know-how played an important part in the emergence of street supporters. It was their chants of tae-han-min-guk, their red shirts and scarves and their giant t'aegŭkki flag that provided the basis and precedent for street supporters and their t'aegŭkki fashion. However, this relationship quickly spiraled out of the Red Devils' control. The group's carefully designed visual signifiers and performances were adopted by the nation, but their founding ideologies and principles of promoting football, a football-supporting culture and independence from corporate influences were left behind. Even the name 'Red Devils' was no longer quite their own: it had become "a common noun rather than a proper noun", ${ }^{106}$ referring to street supporters as a whole rather than the group. It was easy for street supporters to register on the Red Devils website, learn their chants, copy their shirt design and join them in the 'supporters' seats' ${ }^{107}$ - even if they had no desire to learn more about the group, or take football and supporting seriously. While the original Red Devils were lovers of football first and foremost, many street supporters did not share such a passionate attachment to the sport. Rather, they were attracted by both a vague but compelling sense of national pride and the prospect of an entertaining and captivating spectacle.

Ultimately, the street support phenomenon was not centered on football or patriotism per se. The

\footnotetext{
104 “seksyŏn TV yŏnyet’ongsin” (Section TV Celebrity Correspondence). Seoul: MBC, June 2002.

${ }^{105}$ See: "A report on the 2002 FIFA World Cup Korea/Japan in Seoul". Seoul: Seoul Metropolitan Council, 2003.

Also See: G. H. Joo (2002) p175.

106 “k'o be'in'gŏn pulgŭnangma'inga kungmininga" (Whose nose has been cut off - the people, or the Red Devils?) 2008. Ohmynews.

http://www.ohmynews.com/NWS Web/view/at pg.aspx?CNTN CD=A0000315075\&PAGE CD= (accessed 18 August 2010)

${ }^{107}$ S.Y. Lee \& M.S. Ahn (2002) pp30-2. J.Y.Lee (2002) p86.
} 
act of watching football and the sense of national pride complemented the core experience of a spectacular environment, with its intoxicating rhythms of hyperactivity. ${ }^{108}$ This spectacle was grounded in powerful but nonspecific ways in the discourse of Korean nationality, and manifest through familiar forms of commodity consumption. Abstract ideas of nationality and the practical activity of spectacular consumption were combined in iconic visual signifiers; in the performative nature of participation; in the consumption of fashion, music and celebrity culture; and in an overwhelming sense of solidarity that reassured the willing and compelled the unwilling. ${ }^{109}$ The street support was a spectacle of commodified nationality, whose participants experienced a collective fantasy of uncommodified nationality.

\section{Making the Spectacle}

The emergence of the street supporting phenomenon and its superseding of the original Red Devils in the symbolic order had important consequences for the ways in which Korean nationality was produced during the 2002 World Cup. At the time, the general consensus, in the media and elsewhere, was that the street supporting phenomenon was a spontaneous explosion of national pride, a dormant desire that had found an outlet through the mega-event. But this idea of 'spontaneity' was largely applied retrospectively. The surprising and unique nature of that visible result then made it a foregone conclusion: the overwhelming level of participation and enthusiasm seemed to defy ordinary explanations. Accordingly, contemporary analyses of the phenomenon - both media and scholarly - looked to abstract explanations of Korean mentality and culture to explain the street supporters. But what was not examined was how they were able to take to the streets. The media played a crucial role in this process, contributing to both the popularisation of street support and its commodification. It helped ensure, both in the lived experience of participants and first-hand observers and in the mediated image, the transformation of the Red Devils from a supporter group to a spectacle of street support. That there was a strong element of patriotism in most of the street supporters cannot be disputed; but the mechanisms that enabled them to express this patriotism were provided by the mass media, which produced a system that facilitated a strong affective response through the consumption of an entertainment spectacle.

\footnotetext{
${ }^{108}$ G. H. Joo (2002) p175
}

109 J.M. Kang (2006) p251 
The chronology of such a transformation must begin with the Red Devils as a supporters' group, and the type of media coverage and exposure they had been receiving prior to the 2002 World Cup. As late as May 2002, the Red Devils were at the fringes of the media landscape of World Cup coverage. Furthermore, this coverage confined the Red Devils within a familiar archetype of the 'eccentric fan'. In one televised feature on the group ${ }^{110}$, the media focused not on the Red Devils' organisational characteristics or the details of their supporting activities, but on a dedicated family of supporters. The program opened with unassuming and domestic shots of apartment blocks, happy kids in Red Devils regalia and other familiar and friendly images. The image (Photo D) ${ }^{111}$ of the entire family in supporter kits framed their identity as Red Devils, signified through their striking attire, in the context of a normal Korean family. This established a semantic macrostructure that identified the show as a 'human interest' story. ${ }^{112}$ The program went on to emphasise personal and affective details about the family's dedication to football. The mix of heartwarming images of a happy family and their eccentric fan support established the Red Devils as a strange but loveable minority in Korean society. Similarly, in May 17 2002, the Chosun Ilbo ran a story on the Red Devils under the headline "wŏldŭk'ŏp ŭngwone 'mich'in' yŏrhyŏllamnyŏ" (Fanatical about cheering for the World Cup),

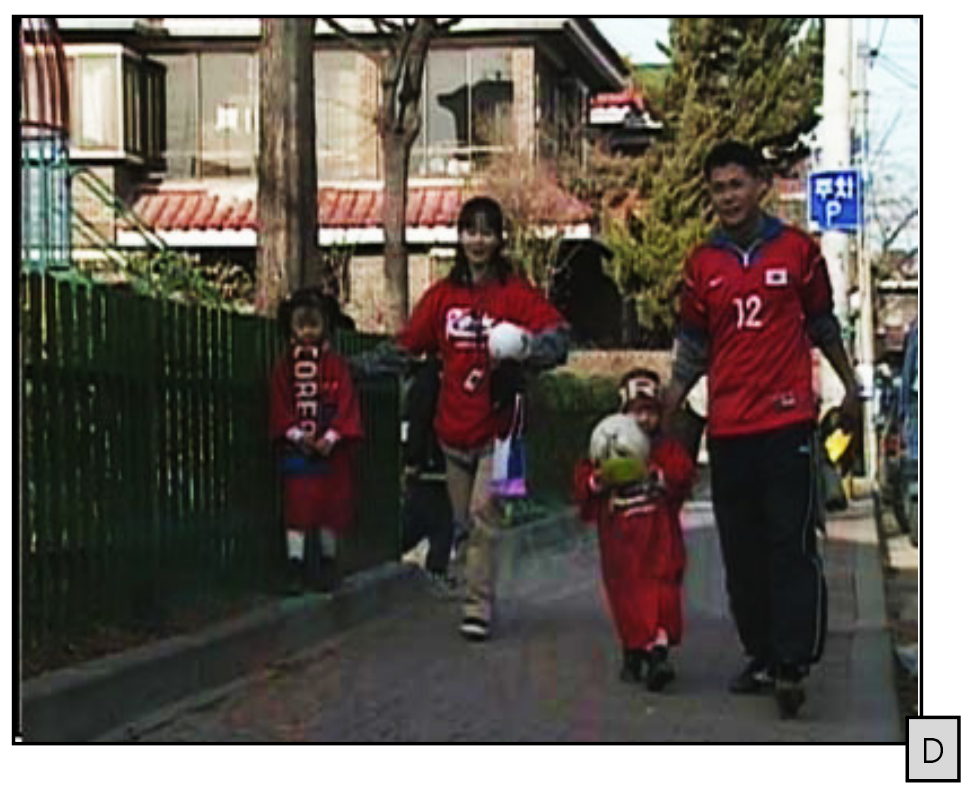
featuring anecdotal stories of Red Devils:

"[Jung, a Red Devil] turns up early to his KTF office every day to contact his fellow Red Devils and discuss new ideas for supporting. He also attends every World Cup-related event without fail. He says that his father, Jung Myung-Hyeon (55, Professor of Medicine, Yonsei University) had not approved of his participation in a supporters' group, but is now much more understanding.

[Jung:] 'My parents were very worried in the beginning. I think once, my mother came to me and said, 'they showed you with your face painted red and screaming on

\footnotetext{
110 “ch'ulbal 2002 wŏldŭk'ŏp - 12pŏntchae taep'yosŏnsu pulgŭnangma" (Start! World Cup 2002 - The '12 ${ }^{\text {th }}$ Player', the Red Devils). Seoul: KBS, January 2002.

111 ibid.

112 See: T. van Dijk (1988) pp13-4.
} 
television' - she was horrified!'”113

The fanatical level of devotion demonstrated by Jung may appear strange or laughable, depending on the audience. In tandem with the headline, the article implicitly emphasises the abnormality of the Red Devils. But this difference from the norm is never produced in such a way as to render the Red Devils dangerous or incomprehensible. The level of abnormality remained at an 'acceptable' level. They were to be consumed as an entertaining and heart-warming interlude in the general narrative of the World Cup. Though the press and broadcast media did not hesitate to explicitly instruct their audience on matters of public order and hospitality, they made no real effort to encourage ordinary Koreans to take up the cause of these football fanatics. As late as the international friendly between Korea and England, held a week before the World Cup, the street supporting 'phenomenon' was non-existent: only a few hundred Red Devils covered themselves in red and engaged in organised, practiced chanting. ${ }^{114}$

However, this pattern of coverage quickly changed when journalists began to notice the growing numbers of Koreans taking to the streets to watch and support their national team. Seemingly out of nowhere, the casual and unfocused gatherings of spectators in the pre-tournament friendlies transformed into highly enthusiastic and dedicated gatherings of supporters growing larger and more fanatical with every World Cup match. At the beginning, the street support phenomenon was to an extent spontaneous, although individual interest in the World Cup and a desire for festivities was cultivated by government, media and business-driven campaigns to build awareness and enthusiasm. Yet by the time of the third Korean match two weeks into the World Cup, the media had fully adopted the role of reporting on street support, interpreting and bestowing upon it a greater significance. The semiotic elements of the street supporters were appropriated and positioned as the primary signifiers of the 2002 World Cup. Newspaper articles reporting on the street supporters became more and more common. In contrast to the model of the eccentric, which was used with regard to the Red Devils, the language used for street supporters became more inclusive and celebratory, and articles mobilised discourses of national pride and identity to interpret the events. The Donga Ilbo published the following in the wake of Korea's first World Cup match against Poland:

"...some thirty thousand citizens had been cheering for the Korean team at the Daegu National Debt Repayment Commemoration Park, where giant screens had been

\footnotetext{
113 “wŏldŭk'ŏp ŭngwone 'mich'in' yŏrhyŏllamnyŏ” (Fanatical about cheering for the World Cup), Chosun Ilbo, 17 May 2002. Special Features section.

${ }^{114}$ MBC sŭpeshŏl - pulgŭnangma, hanbandorŭl ch'ukcheŭi jangŭro (MBC special - The Red Devils, and Korea a land of festival). Seoul: MBC, July 2002.
} 
installed. When the final whistle blew at ten forty-three in the evening, they all shouted 'tae-han-min-guk' as one and celebrated [the victory]. The citizens stayed on for some thirty minutes after the end of the match, watching key highlights through the screens and celebrating the victory with each other."115

"Approximately one hundred thousand people completely filled the roads. The citizens' red shirts recalled a 'red sea'... when Hwang Sun-Hong with a cool finish scored the first goal, shouts shook the sky and the earth, and the citizens went mad with excitement. Together with the 'Red Devils' supporters, the citizens waved their t'aegŭkki, hugged each other and cried 'tae-han-min-guk'.,116

Though the core activity they describe remained similar to the older coverage of the Red Devils, the way in which they were presented was very different. Headlines of the above articles featured phrases such as "when the nation became one" and "we created a legend", which immediately disposed readers to identify with the street supporters, establishing them as normative Koreans. In addition, the street supporters were consistently interpellated as 'citizens'. While this terminology is not as unusual in Korean as it is in a Western context, it brings to the fore the subjectivation of street supporters as Koreans. These articles were also replete with the use of poetic and emotional language, a very unusual strategy for newspapers of such conservative leanings. Their discursive techniques complemented each other to create a series of media texts that positioned the audience in an identical space with street supporters, and in doing so, more or less compelled participation - as if asking, 'you are a Korean like us... aren't you?'. These chronicles of 'all Koreans as street supporters' were produced in great quantity and with a high level of uniformity from early June onwards, as the Korean media began to note and encourage the phenomenon. The two extracts above were, in fact, published on the same day, only a few pages apart from each other with additional, similar stories of street supporters squeezed in those few pages. These stories in the print media, in general, followed a common pattern involving:

- A headline using inclusive and exhortative language, and discourses of solidarity and national pride

- A lead-in using poetic, grandiose language for emotive effect

- Anecdotal stories of dedicated street supporters

- Occasionally, numerical figures and statistics, such as the size of congregations, to

115 “han'guk-p'olandŭjŏn... 'taehanmin'guk' hanadoen nal” (Korea vs Poland... when the nation became one), Donga Ilbo, 5 June 2002. Society section.

116 "han'guk-p'olandŭjŏn: 6wŏl 4il sinhwarŭl mandŭrutda" (Korea vs Poland: On the $4^{\text {th }}$ of June, we created a legend), Donga Ilbo, 5 June 2002. Society section. 
highlight the scale of street support

- Occasionally, mention of foreigners' amazement and approval

- Occasionally, reference to displays of public order and civic responsibility

- A conclusion invoking discourses of solidarity and national pride ${ }^{117}$

This pattern imposed a chronology of its own, whereby the headline and lead-in 'installed' a taxonomic framework of nationality and patriotism, and then mobilised stories of individual street supporters and events to support this interpretation. ${ }^{118}$ Therefore, the structure and discourse of these stories presented the street supporters not as extremes but as norms; their behaviour was not only to be admired, but to be imitated and internalised. This pattern was also maintained in television coverage, although in different forms to fit the medium. The aural and visual elements of the street supporters were promoted at every opportunity: show hosts and celebrities donned 'Be the Reds' shirts and worked the chant 'tae-han-min-guk' into their sentences, even as they offered token apologies to the audience for their 'unprofessional' level of enthusiasm. ${ }^{119}$ The shots of street supporters were, after the highlights of the Korean matches themselves, the most frequently broadcast image in World Cup coverage, and supporters' songs were used as background tracks even in the news.

Finally, corporate marketing and sponsorship also contributed to the popularisation of the street support phenomenon. 'O-p'ilsŭng K'oria' was by far the most popular and iconic supporters' song in the 2002 World Cup. Adopted from a local sports club by the Red Devils, it had been in use for some time before the tournament: however, it was only when SK Telecom remixed the song, enlisted the voice of Yun Do-Hyŏn, and produced it as soundtrack for an advertisement that the song became nationally popular. ${ }^{120}$ Advertisements are an important part of the Korean media landscape. Factors such as a dominant presence of high profile celebrities, investment leading to high production values and a focus on narrative is particularly pronounced in Korea. Consequently, they are seen as fully legitimate media texts with a powerful influence on the public image of not only the advertisers and their products, but the celebrities and cultural tropes that feature in

\footnotetext{
${ }^{117}$ Examples of this pattern include: "4700mani kamgyŏk... kwanghwamun dŭng sushipman inpa 'hŭngbunŭi togani" (The joy of 4.7 million... hundreds of thousands at kwanghwamun and other locations, a 'cauldron of excitement'), Chosun Ilbo, 5 June 2002. General section.

“taehanmin'gukiyŏ! yŏngwŏnhara!... sŏul, t'aegu ŭngwŏn sŭkech'i”" (Republic of Korea Forever! ... Supporters at Seoul and Daegu), Donga Ilbo, 11 June 2002. Society section. "mungch'yŏtda igyŏtda 'tae-hanmin'guk'" (We were one, we were victorious, 'tae-han-min-guk'), Donga Ilbo, 23 June 2002. Sports section.

118 See: A. Bell (2007), p163, 172.

119 “Aju tŭkpyŏrhan ach'im” (A very special breakfast). Seoul: MBC, June 2002.

${ }^{120}$ See: G.H. Joo (2002) p182, and Seo (2002) pp32-3 in J. Horne \& W. Manzenreiter (2004) p195
} 
them. ${ }^{121}$ In this context, the SK Telecom advertisement built enthusiasm about street supporting and the World Cup. The company continued to assert this role, with another advert featuring Red Devils members teaching the viewers the 'tae-han-min-guk' chant. ${ }^{122}$

The combination of media coverage and corporate marketing propelled the street supporting phenomenon to extraordinary levels of participation and enthusiasm. They provided the exposure and the tools for the phenomenon to flourish. Though the media had not and could not have given birth to the phenomenon, it played a key role in popularising it and providing it with an iconic status in the public mindset. The Red Devils continued to be important, especially in organising support at the ground level. However, as the street support grew larger, media coverage determined the terms of its symbolic existence, and framed the ways in which it would be interpreted and experienced. The result was an entertainment spectacle that encouraged and even compelled Koreans to participate through consumption.

\section{A Commodity Spectacle}

In the vernacular, this entertainment spectacle was described as 'World Cup fever'. Media enthusiasm may have appeared as 'spontaneous' and unguided as the phenomenon of street support did, but in fact was organised in a way that maximised potential for commodification. The World Cup fever was cultivated to establish consumption of entertainment commodities as a central mechanism for the creation and satisfaction of desire. The target audience of this media spectacle (and the discourse of World Cup fever) was disposed to find satisfaction and fulfilment in consumption - not only the desire for entertainment or drama, but also the articulation of national pride.

The street support phenomenon, therefore, can be conceptualised as a 'commodity situation', where Korean nationality is produced as a spectacular commodity. The idea of the commodity situation comes from Arjun Appadurai, who removes the commodity from the narrow definition of an exchange of goods for money in capitalist societies, pointing out that even a gift is a social act that is a form of exchange involving social capital. ${ }^{123}$ He suggests that "the commodity situation in

\footnotetext{
${ }^{121}$ The unusual emphasis on celebrity endorsement is discussed in: James Turnbull, "Korean Advertising: Just Beautiful Women Holding Bottles?", The Grand Narrative, http://thegrandnarrative.com/2009/12/07/korea-gendered-advertising/ (accessed 1 September 2010) and H.J. Park (2005) pp144-5.

${ }^{122}$ SK Telecom. “pulgŭnangma paksup'yŏn” (Red Devils, Clapping Episode). Seoul: KBS, May 2002.

${ }^{123}$ A. Appadurai (1986) pp11-13
} 
the social life of any 'thing' be defined as the situation in which its exchangeability (past, present or future) for some other thing is its socially relevant feature."124 Street support, both as an activity undertaken by individuals and observed by others, was appropriated by a number of fields to establish such commodity situations. These ranged from on-the-spot sales of various World Cup and Korea-related merchandise, which directly linked commodities to the lived experience of street support, to the bombardment of news and entertainment media coverage on the street supporters, which reorganised the image, discourse and ideology of the phenomenon into a consumable media text. In Appadurai's terms, the 'commodity candidacy' of the street support phenomenon was maximised in the contexts of entertainment and nationality, ${ }^{125}$ and resulted in an organic formulation of a varied, pervasive and captivating spectacle. As the media, large corporations and small businesses all worked to activate the commodity potential in the street support phenomenon in their own particular ways, the consumer-subject was increasingly positioned in the midst of a relentless flow of entertainment programs, news reports, informative and instructive communiqués, World Cup merchandise, corporate sponsored events and promotions, celebrity concerts and more.

In this respect, it is crucial to understand the ways in which the media coverage colonised the social life of the street supporter phenomenon as a commodity situation. Central to this process was the dramatic increase in the quantity and prominence of World Cup coverage between late May and early July, 2002. The media coverage soon reached saturation level: on the evening of Korea's shock victory against Portugal, Koreans were bombarded with almost two hours of euphoric World Cup coverage in prime time news, and over a dozen articles from both Chosun Ilbo and Donga Ilbo the next morning. It was an extraordinary moment removed from many conventions of media discourse, wherein the significance invested in the victory was used to justify a temporal and spatial demarcation of such a 'special scene', and the unusual act of eschewing 'real' news for euphoric celebration was normalised. ${ }^{126}$ Significantly, the new commodity situation that emerged as the street support phenomenon was coterminous with this extraordinary moment. In the same way that the 'World Cup fever' normalised the news media's celebrations, it generated a bewildering environment which imposed its own rhythms of consumption. ${ }^{127}$ For however persistent and unrelenting the coverage seemed to be, there was in fact a 'rhythm' of crests and troughs that established systems of anticipation, progression and investment on the part of the audience. The audience gradually came to internalise this rhythm of consumption and learnt to

\footnotetext{
124 Ibid., p13

${ }^{125}$ See: Ibid., pp14-15

${ }^{126}$ Mega-events and media events themselves are such removed fields, discursively set apart from 'everyday life': see D. Dayan \& E. Katz (1992) p89, pp103-4 and M. Roche (2000) p7.

${ }^{127}$ See: K. Hetherington (2007) p11, 23 for the 'bewildered' consumer.
} 
enjoy its pleasures. This rhythm was in fact more effective at captivating the audience than a chaotic and unceasing bombardment of information, because it could accommodate varying degrees of enthusiasm and consumption. It was not so much a heavy-handed inculcation of consuming subjects, but rather a relationship of consumption wherein the consumer possesses a degree of agency in the choice of specific commodities and interpretations, even as these choices are inflected by the ever-present clamour and logic of this rhythm.

The print media were particularly characterised by this rhythm, in part due to the rigidity in their format and structure. Based loosely on regular, sports coverage, newspapers built their coverage around three basic 'phases', using each Korean match as a focal point. By focusing on the matches, the rhythm of coverage was complemented by the rhythm of the tournament itself. Two or three days before the match, a 'build-up' phase would set the interpretive framework for the coming match, introducing narratives and roles such as player milestones or subplots of rivalry and revenge. ${ }^{128}$ On the $4^{\text {th }}$ of June, for instance, Donga Ilbo anticipated Korea's World Cup match against Portugal that night with a front page cover story, "Making the myth of Incheon: Korean football's fateful clash against Portugal". ${ }^{129}$ It went on to provide subplots for the upcoming match, such as the rivalry between Ahn Jung-Hwan and Pauleta, largely invented by the article itself. Anecdotes about excited street supporters were also a key part of the build-up phase, as shown by the following article which appeared the day before Korea's match against Poland:

"Many office workers were busy looking up various football-related news during the day, and looking for locations with giant screens to watch the game and support the team.

Park Sŏng-Soo (32, office worker, Seoul) said: 'I'm already anxious, because the Poland match is the most important in qualifying for the knockout rounds... I've been busy looking up places to support, and I've decided on Sejong-ro so now I have to let all my friends know.

Restaurants were also busy preparing for the game, with various promotions on hand. One family restaurant in Apgujŏngdong has offered a free glass of beer every time Korea scores, and has prepared by ordering in 8 barrels of beer and putting all

\footnotetext{
${ }^{128}$ See: R. Brookes (2002) p91, 95 and B. Smart (2006) pp192-3

129 "'inch'ŏn sinhwa mandŭnda' hangukchukku p'orŭt'ugalgwa unmyŏngŭi taegyŏl" (Making the myth of Incheon: Korean Football's fateful clash against Portugal), Donga Ilbo, 14 June 2002. General section.
} 
employees on alert."130

These stories in the build-up phase operated to produce an imaginary of an excited, optimistic, positive and unified Korea and, alongside it, a continuous and composite grand narrative of the Korean team's adventures. The former was a sense of a totality of festival that compelled participation, directly or through consumption of media texts, while the latter provided an emotional investment in the ongoing narrative, again encouraging individuals to return to the World Cup and media coverage of it to satisfy that investment. The myriad of statistical, historical, anecdotal and symbolic elements referenced was of secondary importance: what mattered for the media was to produce stories adhering to familiar narrative frameworks, and encouraging enthusiasm and national identification. For instance, the media positioned the match between Korea and Italy as a rematch of North Korea's famous victory in the 1966 World Cup, thereby applying an extra layer of narrative interest into the coverage. It seemed to matter little that the victory in question had been achieved by South Korea's 'other Self'.

Immediately following each match, media coverage would reach its climax. The newspapers devoted the majority of their pages to reports on the match, as did prime time television news programs. These often attempted to convey the raw sense of euphoria during the match itself, and used the momentous occasion to indulge in figurative and heightened language. Following Korea's victory over Poland, the Chosun Ilbo and Donga Ilbo covered their first few pages with ecstatic proclamations of victory:

"We have finally done it. The dream of a World Cup victory. Korea's taeguk warriors defied Poland's ferocious attacks to grind out a priceless victory. Hwang Sun-Hong's opening goal was absolutely brilliant, and Yoo Sang-Chul's second half goal finished them off completely. 47 million citizens celebrated, and the Red Devils and street supporters' cheers pierced the skies. We had not known just how sweet the taste of a World Cup victory would be."131

"We won. We won 2-0. The first World Cup finals victory that we so craved - that precious dream is now reality. How long have we waited for this? It is a proud victory for the t'aeguk warriors, drenched in sweat after 90 minutes of desperate struggle. It is also a victory for all citizens who, in the Pusan Asiad stadium, by the giant screens in

\footnotetext{
130 "han-p'olandŭjŏn D-1 p'yojŏng" (Korea-Poland D-1), Donga Ilbo, 4 June 2002. Society section.

131 “wŏldŭk'ŏp 2002, urinŭn haenaetda" (World Cup 2002, We have done it), Chosun Ilbo, 5 June 2002. General section.
} 
Seoul's Sejong-ro, and in homes all over the country, all became Red Devils and screamed 'p'ilsŭng K'oria'..."132

Direct and explicit language was used to wax lyrical on 'our victory'. After Korean victories, discourses of national pride and solidarity came to the fore more than at any other point during the World Cup. This triumphant and totalising discourse was grounded in the textual content of the earlier build-up phase, which had set the interpretive framework in such terms. The euphoric discourse of national success and dramatic victory then completed - for the moment - the production of an imagined Korea and the story of the Korean team. The Korean media encouraged the audience to indulge themselves in feelings of optimism, triumph and pride, and simultaneously provided the means by which to do so. To this effect, the Korean media sought to satisfy the constantly diminishing desire to relive the memories and sensations of the match and maximise the return of audience interest on their investment. This comprised the 'evaluative' phase, where the various narratives and themes surrounding the game were revisited from various angles. Typically, these consisted of the following: 'football' stories mobilising the discourse of the sport for a technical analysis of the match; 'personal' stories discussing milestones, achievements and other vagaries of an individual player or coach's experience; 'exotic' stories of eccentric and unusual events related to the match; and finally, stories that examined the impact of the match in terms of Korean nationality. These 'evaluative' texts sustained the audience's interest, and provided a connection between one match and the next. For instance, the following articles were published after Korea's matches against Poland and the United States, respectively, and used the template of a 'personal' story:

"Jung Ji-Won (32) had been watching her husband's match in Pusan's Asiad stadium. And when Hwang Sun-Hong's shot crashed into the Polish net, she burst into tears. 'I was in tears throughout the first half, because I kept remembering all the disappointments my husband has had to experience in past World Cups', said Jung. 'He called me five minutes before the match and said not to worry, that he's feeling great today..."133

"Hwang Sun-Hong suddenly felt dizzy. The area next to his right eye had struck hard against the back of Hadjuk's head, and a stream of blood flowed from it. Hwang wrapped bandages tightly around his head and ran. The eye was swollen and

\footnotetext{
132 "igyutda, t'ae hanmin'guk!" (We've done it, Republic of Korea!), Donga Ilbo, 5 June 2002. General section.

133 “'nampyŏni jun saeng'ae ch'oegoŭi sŏnmul'” ('The best gift my husband gave me all my life'), Chosun Ilbo, 5 June 2002. Society section.
} 
throbbing, but he could not afford to slow down. He jumped higher for the ball, and eagerly probed the American goal. The $40^{\text {th }}$ minute. Finally, a chance..."134

The first article about Hwang and his wife captures them in an intimate setting, while the second achieves a similar effect by narrating the recent match from Hwang's point of view. These texts, though a few days apart, work in tandem to cultivate an emotional investment in Hwang's progress as well as that of the Korean team, creating connections of significance that inculcate the viewer into the rhythm of the media spectacle. Every stage of the cycle created narrative connections to the stage before and after itself: once readers had, through consumption, committed themselves emotionally, these connections provided them a reason to anticipate the next stage. For just as the cycle of build-up, match reports and evaluation closed, another would open up for the next match. Even for sporadic, half-interested consumers, the cycle was regular and familiar enough to allow them to keep abreast of developments, and at any time, re-enter the flow of stories. The rhythm of the stories imposed an order on the coverage that facilitated consumption at all levels.

Most significantly, the imposition of such a structure represented the dictation of commodity logic over the content of the news. The rhythm was a spectacular mechanism: it was devoted to the production of maximum entertainment and the cultivation of a persistent environment of consumption. The media channels and industry workers had more or less independently worked according to a logic of maximising the commodity situation at hand. This commodity logic had then, on a wider scale, organically produced a rhythmic spectacle whose effect was to produce the audience as subjects of Korean nationality, and in turn satisfy the passionate attachment of that subject.

The mechanisms of commodity spectacles transformed the World Cup and the street supporting phenomenon in other ways. As mentioned above, one of the most memorable aspects of the phenomenon was the emergence of the 't'aegŭkki fashion'. Prior to the tournament, the t'aegŭkki had occupied a position in the public mindset more akin to the American national anthem than to the American flag: respected, but not loved. Amongst the street supporters, however, the sporting tradition of wearing striking supporting attire had taken an extreme form, as they manipulated the t'aegŭkki and other symbols of Korean nationality to produce face-paints, bandanas, capes and other fashion items. This presented extremely attractive potential for a commodity situation in the context of news and entertainment media. On one hand, t'aegŭkki fashion provided a wealth of visually striking and attractive images, ranging from comically eccentric accoutrements to the sight

\footnotetext{
134 “hwang sŏn-hong 'pungdaet'uhon'... mimunjŏn nubyŏ” (Hwang Sun-Hong's wounded heroics... probing the American goal), Chosun Ilbo, 11 June 2002. General section.
} 
of scantily clad young women: at the same time, the immediate association with discourses of nationality and patriotism made it commodifiable in a different way, creating a product that was at once sensual and ideological. As such, there was a certain duality in the ways in which this trend was reported by the media. Firstly, the media imposed an interpretive framework of an evolution in Korean nationality. The media frequently argued that the trend represented familiar yet new and modern form of Korean identity, and that traditional patriotism could coexist with the individualism of contemporary society.

"The t'aegŭkki, formerly a symbol of authority and solemnity, was used by the youth this World Cup as a great way to express their patriotism... One of the great achievements of this World Cup is that the taboo regarding the t'aegŭkki was broken, and has become a very familiar figure. I'm sure that even after the World Cup, our youths will roam the streets proudly sporting the t'aegŭkki on their t-shirts, as opposed to the American flag or the Union Jack..."135

Combined with academics and other institutionally authorised 'experts' mobilised to provide opinions, the media narrative effected an articulation between a sense of the sacred and the fashion of the street supporters. Yet alongside this discourse of national evolution was another system of signification: this patriotic narrative was accompanied by striking images of t'aegŭkki fashion that, even by itself, spoke a different language of fashion, bodily aesthetic and social capital to the younger generations. A small hint of such a multiplicity can be found in a television program, where two young male street supporters are interviewed on the spot:

Reporter: Why are you wearing the t'aegŭkki?

Supporter A: To look cool.

Supporter B: $\quad$ Argh, no! If you say that - can you edit that out? [pause] To wear the t'aegŭkki means that the nation is in our hearts. This nation from the nation, this nation-

Host: $\quad$ He's a bit overexcited, isn't he? *laugh*

Supporter B: $\quad$-so we're all being united through the t'aegŭkki! At this rate reunification [between North and South Korea] won't be a problem!

Reporter: $\quad$ But you wouldn't have worn it before.

Supporter B: $\quad$ Of course not. How could we wear it? But now, it's the World Cup!

135 “'kaesŏngmanjŏm' wŏldŭkŏp p'aeshŏn" ('Full marks for individuality' - World Cup fashion), Chosun Ilbo, 22 June 2002. Supplements section. 
Reporter:

Supporter B:
Do you now feel more patriotic?

Absolutely - and it's because of the World Cup! $!^{136}$

When Supporter A initially gives a matter-of-fact answer, 'to look cool' (or 'to stand out'), Supporter B hastily silences him, implying not that he is wrong but that his frank cynicism is inappropriate for television. Supporter B then gives an excited and possibly ironic performance that echoes the media discourse of patriotism and national evolution. In fact, the desire to join in celebrations, to avoid missing out, to 'look cool' and stand out, perhaps to preen for their female counterparts, were all significant factors in their decision-making: at the same time, the knowledge that they were participating in a celebration of Korean nationality would have reassured them and justified their actions, and added to the sense of satisfaction. The truth was probably an ambiguous mixture of both that even the boys themselves would be hard pressed to extricate from each other. The two discourses and logics did not have to be, and were not, completely cooperative: t'aegŭkki fashion became a polysemic signifier that was leveraged by both discourses, producing an ambiguous blend of nationality and commodity spectacle that enabled looking and feeling good at the same time. ${ }^{137}$ All this was symptomatic of the overall mechanism of entertainment spectacle. It was a seductive mechanism by which existing and familiar fields of consumption could appropriate discourses of nationality and justify consumption, rendering it simultaneously more attractive and more satisfying. This is not to say that the 'sacred' nature of nationality and the particularities of its discourse were lost; rather, ideas about Korean nationality were asserted and championed through the consumption of a commodity spectacle.

The t'aegŭkki fashion was the street supporters' way of appropriating the imagery of the Red Devils and the discourse of nationality for the purposes of consumption. Meanwhile, businesses and enterprising private citizens were forming a booming market for Red Devils and World Cup merchandise. Whether in the form of promotions for large corporations, mass-produced souvenirs from professional businesses, or handmade flags peddled by street vendors, individuals and businesses rapidly moved to identify and satisfy the fetishistic desire to consume this entertainment spectacle. The commodity potential that they capitalised on was, literally, public enthusiasm and ecstasy:

Reporter: "When do you get the most customers?

Street Vendor: "Well, after the first half, when you get to the second half, we [Korea] gotta smash them two-nil! That's where the money's at."

\footnotetext{
136 “Aju tŭkpyŏrhan ach'im” (A very special breakfast). Seoul: MBC, June 2002.

${ }^{137}$ See: D. Kellner (2001) p17
} 
Reporter: "That means that whether Korea wins or loses really determines whether

they go home happy or not. When the Korean team wins, they can double or triple their profits, but if it's a draw or a loss, they could even lose money."138

Like the rhythm of media coverage, the pervasive attraction of merchandise extended the lived experience of street support, allowing the consumer to enjoy the spectacle at all times and in all ways. The time and space of the potential consumer were colonised by other commercial interests as well. Celebrities held concerts and shows at scenes of street support, or used media interest to their advantage by allowing themselves to be photographed at matches or in the streets.

Corporate advertisements during this period drew extensively on images and sounds of the Red Devils and street supporters as a performative discourse of their desired corporate image - most commonly familiar and chic, and/or patriotic and ethical. These various forms of commodification did not originate from a single source: a number of fields and industries operated independently under the logic of the commodity. Inadvertently, but unsurprisingly, their efforts collaborated, despite possible contradictions or contestations in minor matters, to form a pervasive entertainment spectacle. ${ }^{139}$

Curiously, one of the most important reasons why the Red Devils and the street supporting phenomenon had such powerful potential for commodification was that they were seemingly not commodified: the media could provide a plausible illusion that the act of street supporting was not 'tainted' by commercial interests, and was instead grounded in a sacred sense of nationality. As discussed in Chapter 2, this was a Lacanian 'universal Lie'140 at work. In general, the Korean subject, being founded on a passionate attachment committed to the ideology of Korean nationality, could not wholly reject or subvert the dominant

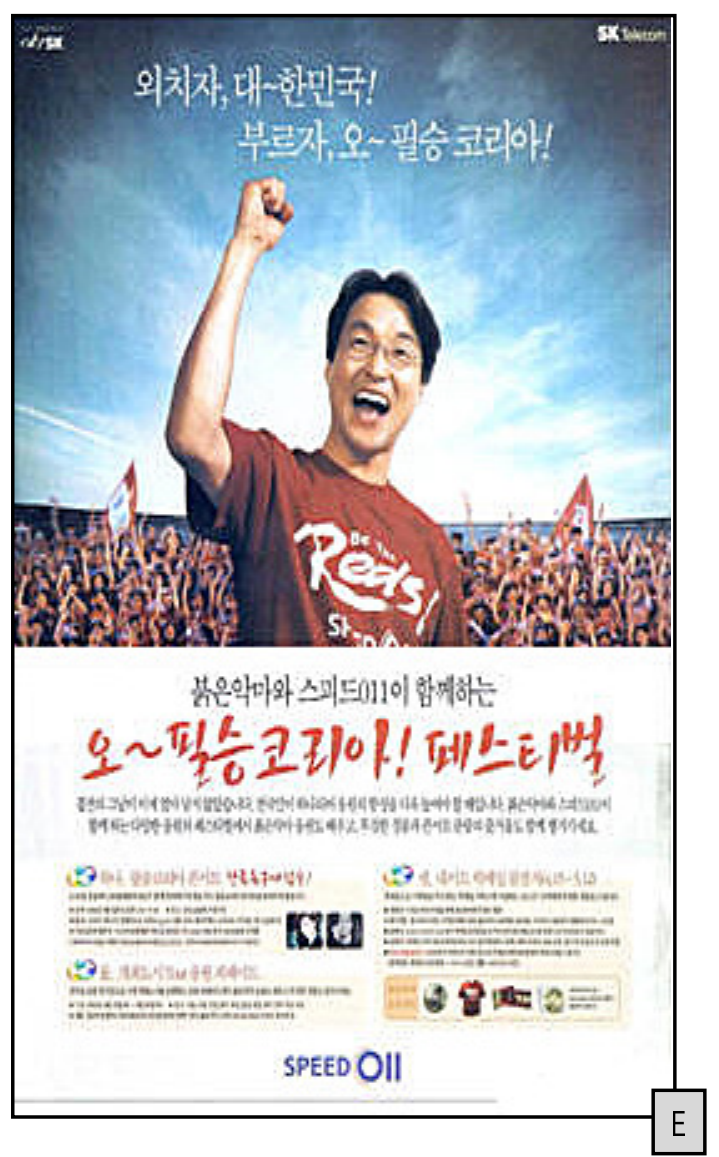

\footnotetext{
138 “Aju tŭkpyŏrhan ach'im" (A very special breakfast). Seoul: MBC, June 2002.

${ }^{139}$ See: D. Kellner (2003) p11

${ }^{140}$ S. Zizek (1997) p130
} 
discourse of national pride and celebration that was so intimately linked with the spectacle at hand. ${ }^{141}$ The sense of the 'sacred' in nationality, therefore, was critical to the popularity and desirability of the entertainment spectacle that built up around it. No matter how spectacular and commodified manifestations of the Red Devils and street support became, there had to be a discursive performance that said 'to consume this spectacle is to participate in a celebration, affirmation and revitalisation of Korea and Korean-ness'. The discourse of nationality acted as the 'face' of the entertainment spectacle. For many Koreans, it was more 'natural' to accept and consume the spectacle to fulfill their passionate attachment to their own identity as Koreans than to reject it and risk questioning their own subjectivity. ${ }^{142}$

In this context, it is not surprising that the Red Devils' refusal to themselves capitalise on this commodity potential aided their commodification. Despite resisting official sponsorship deals or corporate and political affiliations, they did not, and realistically could not, stop all those who used their name, logos and visuals without authorisation, allowing a huge variety of 'Red Devils' advertisements and merchandise to proliferate. ${ }^{143}$ Thus a paradoxical relationship between the Red Devils the group and the Red Devils as a commodity was in operation: on one level, the visual, aural and symbolic elements of the Red Devils could be endlessly commodified, while on the other, the Red Devils as a group were still seen as pure and free of commercial interests. One of the most successful attempts at balancing the sense of the sacred with the logic of the commodity was an advertising campaign run by SK Telecom in mid-2002. As the only exception (at the time) to the Red Devils' stand against commodification, SK Telecom secured the rights to use the Red Devils in their campaign in exchange for provision of operational funds. ${ }^{144}$ In Diagram E, a typical SK Telecom advertisement can be seen using the colour red, the 'Be the Reds' t-shirt and close-ups of screaming supporters as dominant visual components, with the words 'Shout, tae-han-min-guk! Sing, o-p'ilsŭng K'oria!' along the top. ${ }^{145} \mathrm{~A}$ variant added in a large t'aegŭkki for additional effect $(\text { Diagram } F)^{146}$. The company also held live promotional events

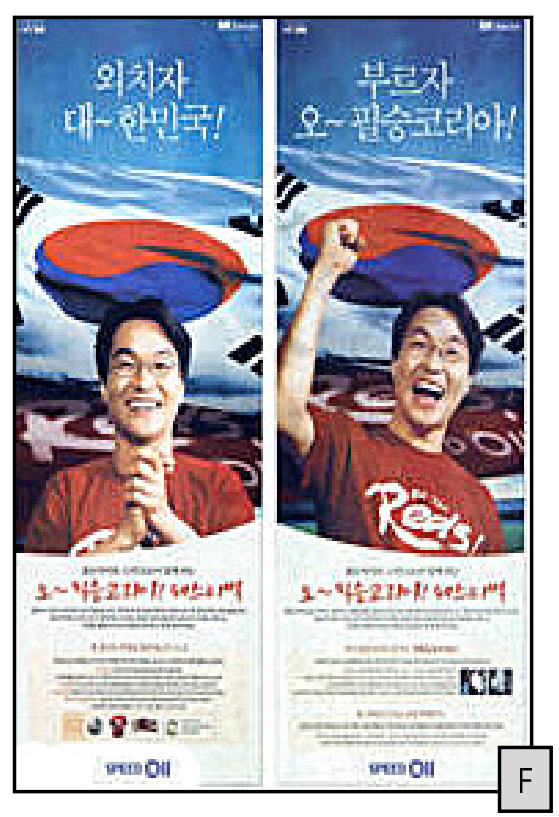

\footnotetext{
${ }^{141}$ See 'passionate attachment', J. Butler (1997) pp7-9

${ }^{142}$ See: H. J. Lee \& Y. H. Cho (2009) p12

${ }^{143}$ S.H. Yi (2004) p53, 146

144 ibid., p53

145 “sŭp'och'ŭ mak'et'ing sarye yŏn'gu - KTFwa SKTŭi wŏldŭk'ŏp mak'et'ingŭl jungsimŭro" (Sports Marketing Study - KTF and SKT's World Cup Marketing). 2008. DC Korea. http://dckorea.co.kr/tt/171 (accessed 22 June 2010).

146 ibid.
} 
such as the 'Red Devils Support Parade', distributing red shirts and balloons and instructing the public in the Red Devils' supporting conventions. In these advertisements and events, SK Telecom avoided prominent use of product placement or other direct means of advertising: rather, they simply ensured the association of their company image with the Red Devils' visual signifiers and forms of support. In this way, SK Telecom was able to preserve the sense of the sacred as much as possible, and appropriate it for the commercial purposes of brand image and awareness.

Despite this accommodation, the eventual fate of the Red Devils showed how fragile this balance was, and how easily the illusion of the sacred could be broken. In 2002, the Red Devils' strong commitment to resist capitalising on their popularity and influence contributed to their powerful commodity potential. But the enormous growth in their popularity and prominence and the rise of external commercial interests began to transform the organisation. For the 2006 and 2010 World Cups, beset with challenges presented by an enormous membership and the pressure of holding bigger and better supporting campaigns, the Red Devils' management accepted several lucrative offers for corporate sponsorship, and also derived income from the sale of shirts and other supporting paraphernalia - items they had distributed without cost in 2002. The Red Devils and their sponsors also took to promoting new chants and songs for every World Cup, in order to produce new advertisements and merchandise. The result was that while street support continued to be a popular spectacle in these two subsequent World Cups, the Red Devils were no longer synonymous with the street supporters or the Korean nation as a whole as they had been in 2002. By 2010, some were even calling for its disbanding, arguing that the large-scale celebrations that had originally defined the group in such positive terms had now become a signifier of their commodification. ${ }^{147}$ The illusion that the Red Devils were 'pure' manifestations of a sacred Korean nationality had been broken by excessively explicit forms of commodification, and the logic of the commodity overwhelmed the discourse of sacred nationality. This rift was thrown into light by a media controversy regarding conflicts between the Red Devils and casual supporters during the 2010 World Cup:
"...but many [street supporters] have reported unpleasant experiences while supporting out in the streets. This is because some supporters' groups are said to be 'hogging' space in public viewing areas, discriminating against those who are not members, and because supporting is turning too commercial and losing its heart...

\footnotetext{
147 See: "sŭp'onsŏ ŭngwŏndan' pulgunangma, t'oejangbak'ŭinŭn dabi upda" (A 'Sponsor Supporters' Group' - the only solution is to send off the Red Devils) 2010. Pressian. https://member.pressian.com/article/article.asp?article num=40100609090032\&Section=08 (accessed 1 September 2010)
} 
...there was a restricted area in the Seoul plaza reminiscent of the DMZ [Demilitarised Zone]. This was dividing the Red Devils and the ordinary citizens. The Red Devils had taken up what is called the 'royal seats' - the best places to watch the match from and one of their sub-groups, called 'Real Red', had stopped ordinary citizens from joining in... Following this, there is growing criticism that the Red Devils supporters are treating our national football team's matches as theirs and theirs alone..148

A gap had grown between the Red Devils and 'ordinary citizens'; while the individual experience of the entertainment spectacle remained, it had become unmoored from its original code of signification, and grown hollow. The discourse of unity and solidarity that spoke so strongly to Koreans, for whom the nation is still divided, had lost its legitimacy. The Red Devils' transgression was not necessarily their involvement in commodification, which was in fact an important part of their activities in 2002 as well. The issue was that their involvement could now be interpreted predominantly in terms of commercial exploitation, through a type of discourse that was mostly foreclosed by the media in 2002. When the sense of euphoria that had dominated media discourse was replaced by an explicit discourse of commodity and spectacle, the Red Devils were no longer as attractive a commodity or viable as a signifier of Korean nationality. The life of the Red Devils and street supporters as an entertainment spectacle shows that many spectacular commodities do not operate by themselves: even as their practical operations are guided by the logic of the commodity, they rely on the performance of a different kind of discourse - in this case, the belief that Korea is great, Korea is something to be proud of, and that Korea is being born again.

\section{A New Korea}

The mechanical operations of the media coverage of the Red Devils and street supporters as a spectacle had produced a consolidated and consistent discourse of Korean nationality that generated understandings of Korea's place in the world, what it meant to be Korean and what was happening to Korea through the World Cup. This discourse used the 2002 World Cup to herald Korea's progress, and put forward an imaginary ' $\mathrm{New}^{\prime}$ Korea - a series of positive, future-oriented affirmations that reassured Koreans of their subjective foundation and renewed the disciplinary power of that subjectivity.

\footnotetext{
148 “wŏldŭk'ŏp ŭngwon ch'anmul' pulgŭnangma ŭngwon nollan" ('A damper on World Cup support': Controversy over Red Devils' supporting). 2010. Edaily News. http://www.edaily.co.kr/news/NewsRead.edy?DCD=A00107\&SCD=DA35\&newsid=02151686593003032 (accessed 22 June 2010).
} 
This process was characterised by a number of different techniques. One was periodisation, or demarcation: the World Cup, as a 'mega-event', was used to draw a narrative trajectory of progress, from 'Old' to 'New' Korea. ${ }^{149}$ This meant that the 'Old' Korea, while not condemned, was attributed with various imperfections and flaws. On the other hand, media coverage, in its praise of a new Korea, implied a Korea that had been held back and was yet to reach its full potential. The 'New', post-World Cup Korea was meant to heal these blemishes and help Korea to fulfill its destiny. The below post-World Cup feature from Chosun Ilbo was just one of many media texts that celebrated this development, and helped establish it as truth in the public consciousness.

"The sight of hundreds of thousands of people gathering, and then cleaning up before returning home in an orderly fashion, was a source of amazement for many foreigners...after the Italy match, Lee Sŏng-Wŏn (18, Sŏil High School) helped clean up after the street supporters with his friends. 'We enjoyed the supporting - now is the time to clean up', he said. Those who could remember the 1988 Olympics' [government-initiated] campaigns like 'let's not hang our washing in the windows' for homes between the Kimpo airport and Seoul could only be amazed at how times had changed... By participating voluntarily, maintaining public order and celebrating our victory, Koreans' civic mentality developed into a sense of pride. These proud Koreans made a giant step forward into becoming global citizens in their own right"150

"The World Cup street support has brought our neighbours together. The experience has brought together apartment dwellers, who had barely known who was living next door, to become like a family. While the players bonded together to defend on the pitch, our neighbours were also all about teamwork, dividing the tasks into teams like 'screen team', 'food team' and 'supporter team',.151

Rubbish-collecting volunteers, neighbourhood communities and other organs of orderliness and community were commonly used by the media to advocate a newfound sense of civic responsibility and brotherhood in Korea, and dispel fears that the rapid urbanisation and technological advances of the preceding decades was producing an increasingly selfish, isolated and blasé populace. The journalists employed emotive language throughout to frame this idea not

\footnotetext{
${ }^{149}$ See: M. Roche (2000) p224 in J. Horne \& W. Manzenreiter (2002) p196.

Also See: M. Roche (2000) p5.

150 "2020 miraero gaja: kkumŭn irulsu itda (4)" (2020, to the future: Dreams can come true (4)), Chosun Ilbo, 5 July 2002. Special features section.

151 “sŏrŏ kkyŏango hwanhohago... wŏldŭk'ŏbi yŏn 'maŭmŭi mun'” (Celebrate in each other's arms... the World Cup opens our hearts), Chosun Ilbo, 25 June 2002. Society section.
} 
in terms of administration and government, but a humanising transformation in the Korean people. This use of language even extended to the use of quotes. It is common practice in the Korean media to edit or paraphrase direct quotations without notice, often standardising the language variations in speech levels and regional variants into a homogenised register. In the above case, the Chosun Ilbo placed poetic phrases in the street supporters' mouths: the teenager's statement would not be out of place in the very public order campaigns that the journalist proclaims now obsolete. Other articles were even more explicit in their periodisation:

"It was exactly 15 years ago. These same streets, on the $10^{\text {th }}$ of June, 1987. It was the same day, and the same place, where the 'June Democratic Movement' began, with cries of 'abolish the [fascist] constitution' and 'we want our vote'. The frightening visage of policemen guarded these streets: the area near the Anglican cathedral was completely shut off. But in exactly the same place, we were now joining our voices to cry 'tae-han-min-guk' and 'o-p'ilsŭng K'oria'. And I saw the birth of a new generation, full of confidence and pride."

As shown above, many of these articles constructed a collective memory of nationwide protests against the military dictatorship in the 1980's in such a way that they provide a useful contrast between the old and new. This is particularly significant in the light of how memory of Japanese imperial rule had shaped Koreans' discourse of Korean-ness in previous decades, to the point where negative characteristics of the Korean people, such as cronyism and nepotism, were perpetuated by the Japanese and internalised by the Koreans as the reason for their subjugated status. ${ }^{152}$ The difference was that the periodising discourses involved a more confident and optimistic construction of collective memory, where the technique of demarcation could be used to overcome enduring ideas about Korean flaws, and the street support could be presented as both catalyst for and evidence of Korea overcoming its traumatic history. This discourse, I suggest, was a reflection of emerging generations who had no direct experience of Japanese rule or military dictatorship and were exposed to the results of rapid economic growth and increasing global cultural influences - generations that the 'New Korea' purported to represent.

The World Cup was therefore used to establish a chronology of national transformation, and in turn naturalise an exclusion of undesirable elements and qualities from the index of normative Korean nationality. This technique was not new: Kim Young-Sam's presidential campaign in the early 1990's had promised to cure the 'Korean disease', which might include "all that was wrong

${ }^{152}$ K. K. Han (2003) pp15-7: “...many Koreans internalised these foreign views of Korea and... came to blame themselves and their culture for their loss of independence, failure to modernise, and poverty." 
with the Korean society and the Korean state". ${ }^{153}$ The difference was that the World Cup as an entertainment spectacle had been able to produce a level of enthusiasm and participation that made the discourse more compelling than any political speeches could have been. There was a sense that Korea had simultaneously embraced new and exciting characteristics to become a 'better' Korea than it had ever been, and revitalise traditional characteristics to realise the Korea that always should have been.

The discourses that brought into being this 'New Korea' were consolidated around the idea of the 'W Generation', or 'World Cup Generation'. Also called the 'R Generation' for 'Red', this term emerged in the media in mid-June, and by end of the month was being used broadly. This technique of interpellation helped identify, from the events of the street support phenomenon, a specific entity that could be named and referenced - and one which had already built up a corpus of symbolic signifiers and ideologies. The interpellation of the W Generation embodied the 'new Korea' that had been demarcated from earlier periods: the characteristics of this emerging entity, such as voluntary participation, orderliness, confidence in individual expression and 'pure' national pride, were depicted as representing a new national identity 'cleansed' of the political agendas and revolutionary mindset of the previous decades' democratic movements.

"A new human race was born in Korea, June 2002 - the World Cup (W) Generation. Ranging from late teens to twenties, they were armed with a kind of confidence that could not be found in older generations. Experts concluded that they brought the joys of play and voluntary participation to a people mired in a group mentality of selfsacrifice."154

"They [the W Generation] drew the t'aegŭkki on their faces, wrapped it around their bodies, and poured into the streets. They confidently expressed what they like and what they don't like... the defeatist mentality, the cynicism and resentment of the older generations were nowhere to be seen."155

This optimistic, future-oriented discourse actively disassociated the younger generation from preexisting tropes of individualism and political apathy to which they had often been subjected: in fact, the descriptions of the W Generation's 'joy of play' and 'voluntary participation' inverted them into

\footnotetext{
${ }^{153}$ S. Kim (2000) p242.

154 "2020 miraero gaja: kkumŭn irulsu itda (7)" (2020, to the future: Dreams can come true (7)), Chosun Ilbo, 9 July 2002. Special features section.

155 "ŏpgŭreidŭ K'oria” (Upgrade Korea), Chosun Ilbo, 27 June 2002. General section.
} 
positive tropes. ${ }^{156}$ These processes had two key implications. The first, more obviously, involved a production of an optimistic future for Korea and Koreans that targeted a desire to be globalised, but to feel that Korean nationality remained relevant. The second carried the subtle implication that pre-W Generation Korea was problematic. 'Old' Koreans in these descriptions are seen as oppressed, violent and resentful; this retroactive definition tapped into more banal discourses of self-deprecation and critique common to many nationalities. A similar discursive technique had in fact been used by the government at the time, whose 'Bright Smile Movement' campaign simultaneously told Koreans they were not perceived as very friendly, and then offered to educate them on the performance of friendliness. ${ }^{157}$ In light of this problematisation, the new Korea was defined as a transcendent Korea, and/or a Korea which had restored a quintessence imagined to have been present in the past. Once again, the ambiguous and therefore flexible mixture of both narratives allowed for a vague yet enduring imagination of Korean progress. Within this grand narrative, the W Generation came to personify discourses of nationality that articulated what Korea is, what Korea is becoming and what Korea should be. The descriptions of the W Generation show how such concepts joined to form a taxonomy of associated ideas.

This taxonomy derived its power to establish itself as a regime of truth from emotive language that invoked the audience's passionate attachment to a Korean identity. Journalists laid aside conventions of impartiality, such as the controlled expression and tone of a news anchor or the use of 'dry' language, and indulged in dramatisation. The columns of Cha Bum-Keun, a Korean football legend, exemplified the ways in which the media communicated, and thus amplified, excitement and pride:

"How...

Did this really happen?

Dear God...

Bring it on!

Bring on Spain!!!!!

$[\ldots]$

What you went through to give us this joy. You spent so long with your eyes only on the ball. What other footballer in the world could have done the same? The stars of

\footnotetext{
${ }^{156}$ These sentiments were best expressed in one television documentary: “A generation which communicates with the computer. An 'internet generation', criticised for not caring about society, not caring about anyone but themselves. But in street support, they showed an amazing energy that older generations could never have imagined." "MBC sŭpeshŏl - pulgŭnangma, hanbandorŭl ch'ukcheŭi jangŭro" (MBC special - The Red Devils, and Korea a land of festival). Seoul: MBC, July 2002.

${ }^{157}$ Y.S. Choi (2004) p25
} 
Europe? They could never do it. Never..."158

Having begun with technical and professional analyses of football tactics merely weeks earlier, Cha's columns soon shed their professional language, air of impartiality and even the formatting conventions of newspaper articles. Written during the World Cup, these outbursts of joy were all the more convincing for their hyperbole, as they gave voice to and amplified the excitement in the audience. These were followed by equally poetic evaluations after the tournament, as the media reappropriated this emotion and gave it a nostalgic and historical form. The first few days after the World Cup final saw a series of almost identical documentaries about the Korean team's journey from both major national broadcasters. These documentaries' solemn eulogies of the events had worked to create memories for the audience. One such documentary combined epic, orchestral music, slow dissolving montages of national visual motifs, a trembling female voice and even a poem to provoke an inspirational and respectful passion for South Korean nationality. ${ }^{159}$ Their hyperbolic language constantly pushed the narratives to become 'larger than life', compelling an understanding of the Korean team and the street supporters not as footballers and football fans, but something more. Another television program even injected an aesthetic sense of heroism into shots of Korean footballers in training, using a combination of rain-misted cameras, close-ups, slow

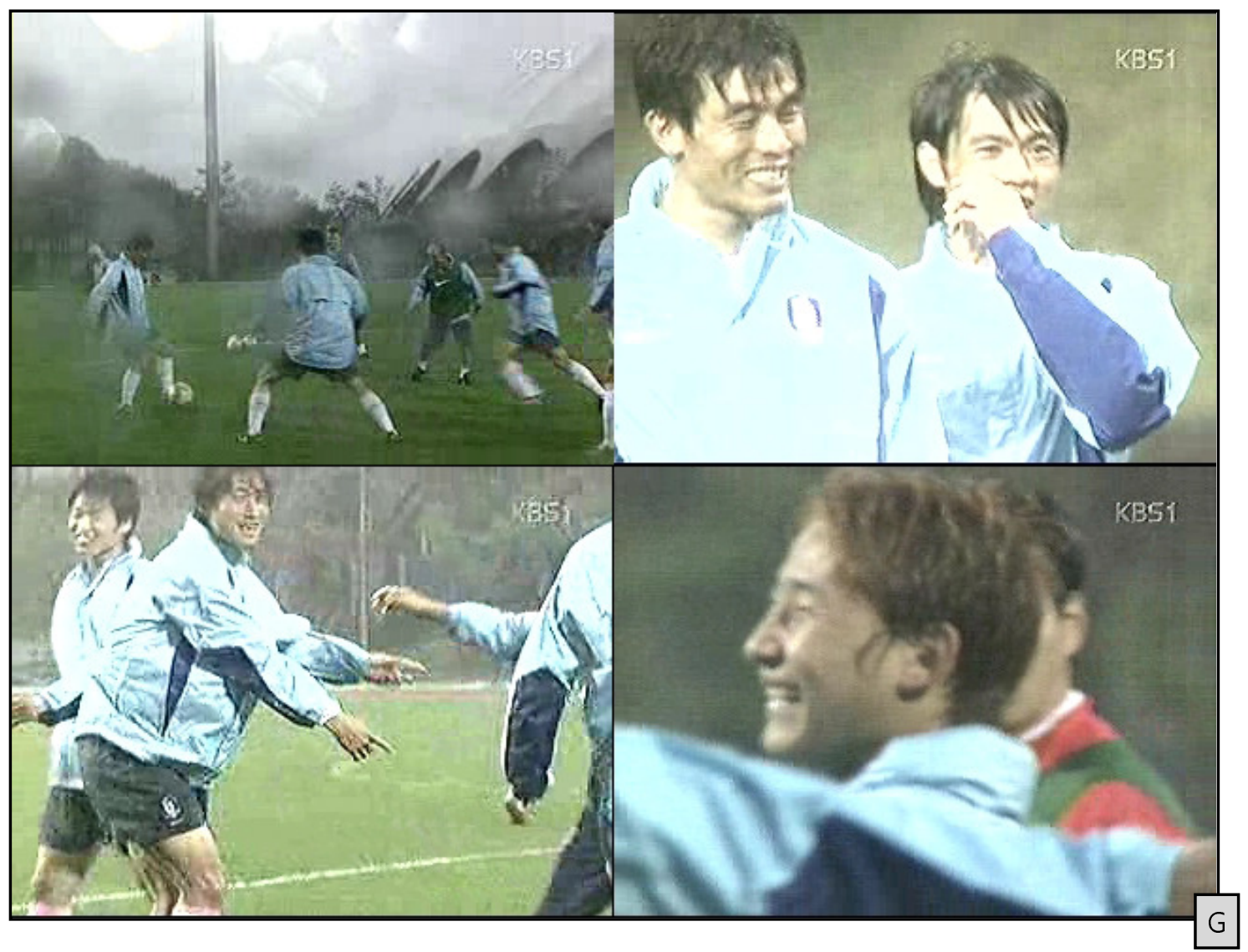

158 “han'guki kanda... nugudŭn dŏmbyŏra!” (Korea is coming... bring it on!), Chosun Ilbo, 19 June 2002. Sports section.

159 "Gwŏrui hamsŏng, taehanmin'guk" (The shouts of June, tae-han-min-guk). Seoul: MBC, July 2002. 
motion, piano music and poetic narration (Photo $\mathrm{G}):^{160}$

"Their road to the knockout rounds was long, but not in vain. They had a coach who recognised their ability, and teammates to share their sweat and laughter. The training on that day, on the rainy ground, would remain in their minds long after they had left."161

This emotive language referenced a sacred element in Korean subjectivity - that is, love of 'our' nation. Specific elements, such as the current state of society or particular facets of Korean mentality, could be isolated and criticised, but not the basic passionate attachment to the abstract notion of 'Korea', of 'our nation'. This reference helped foreclose negative or disjunctive interpretation of this national transformation: the W Generation's provocative outfits, wild manipulation of the t'aegŭkki and unashamed passion for play could potentially have been interpreted as an erosion of traditional Korean values or the development of an 'un-Korean' Korea. Instead, the discourses of national transformation, both in its periodisation and its interpellation of the 'W Generation', had the effect of reaffirming the validity of Korean nationality for its subjects.

This affirmation also had a disciplinary aspect. The inverse of national pride and identification is coercive normalisation. The media ensured that the 2002 World Cup, and the discourses of nationality around it, could not be ignored. Not only were they given an inordinate level of attention and exposure, almost all of that exposure was positive and imperative. The media texts depicted a Korea where everyone was an excited street supporter, proud of Korea, and supportive of the World Cup as a whole. A discourse of solidarity swept the media landscape: it was perhaps not as iconic as the 'W Generation' or the images of t'aegŭkki fashion, but it was even more pervasive. Journalists and media commentators often applauded the emergence of a happy solidarity demonstrated voluntarily by all Koreans. Articles combined the aforementioned techniques of periodisation and interpellation with this idea of solidarity:

"Solidarity was often forced on us. To have the same hair, to wear the same clothes, to see the world with the same eyes, to judge things by the same standard - that was supposed to make us one... we didn't really know what 'becoming one' meant. We just thought, vaguely, that to become one was becoming the same as each other.

In June 2002, we were one in our difference... they [the street supporters] kitted out

160 "unmyŏngui gŭraundŭ" (The grounds of fate). Seoul: KBS, July 2002. 161 ibid. 
with unique red clothes, painted their bodies, carried mobile phones blaring supporter chants and rode roller blades. They scribbled messages on the sacred t'aegŭkki, donned it like capes and bandanas... they generated an amazing energy and made us truly one. Soon, their youthful image became the face of all Koreans."162

There was, again, a juxtaposition of the forced solidarity of the military dictatorships, where the threat of violence-induced sameness, with the voluntary solidarity of the W Generation, who freely engages in patriotic acts. But this discourse of freedom was illusory: it masked an implicit and disciplinary power that rendered this new solidarity 'forced' in different ways. ${ }^{163}$ In fact, these celebratory texts contributed to a disciplinary influence by building media discourses that stressed solidarity and 'sacred' nationality - a subjectivating spectacle of oneness. ${ }^{164}$ The discourse of Korean triumph, a new Korea, the W Generation, a new solidarity - these all masked the commercial aspect of the phenomenon and its mechanisms as an entertainment spectacle. Although most Koreans had direct contact with the phenomenon, they were only able to see a small part of a chaotic whole: as such, the media played an important role in formulating this collective imaginary of a revolution of the sacred into a new generation of nationalism. Alternative interpretations having been foreclosed, the Korean subject was compelled to accept this idea of national transformation. To deride the street support, to be cynical of Korea's success, was to place oneself outside the redrawn boundaries of Korean normality.

Ultimately, it is difficult to be completely cynical about the idea that the Red Devils and street supporters were spontaneous, liberating, and untainted by commercial interests. It cannot be denied that Korean subjects at the time were moved by an understanding of and belief in a 'sacred' nationality, which reaffirmed the validity, quality and legitimacy of Korean nationality. But the spectacle - that pervasive network of commodification and consumption - was not merely the instrument by which this nationality was manifest. Taking after McLuhan's old adage that the 'medium is the message', the spectacle rearranged elements of nationality into modular signifiers as it appropriated them. The existing systems were unanchored and reorganised to produce spectacular, commodified manifestations of nationality, embodied in scenes of street support. The t'aegŭkki, the Korean flag exemplified this process: its historical origins, its common context of use and appearance, its visual form and its social capital were extended, transformed and redesignated by not only the

\footnotetext{
162 “sosŏlga ishinjo ssiga bon 'kilgŏri ch'ukche”" (Author, Lee Shin-Jo's look at the street supporting phenomenon), Chosun Ilbo, 29 June 2002. Supplements section.

${ }^{163}$ This contrast, in fact, mirrors the difference between sovereign forms of power, predicated on the possibility of violence, and disciplinary power, which seeks to inculcate willing and self-disciplining subjects. M. Foucault (1973, 1974 [2006]) pp56-8 and M. Foucault (1977, 1978 [2007]) pp4-11

${ }^{164}$ Also see: H.J. Lee \& Y.H. Cho (2009) p6
} 
street supporters themselves, but by the media and businesses as well.

Therefore, the street support phenomenon cannot be understood as a simple transformation of Korean nationality along a linear trajectory - from beleaguered under the Japanese, to rigid and abused under military dictatorship, to finally free and individualistic with the 'W Generation'. It was, rather, a displacement of Korean nationality from the realm of the 'sacred' to the realm of the spectacle, wherein the body becomes a site for the performance of identity, the symbol is removed from its origins, multiplied and used for its own sake, and the act of consumption emerges as the most powerful and familiar demonstration of approval and preference. This is how we can understand and conceptualise the extraordinary phenomenon of the Red Devils and street support in a way that does not ignore or distort its two most striking aspects: the claim to and attachment to the sacred, and the mechanisms of spectacle and commodity around it. Both were real and significant forces that moved the emotions and behaviour of the consumer-subject. Spectacular nationality did not mean the end of its sacred allure nor passionate attachment to it. Rather, it implied a transformation of the ways in which it was produced and consumed, and introduced the media as a key integrated and naturalised mechanism. The media coverage of the Red Devils and street supporters showed that the idea of sacred and pure nationality could retain its legitimacy and influence in the passionately attached subjects, even while elements of that nationality were reconstructed to maximise their commodity potential. The spectacle, in fact, might even complement 'sacred' nationality, by making it more attractive, more familiar and more compelling. 


\section{The Global: Nationality and the Double-Sided Gaze}

The phenomenon of the Red Devils and the street supporters involved a positive, internally oriented assertion of South Korean nationality. It was an attempt to define and produce Korean nationality in terms of knowledge specific to its subjects and legitimise it in their own terms. But Korean nationality does not exist in a vacuum: it is shaped through relationships of both inclusion and exclusion, and the affirmation of what it is is always accompanied by the rejection of what it is not - the Other as referent. ${ }^{165}$ During the 2002 World Cup, Koreans were acutely aware that the eyes of the world were watching. The government and media, as with the Olympics, proclaimed the event an opportunity to advertise Korea to the world, and gave optimistic projections about the impact it would have on Korea's economy and reputation. The high profile debates on the challenges of globalisation in the mid-late 1990's had also contributed to a pervasive impression of Korean nationality on the world stage during the tournament.

This sense of the panoptic visibility of Korea was encouraged by the media. Their coverage at the time demonstrates a constant fretting over external opinion that entailed a discursive invocation of a foreign gaze that would inform the ways in which Korean nationality was described, performed and communicated. I suggest that a 'double-sided gaze' operated in the media discourse of Korean nationality during the 2002 World Cup, wherein Korean subjects were constantly made to gaze back to the foreign Other - or rather, an imaginary Other of their own making - in order to determine what was desirable and valuable for themselves. This gaze worked to position Korea within a wider significative context of the global: consequently, the 'Other' would come to play a crucial role in the production of the Korean Self.

The operations of this double-sided gaze, and its implications for the way nationality was produced and understood, were perhaps most clearly demonstrated through the remarkable case of Guus Hiddink. As a Dutch manager of the Korean national football team, Hiddink was used as a site for discourses of nationality that both championed Korea by condemning the Other and validated Korea through the Other's approval. Guus Hiddink's career in the Korean media shows that concepts of Korean-ness and foreign-ness are not 'primordial', but fluid discursive constructions that can be manipulated. Nationality does not provide a base category that

\footnotetext{
${ }^{165}$ See: T. Schirato (2007) p62
} 
irrevocably differentiates the Korean and the foreign and from which all other distinctions emerge. Rather, nationality as a taxonomic system is a collective imaginary fuelled by media narratives, positioned and defined against the simulacrum of other nationalities.

\section{The Landscape of the Global}

This complex relationship was grounded in, and symptomatic of, a particular understanding of the global. The global refers to not only contemporary debates on globalisation, but the various nonKorean nationalities which act as the Other. This concept was consistently employed as a discursive technique in Korean media coverage of the 2002 World Cup. In other words, a set of familiar discursive constructs defined the global, positioned Korean nationality in relation to the global, and produced ideal norms and subjective values.

That the 'global' should have featured prominently in discussions of a mega-event such as the World Cup is not surprising. Host nations of modern mega-events have regarded them as opportunities to assess their reputation in the eyes of the world and exert a transformative influence over that reputation. The liberal use of motifs from Mediterranean Sea myths in the 1992 Barcelona Olympics employed the same logic as the Korean government's designation of 'Olympic food' in 1988, and the Chinese government's programs to train its citizens in queuing for the 2008 Beijing Olympics. In each case, the host country identified the mega-event as a mechanism by which extremely large audiences can be mobilised into a positive celebration of nationality. ${ }^{166}$ At the same time, other nationalities were appropriated to produce a backdrop of national characteristics against which the host nationality could be positioned. Throughout the 2002 World Cup, the media constantly developed sets of terminology and narrative roles that harked back to universal ideas and categories. These simplified, archetypical dichotomies included the contrast between African physical prowess and European technical sophistication, ${ }^{167}$ and the use of players such as Beckham and Ronaldo to create iconic motifs that could stand in for entire nationalities. ${ }^{168}$ The majority of nationalities were integrated into this taxonomic system, enabling a standard of comparison and judgment that could then be applied to categorise and make sense of those nationalities. The range of archetypes and the flexibility of discourses involved meant that, if required, the host nationality could be positioned so that comparison with other nationalities

\footnotetext{
${ }^{166}$ See: M. Roche (2000) pp186-9 and J.F. Larson \& H.S. Park (1993) p154 and D. Dayan \& E. Katz (1992) pp7-8

${ }^{167}$ See: "yurŏp chojikryŏk nammi kaeingi nullŏtda" (European discipline defeats South African trickery), Donga Ilbo, 2 June 2002. Sports section.

${ }^{168}$ S. Satoshi in J. Horne \& W. Manzenreiter (2004) p182
} 
would legitimise and favour it. In the context of Korean media coverage during the 2002 World Cup, characteristics attributed to foreign nationalities were frequently invoked in order to justify and promote Korean nationality.

At the same time, other nations employ the technique of categorisation to make sense of host countries during mega-events. One study of American media coverage of the 1988 Seoul Olympics showed how nationhood could be distilled into a single narrative model - in this case, of war. Despite the fact that thirty-five years had passed since the armistice, the Korean War was still the defining framework by which the media presented Korea. ${ }^{169}$ The images in the U.S. coverage were a collection of scattered, ambiguous and non-explicit signs that, through sustained consumption, were stitched together to form vague but entrenched impressions of Korean nationality. Host nations, however, are becoming more aware of such processes, and are employing increasingly sophisticated techniques to leverage the attention of the world more effectively. For the 2002 World Cup, the Korean government and media employed high-level policy directives, special government committees, information campaigns, hospitality education programs and so on for this purpose - techniques that have since been taken up by, for instance, South Africa and India for the 2010 World Cup and 2010 Commonwealth Games. The ambition and hope for an improvement in 'global standing' inspired constant invocations of the non-Korean Other, which would in turn determine what it meant to be 'Korean'. Throughout the 2002 World Cup, the media consistently acknowledged and promoted the belief that the world was watching Korea, and Korea needed to impress those watching. The Korean nationality produced through this media coverage was a performance oriented towards a global Other. ${ }^{170}$

This outward-looking gaze was also motivated by Korea's complex relationship with globalisation the phenomenon of trans-local movements of people, capital, products and ideas. ${ }^{171}$ Some theorists have suggested that globalisation will precipitate the erosion or even the destruction of the nation-state, and the subjective influence nationality exerted over its subjects. Certainly, in the case of Korea, fears of 'Americanisation' and the agricultural sector's fierce opposition to free trade agreements had given the idea of a dichotomy between globalisation and nationalism some weight. However, such a model does not fully reflect the ways in which globalisation is understood and the meaning it holds for Korean nationality. By 2002, globalisation was regarded as both an opportunity for and a threat to Korean nationality. In the 1990's, Kim Young-Sam, Korea's first democratically elected civilian president, had run on an election platform of 'Creating a New

\footnotetext{
169 J.F. Larson \& H.S. Park (1993) pp204-5, 212-4

${ }^{170}$ See: H. J. Lee \& Y. H. Cho (2009) pp2-3

${ }^{171}$ See: A. Appadurai (2006) pp586-7
} 
Korea' (shinhan'guk changjo). This slogan eventually came to revolve around the idea of globalisation, or 'segyehwa', an overarching initiative that called for more interaction with the world across economic, political, cultural and social fields. This discourse of national transformation and evolution integrated the debates on globalisation by presenting it as not merely the best, but the only route for Korea. ${ }^{172}$ It tacitly but powerfully argued that isolationism was not an option, and helped establish a belief that globalisation was inevitable and Korea had to adapt in order to prosper. ${ }^{173}$ This belief has lasted long after Kim and his policies, despite the traumatic experience of the 1997 Asian economic crisis.

This dominance of the ideology of globalisation, however, did not represent the subservience of the local to the global: rather, it was a case of Korea's deep-seated and powerful nationalism appropriating discourses of globalisation for its own purposes. Shin Gi-Wook claims that "most Koreans appear to see no inherent contradiction between nationalism and globalisation. Rather, they seek to appropriate globalisation for nationalist goals." ${ }^{174}$ Shin argues that this appropriation has been motivated by a social Darwinist belief that globalisation presents an 'evolutionary' challenge for nation-states that must be met. I suggest that such a motivation is at once optimistic and pessimistic: the Korean embrace of globalisation hopes for the expansion of Korean culture and industry onto the global stage, just as it fears their destruction under foreign influences. In addition to this uneasy relationship was a deep-seated tendency for Korea to see itself as an underdog. Originating from a series of traumatic experiences including Japanese conquest, poverty, civil war and military dictatorship, it involved a defensive mentality and a constant urge to prove Korea's legitimacy. During the 2002 World Cup, the Korean media told the story of the national football team as that of underdogs, overcoming all odds to prove doubters wrong, and a parallel tale of Korea as a small nation that could compete with the 'best' in the world. This defiant mentality helped to consolidate Korean ethno-nationalism in the face of globalising forces, as well as adopt globalisation and the global as an opportunity for the export and validation of Korean nationality. All in all, the Korean media's discussion of Korean nationality during the 2002 World Cup took place against a global backdrop, and through frequent and prominent invocations of the discourse of globalisation. Nationalities from across the globe provided the Other by which the Korean 'Self' could be evaluated, and the belief that such an evaluation was both valid and desirable. In such a discursive framework, globalisation was not something to be justified, but itself a justification for other decisions and arguments.

${ }^{172}$ S. Kim in S. Kim (2000) p242 and S.C. Yoon \& M.S. Ahn (2002) pp18-9

${ }^{173}$ S. Kim in S. Kim (2000) pp243-4 and G.W. Shin (2003) p6

${ }^{174}$ G.W. Shin (2006) p208 


\section{A Hierarchy of Nationality}

Specifically, the media frequently invoked a prevalent and powerful signifier in contemporary Korea: that of the sŏnjin'guk. Loosely translated as 'elite nation' or 'advanced nation', sŏnjin'guk is ambiguous in its specific characteristics but as a whole a very resonant idea in Korean society. Countries described by the term sŏnjin'guk are perceived as not just rich, but 'advanced' in areas such as civil liberties, democratic institutions, economic strength, political and diplomatic influence and quality of life. Over time, popular stereotypes such as the cultural sophistication of the French or the diligent industry of the Germans have played a significant role in determining which nations are sŏnjin'guk, as well as what defines a sŏnjin'guk in the first place. The sŏnjin'guk provides both a point of reference and the gold standard in contemporary Korean society, and was frequently invoked by the media during the 2002 World Cup in this manner:

"There are many factors that will decide this World Cup's success. The first is that this World Cup needs to be judged as better prepared and better hosted than any other. In particular, Korea's involvement will be very carefully compared against that of co-hosts Japan. It is crucial that this World Cup is used to make the world recognise very clearly that we are a sŏnjin'guk."175

This article, in anticipation of the World Cup, argued that Koreans could use the tournament to make the world at large recognise Korea as a sŏnjin'guk. Not only was the notion of sŏnjin'guk established as something to aspire to, the achievement of those aspirations was to be judged by external recognition. For this reason, the press and broadcast media frequently reported on the way various sŏnjin'guk were talking about Korea during the tournament. Excerpts like the following were very common:

"A British daily, the Guardian, introduced Ahn Jung-Hwan (26, Perugia) as Korea's leading player. Ahn was introduced $22^{\text {nd }}$ in a feature called 'Rising Stars', which introduced players with the potential to catch the eyes of the world through this World Cup..."176

Football was integrated into this comparative matrix of national characteristics. In another

\footnotetext{
175 “wŏldŭkŏp sŏnggongŭi 'chatdae”” (The standards of World Cup success), Chosun Ilbo, 27 May 2002. Letters section.

176 "yŏngguk sinmun, anjŏnghwan 'ttŏorŭnŭn ch'ukkusŭta' 22e sogae" (British paper: Ahn Jung-Hwan is $22^{\text {nd }}$ on 'Rising Stars'), Chosun Ilbo, 31 May 2002. Sports section.
} 
example, the words of Roger Lemerre, the French manager, were mobilised as an authoritative statement on the quality of the Korean team:

“Korea's fighting mentality was truly amazing... France was pushed back by Korea's attack. The truth is that we were not strong enough when fighting for the ball... We did not even imagine that Korea would come out and show such fighting spirit..."177

These quotes are of particular interest because of the way they were 'cropped' from the interview as a whole, and because of decisions made in their translation. Comparisons with English renderings show significant differences. The Independent's version, for instance, reported Lemerre's comments about Korea's attacking prowess and strength as follows:

"We have had to fight hard to cope with the skills, with the physical challenge proposed by the Koreans and with their strong will. But we never gave it up and we managed to win in the end. ${ }^{1778}$

The Chosun Ilbo's comments emphasised Korea's successes, and implied that their performance on the day was superior to France's. The Independent's version appeared to use mostly the same sections of the interview, but implied that the Korean team, despite their hard work, never seriously threatened the French. Meanwhile, the BBC used different and much shorter sections of the interview, producing yet another version of Lemerre's comments. ${ }^{179}$ The Chosun Ilbo emphasised Lemerre's praise of the Korean team, translated them in a more positive manner than their foreign counterparts had, and excluded ambiguous or unfavourable comments. The translation even used the Korean word 'hwaiting', a borrowing from the English 'fighting' that has come to carry the connotation of maintaining a fighting spirit and has no direct correlative in English or French. This was not so much an act of sabotage or dishonesty - selective quoting is commonplace in the media - but a way for the Korean media to emphasise that a sŏnjin'guk manager recognised Korean excellence.

In general, media texts show how sŏnjin'guk were mobilised as supporting examples that justify a core argument about Korean society, and how the legitimacy of these advanced nations in that

\footnotetext{
177 "pulgamdok 'hanguktim jŏnryŏk sangsangdo mothaetda” (French Coach: 'Korea's firepower unimaginable'), Chosun Ilbo, 27 May 2002. Sports section.

178 "Zidane's injury mars gutsy win for France", 2002. The Independent. http://www.independent.co.uk/sport/football/world-cup/zidanes-injury-mars-gutsy-win-for-france652414.html (Accessed 8 July 2010).

179 "Lemerre praises Koreans", 2002. BBC. http://news.bbc.co.uk/sport3/worldcup2002/hi/matches wallchart/friendlies/south korea $v$ france/news id 2010000/2010505.stm (Accessed 8 July 2010).
} 
role was foreclosed. This is an extension of the relationship between the local and global discussed above. The constant reference to sŏnjin'guk bears similarities to the postcolonial gaze, wherein the 'colonised' internalises the perspective of the coloniser, and comes to perceive itself as inferior and in need of the coloniser's civilisation. The implicit and foreclosed acceptance of the standards set by sŏnjin'guk makes Koreans not a passive object of external forces that establish the sŏnjin'guk standard, but a willing subject who - as the Korean journalists do above - actively work to identify the standards by which subjection occurs. On the other hand, the optimistic and even defiantly confident tone in the above excerpts suggests that there is more to this process than subordination. Korea is consistently depicted as a nation that is not inherently inferior to sŏnjin'guk, but one that should and can surpass sŏnjin'guk by their own standards - a nation whose potential merely awaits realisation. The Koreans are thus positioned as underdogs, looking up to the superior sŏnjin'guk, but this inferiority is also portrayed as transitory. In fact, as the World Cup progressed and the Korean national team achieved remarkable success on the football pitch, the discursive role of sŏnjin'guk began to shift. Korea was increasingly placed in a superior position, where it was able to bask in its newfound status. When the Italians expressed outrage at the controversial manner in which they were defeated by Korea, the Korean media belittled their arguments, largely dismissing them as paranoid inventions of bitter losers. One opinion column, headlined "Italy, take a look in the mirror", adopted a particularly patronising tone: discussing the Italian club Perugia's threat to terminate Korean player Ahn Jung-Hwan's contract for knocking Italy out of the World Cup, it argued that Ahn should leave Perugia and move on to a "bigger stage", and implied that Italy was no longer a football sŏnjin'guk. ${ }^{180}$ Korea's victory over a sŏnjin'guk was thus used to reposition Korea, leading to more confident and bullish coverage for the latter stages of the tournament. ${ }^{181}$ Such a discourse of confident assertion presaged a longerterm effect that the Korean team's achievement would have in the collective imagination of nationality.

The idea of the sŏnjin'guk is therefore part of a graduated field of nationalities, a hierarchic grid wherein each nationality and each national characteristic is imbued with a given level of capital. This relationship between Korean nationality and sŏnjin'guk as a whole was only one of many instances of relative positioning. Japan, in particular, was a special case for Koreans to consider: not only had Japan submitted Korea to its rule only decades before, but Japan had since emerged as an economic superpower, widely recognised as the leading Asian nation in many ways. The cohosting arrangement for the 2002 World Cup therefore had potential for a special kind of tension,

\footnotetext{
180 "italiayŏ chasinŭl dorabora" (Italy, take a look at the mirror), Chosun Ilbo, 22 June 2002. Sports section.

${ }^{181}$ See: "t'aegŭkjŏnsadŭl 'urin kangtim... 8gangdo munjeŏpda" (Taeguk Warriors: 'We are strong - we can make the quarter-finals'), Donga Ilbo, 16 June 2002. Sports section.
} 
with Koreans loathe to be outdone by their neighbours on the world stage. Japan and Japanese nationality was thus simultaneously an object of revilement, ${ }^{182}$ an object of admiration and a rival in competition - an Other that functioned in more ways than just as a sŏnjin'guk. The media texts' references to Japan during the 2002 World Cup reflected this complex relationship. On one hand, journalists reported stories of positive Japanese recognition of Korea to show that the World Cup had brought the two nations together: the media depicted a Japan that supported Korea, admired Korea's performance as a host, and voluntary participated in celebrating Korea. ${ }^{183}$ On the other hand, signs of Korean superiority over Japan were gleefully reported as evidence of Korea's progress. When Japan was knocked out of the World Cup before Korea, the discourse adopted a touch of the patronising attitude seen in the discussion of the Italians. ${ }^{184}$

The Korean relationship with the sŏnjin'guk formed only one part of this graduated hierarchy of nationalities; relationships with other Asian nations, for instance, were strongly inflected by a belief in Korea as a regional leader. In the media coverage of the 2002 World Cup, the idea of the 'exotic' provided a useful general framework in which other nationalities, advanced and otherwise, could be understood. The exotic is a technique familiar to media spectacles around the world, wherein signifiers of global nationalities are appropriated for the production of the exotic as a spectacular commodity. ${ }^{185}$ The Korean coverage of the World Cup was filled with sights of supporters and football all over the globe that conformed to pre-existing Korean stereotypes of the strange and exotic. The television media often combined this gamut of exoticness with

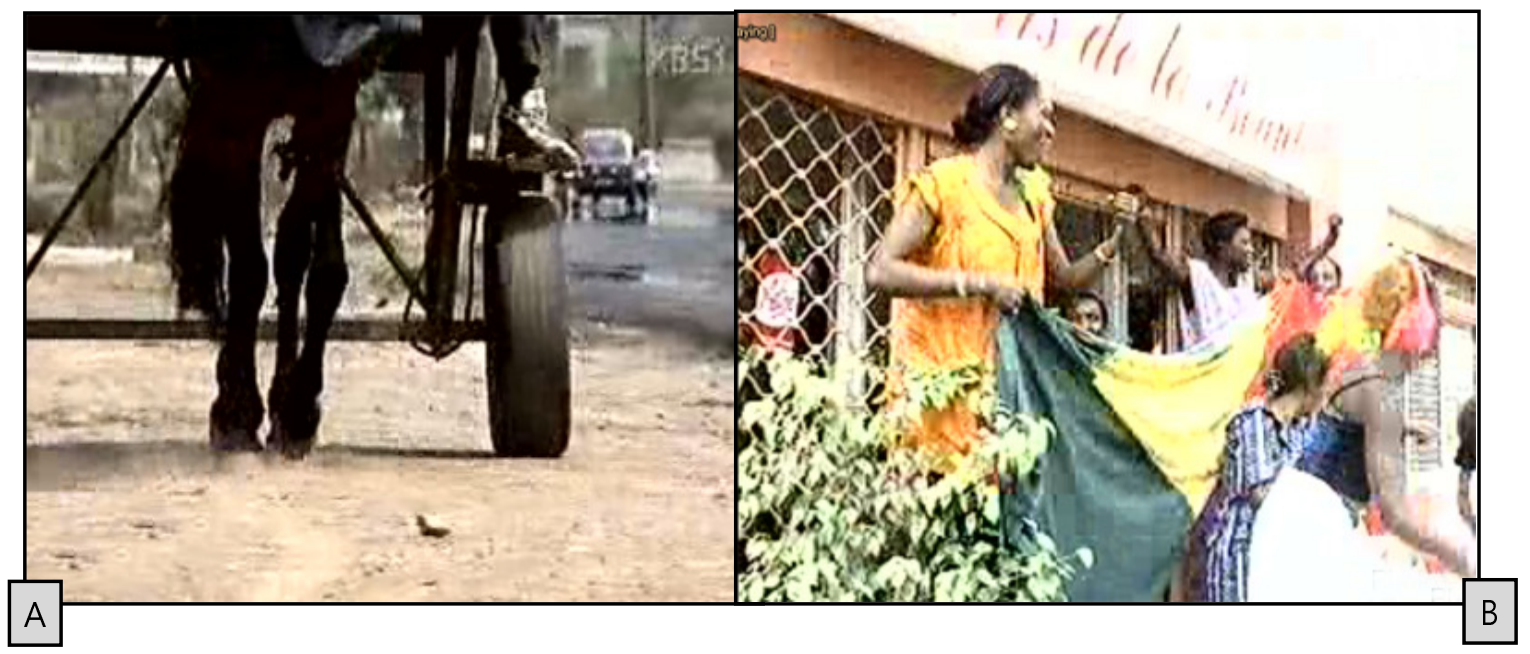

\footnotetext{
${ }^{182}$ See: S. Epstein (2010) p2

${ }^{183}$ See: "ilbon, iljehi han'guk ŭngwŏn" (All of Japan cheers for Korea), Chosun Ilbo, 19 June 2002. Sports section.

Also see: "'tae-han-min-guk' ŭngwŏn yŏlgi il yŏldo dŭlssŏk" ('tae-han-min-guk' shakes the Japanese peninsula ), Chosun Ilbo, 23 June 2002. Sports section.

${ }^{184}$ See: "han'gukchukku 'utgo' ilbonŭn 'ulgo'" (Korean football all smiles, Japanese football in tears), 18 May 2002. Sports section.

${ }^{185}$ G. Debord (1988 [1990]) p7, 15
} 
narrative themes of the 'brotherhood of man' and the 'global village':

"A message of peace was fired, not from Europe or the Americas, but Asia, and echoed around the whole world through the World Cup. The tournament's message of a world in harmony was expressed through the Asian philosophy of mutual understanding.,186

This excerpt was typical of media discourse at the time: the World Cup's universal values, such as peace and harmony, were integrated with perceptions of Asian and particularly Korean values. Various cultures around the world were used to support this depiction. In most cases, the media's depiction of foreign nationalities was achieved by first eliciting awe from the audience over the exotic, then reassuring them that an essential sameness can be found in these strange places through narration, personal stories and so on. One documentary's coverage of Senegalese football fans begins with images of an African urban landscape: a worker drives a horse-driven wagon on a dirt track adjacent to a covered highway (Photo A). ${ }^{187}$ After a brief historical overview, the program stresses that "for them [the Senegalese], football was hope." ${ }^{188}$ As traditional African music plays in the background, slow-motion close ups of Senegal's winning goal against France are shown, followed by scenes of euphoria in Senegal (Photo B). ${ }^{189}$ This structure first defines Senegal by a readily recognisable difference between 'Africa' and Korea, then, using the slogan-like phrase 'football was hope' as a turning point, depicts Senegal in terms of such universal values as solidarity. In the images of celebrating Senegalese, the audience is reassured of not only the universality of these emotions, but also the importance of football, and the legitimacy of their own emotional investment in the World Cup and Korean nationality. At the same time, at the level of media consumption, the exoticity of the Senegalese provides entertainment, satisfying a 'quest for novelty' as a source of commodity potential. ${ }^{190}$

One explanation for the production of these exotic national archetypes was that the World Cup presented a bewildering variety of national cultures, histories and narratives that had to be organised into familiar caricatures for the consumer. The exotic must be different, but not so complex or alienating in its difference as to be incomprehensible or repulsive. In the same documentary, the Senegalese are introduced with reference to the 'Black Continent': this verbal invocation of Africa combines with images of dilapidated buildings and the sound of pounding drums to produce an immediately identifiable blend of poverty and primal energy that typifies

\footnotetext{
186 "kkumŭn iruŏjinda: 31ilganŭi kirok" (Dreams come true: A record of 31 days) Seoul: KBS, July 2002.

187 "chukkuyŏljŏng, segyerŭl chŏngbokhada" (Football passion conquers the world), Seoul: KBS, July 2002.

188 ibid.

189 ibid.

190 See: A. Appadurai (1986) p28
} 
caricatures of modern Africa. It is no different with a sŏnjin'guk such as France. Coverage of French supporters in the same documentary begins and ends with shots of champagne; the laid back, middle-class supporters provide an equally typical image of France as a land of culture, wine and sophistication. Their disappointed but collected demeanour following the defeat illustrates a 'disinterested interest ${ }^{\prime 191}$, excising the violent hooligans and racism that plague contemporary French football. Such a depiction established a contrast between 'cultured' French spectatorship and the chaotic, frenzied Senegalese celebrations. These exotic archetypes of nationalities were then able to be different, but in a way that was immediately understandable: not the truly Other, which was incomprehensible, but the deviant Other. ${ }^{192}$ This happy confluence of difference and sameness made these archetypes attractive as spectacular commodities: as Debord has argued, they were presenting a myriad of consumable differences that nevertheless give evidence for universality. ${ }^{193}$ As the example of France demonstrates, the exotic and the sŏnjin'guk are not mutually exclusive. The ubiquitous gaze of the camera commodified every nationality at handincluding Korean - for consumption that would simultaneously entertain and reassure.

\section{The Double-Sided Gaze}

The discourse of globalisation and the symbolic landscape of global nationalities were key influences in the production of Korean nationality during the 2002 World Cup. The Korean nationality that emerged from this context was performative and spectacular, founded on an impression of panoptic visibility. It was encapsulated by a basic but powerful mantra repeated by the Korean media 'the world is watching us'. To the right (Photo $C)^{194}$ is a typical image from the time: a foreign journalist trains his camera on the Korean masses. The gaze

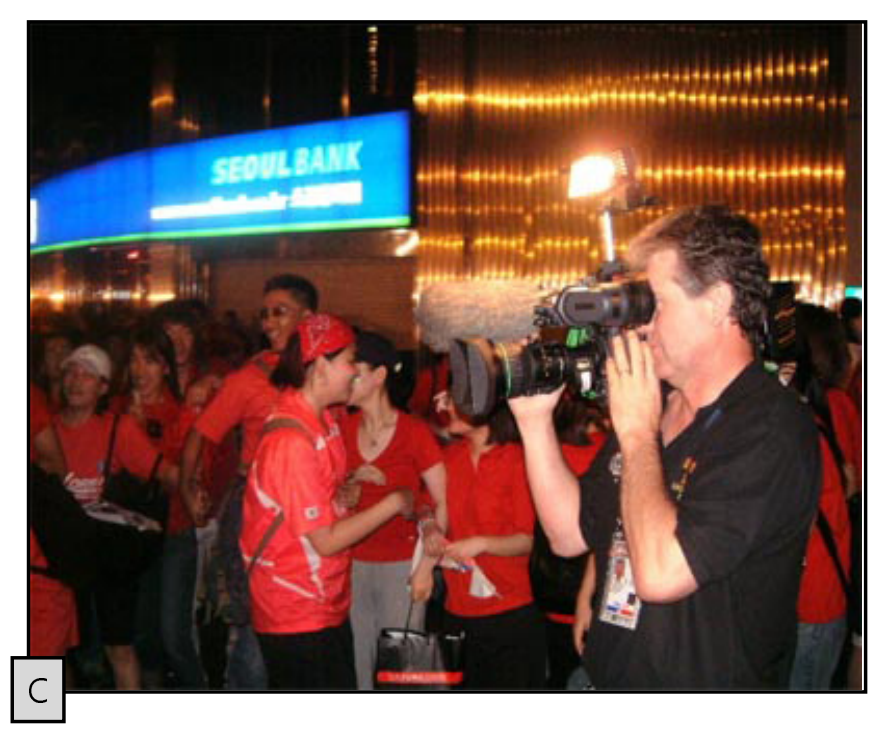

\footnotetext{
${ }^{191}$ Bourdieu identified this as a signifier of class and sophistication in sport as well as other fields. See: P. Bourdieu (1991) p372

192 J. Butler (1997), p27

${ }^{193}$ G. Debord (1988 [1990]) p17, 51

${ }^{194}$ Nam Jae-Woo, 17 June 2002, "kŭnalŭi kwanghwamun 2" (Kwanghwamun on that day, Part 2), Dr. Spark's Columns. http://sparkbbs.dreamwiz.com/cgibin/rbbsview.cgi?section=FREETALK\&start=0\&pos=1955 (accessed 19 September 2010)
} 
of the foreigner, or rather, the Korean awareness of that gaze, rendered Koreans' actions a performance of nationality. "Vision itself became a kind of discipline," ${ }^{195}$ wherein the Korean host imagined and spoke into being a visitor-inspector whose existence exhorted Koreans to performances of nationality, and whose standards and judgments were projected onto it by the hosts themselves. The media spectacle of nationalities was a crucial element that enabled the production of such an Other, which in turn motivated Koreans to perform their nationality. ${ }^{196}$

One of the most prominent and explicit ways in which this disciplinary power was enacted was in the discourse of hospitality. During the World Cup, the Korean press demonstrated unusual levels of directness by exhorting its citizens to improve their behaviour for the event and to be good hosts. The chief motivation was to improve Korea's standing in the eyes of the world - a purpose built on the assumption that Korea would benefit from meeting 'global' standards, and that doing so would help the nation 'go forward'.

"As we prepare the 2002 Korea-Japan World Cup, what might foreigners be thinking about our country? I worry that just as we think of the dark days of Franco's dictatorship with Spain, they might think of Korea's military dictatorship and street protests, and the [1997 Asian] financial crisis. The World Cup will attract the attention of the entire world - I think it will be a unique opportunity to show Korea's transformation and the way Korea really is. By demonstrating a friendly and orderly civic mentality, the public can spread the image of a Korea that one would want to visit again, a Korea that leads the new information age."197

"In contrast to what Koreans might have hoped, foreigners' images of Korea were often negative, such as that it is a 'divided country' or 'a country with unstable economy and politics'. The ' 88 Olympics raised awareness about Korea, but could not change this image. But the Korea-Japan World Cup is providing an opportunity to change this. Journalists and expatriates all over the world are saying that the World Cup is the first time there's been so much positive news about Korea."198

In these articles, the question 'what do others think of us?' frames the entire discussion. A problem is identified (Korea's current image), a solution is provided, and a call for action is made

\footnotetext{
195 J. Crary (1992) p18

${ }^{196}$ See Foucault's analysis of Bentham's panopticon: M. Foucault 1975 [1979]) p201, 209

197 "wŏldŭkŏpttae 'IT K'oria' chŏnparŭl” (Advertising 'IT Korea' during the World Cup), Donga Ilbo, 21 June 2002, Opinion section.

198 “kukkaimiji ŏpgŭreidŭ” (Upgrading our national image), Donga Ilbo, 29 June 2002. Features section.
} 
(public order and etiquette). The majority of the media coverage involving national image adhered to this general format, and conceptualised hospitality as a test for the Korean nation. This discourse was consciously produced by the media and other institutional sources, such as academia and the government. It was grounded in the idea of the global and the implicit normality of Western civil society - with the sŏnjin'guk the ideal:

"The difference between a sŏnjin'guk and a hujin'guk [primitive, backward nation] can be one of economic or military power, but the most important standard is that of civic responsibility. It is expressed through manners and refinement, which are most visibly represented through what might be called 'basic public order'. 'Say sorry when you bump into someone', 'no spitting in the streets', and 'keep the noise down in restaurants' - putting just these three things into practice can upgrade Korea to another level."199

Deviations from this ideal were labeled as 'backward' in order to establish a graduated field of normality, and imply the need for Korea to aspire towards the standards of a sŏnjin'guk, in this case, public order and social etiquette. The Korean imagination of citizens of the sŏnjin'guk and what they might find appropriate dictated instructions on how Koreans should host visitors. In essence, the Koreans were being asked to internalise an imaginary gaze positioned at an external origin.

That a process of collective imagination was involved did not make the idea any less real or effective. The media constantly communicated a sense of visibility and external surveillance, and, while it would not have been internalised completely, it undoubtedly contributed to heightened efforts on the part of Koreans to act hospitably which was appreciated by no small number of foreigners. Thus, "it is too naïve to regard the cleaning process as a proof of increasing social consciousness or civic ethics in South Korea. By promoting and participating in the street cleanings, citizens embodied a nationalism that was symbolic with their global desires and disciplined by the global gaze."200 Therefore, 'Korean-ness' during the World Cup produced a form of Korean subjectivity that established the subject around the central figure of Korean nationality, but mobilised the external Other in order to construct this centre. ${ }^{201}$ Nationality thus involved a certain duality, wherein it was produced for consumption of the Korean subject as well as the Other. Media discourses of national image, national progress and the World Cup as a global

199 "segaji manirado jikija" (Let's keep at least these 3 rules), Chosun Ilbo, 01 June 2002. General section.

${ }^{200}$ H. J. Lee \& Y. H. Cho (2009) pp22-23

${ }^{201}$ See: ibid., pp10-12 
festival therefore looked both inward, to preexisting conceptions of Korean nationality, and outward, to both projected standards of sŏnjin'guk and the forces of globalisation. In this manner, a passionate attachment to Korean nationality was encouraged: matrices of normativity were formulated which induced the Korean subject's desire to perform and promote Korean nationality. 202

To sum up, the characteristics of the double-sided gaze, in this particular case, are as follows. Firstly, as discussed above, it looked to an internal system of values and phenomena to assert that the Korean 'Self' was valid, valuable and normal, but relied on standards derived from the 'Other' to justify this assertion. This can be seen in the way Koreans frequently refer to Korea and Koreans as 'urinara' (our country) and 'urinara saramdeul' (our people), respectively: this ethnicnationalistic Self is clearly demarcated from the Other, and retains a sense of autonomous identity even as it is defined in relation to the Other. Secondly, the Self's relationship with the foreign Other was simultaneously aggressive - establishing the validity and superiority of the Korean 'Us' through unfavourable comparisons - and self-deprecating, recognising the sŏnjin Other as the standard to be met. The gaze therefore mobilises the Other in such a way that Korean nationality in the present is justified, and a narrative of progress oriented around an ideal Korea is presented. Finally, the media constructed a collective imaginary of the 'Other', a Baudrilliardian simulacrum that is more 'real' than the real Other. There were undoubtedly direct contributions from foreign sources regarding impressions of Korea, but Korean media discourse of the Other far superseded this 'primary evidence'. When colonially minded photographers point their camera at indigenous peoples, they use the framing power of that gaze to directly manipulate the visual representation of their subjects. In this case, however, the subjects of the gaze themselves changed and adjusted their behaviour for the camera, seeking to manipulate their own image through an external gaze.

This relationship with and appropriation of the Other cannot be easily tracked by a linear narrative of national progress, from a primitive nation to an advanced and superior one. It is undeniable that for Korea, the turn of the millennium was a time when the defensive mentality regarding Japan and all things Japanese, inspired equally by the traumatic experience of annexation and a keenly felt inferiority complex, was fading as younger generations came of age and Korea advanced economically. But as the operations of the double-sided gaze show, this emerging national confidence was not predicated on a disavowal of the superiority of the sŏnjin'guk. Rather, it was a peculiar manifestation of hybridity; ${ }^{203}$ threatened with displacement by the advent of

\footnotetext{
${ }^{202}$ Also see: “...norms operate as psychic phenomena, restricting and producing desire...”, J. Butler (1997) p21

${ }^{203}$ See: H. Bhabha (1994) pp162-3
} 
globalisation, Korean nationality responded by appropriating foreign standards and methods for its own ideological purposes, all the while deploying assertive discourse that located it in a position of the challenger. As a challenger to sŏnjin'guk, Korea is positioned in such a way that the temporary superiority of sŏnjin'guk can be recognised (thereby authorising the external gaze of the foreign Other) without contradicting the discourse of national transcendence. In this context, descriptions of Korea and the Korean team as an underdog implied a transitory state, wherein it could, at any moment, rise above its current station.

Finally, the media was the primary site for all of these discursive deployments. Even as individuals' personal experience of foreign nationalities increases as a result of globalization, the media continue to play a crucial role in shaping impressions of this Other, and the Self in the reflection of that Other. As the simulacrum "substitut[es] signs of the real for the real itself," 204 so narrative models in the media spectacle shape how the foreign Other, and by extension, the Self are understood.

\section{Guus Hiddink}

The cult of worship around Guus Hiddink, the manager of the Korean national football team, was one of the key features in Korean media coverage of the 2002 World Cup. In his initial months he was vilified, and in that process, became an uncomprehending Other who did not belong to Korean society; yet by the end of Korea's successful World Cup performance, that foreignness had been partially erased and transformed, redefining him as a champion of Korean values. The story of Guus Hiddink, and the trajectory of his public image, is perhaps the most telling example of this landscape of the global, and the double-sided gaze.

In January 2001, the Korean Football Association appointed Guus Hiddink as the manager of the South Korean national football team. On one hand, his glittering credentials and his home nation of the Netherlands - a 'football sŏnjin'guk' - backed up his appointment: on the other, his foreignness was a risk in itself, for both Hiddink and the KFA. A national sports team assumes an importance that renders it a direct representative of the nation as a whole, and its successes and failures become a projection of that nation's position and progress. The idea that a foreigner should take charge of that entity provokes discomfort for many nations: in England following the 2006 and 2010 World Cups, the media and public lambasted their Swedish and Italian managers

${ }^{204}$ J. Baudrillard (2001) pp169-170. Also see 'precession of the model', p178. 
and called for an 'English manager for an English team'. The same treatment could equally have befallen Hiddink.

The first few months of Hiddink's reign indeed appeared to follow such a pattern. Because of a relatively sparse schedule, the few matches that the Korean team did play in came under intense scrutiny: one great or terrible performance could attract the attention of the media and the public, and vindicate or condemn the entire team. When the Korean team succumbed to two humiliating 5-0 defeats against France and the Czech Republic in May and August 2001, these matches were symbolically invested as icons of failure attracting and validating criticism of Hiddink and the Korean team. Chosun Ilbo journalists later recounted that "from this point on, Hiddink and his team begin to tread a thorny path". People began to mock Hiddink by the name of odaeyŏng, which means 'five-nil', but can also be read as a typical Korean name. ${ }^{205}$ Following the second 5-0 defeat, a current affairs program held a panel debate titled "Team Hiddink: Is This OK?" The program opened by assuring the viewers that it was not out to blame Hiddink for the loss:

Host: "I'd like to begin by assuring you that this [blaming Hiddink] is not the case at all. We are here today to discuss... what we - the football association, Hiddink, the players, the public - can do in the remaining time to get a good result at the World Cup..."206

This caveat was in effect a pre-emptive gesture to defend the program's direction: journalists and commentators were acutely aware that their criticisms could in turn be interpreted as a failure to support the Korean team, and by extension, the national cause. In fact, the program and its host clearly and consistently performed two discursive functions: firstly, they established and defended the idea that these defeats represented a clear failure. The provocative program title was followed by a montage of the team's recent defeats, and the questions asked of the panel presupposed issues that had to be resolved: the debate was structured around topics such as "Why are we weak against Europe?" and "Are there no problems with Team Hiddink?" When the guests began to provide optimistic and defensive responses that argued Team Hiddink was 'OK', the host interjected and drove the discussion back to the 'problem':

Panelist: "In particular, the 5-0 [result] against the Czech Republic should not be considered as anything more than a friendly match... the score may have

\footnotetext{
205 “kkumŭn iruŏjinda” (Dreams come true) (2002) p11. Also see: J. M. Kang (2006) p246.

206 "100bun toron: hidingkŭho idaero choŭnga" (Debate 100 Minutes: Team Hiddink: is it OK like this?) Seoul: MBC, August 2001.
} 
been 5-0, but I could find many positive things to take from that match."

Host: " [smiling] Even so, 5-0 is a fairly embarrassing result in a first team match... there's not a lot of time left, and some people are saying, how long can this go on? Please point out some problems as well."207

Secondly, the program consistently problematised Hiddink's leadership as the reason for that failure. This is, on the surface, a natural course of action: he was the coach, and his assumption of the position was the major recent change in Korean football. But more significantly, the program was discursively isolating and locating the Korean team's flaws and problems within the person of Hiddink - his profile, his actions, his policies. Comparisons with Philippe Troussier, the French manager of the Japanese team, also demonstrated the competitive anxiety regarding Japan. The football experts on the panel pointed to Hiddink's lack of knowledge about Korean culture and players, as well as his excessive physical training, as stumbling blocks in the Korean team's World Cup bid:

Panelist: "To manage a Korean team, you need to understand Korean culture: and to direct that team's tactics, I think you need to be able to at least say basic football terms [in Korean]... we need to see that kind of effort, or signs of that effort [from Hiddink.]"208

For several months, Hiddink continued to be the target of negative media coverage. In February 2002, the Gold Cup had just ended, and "Hiddink became embroiled in the 'girlfriend controversy'. It was made known that his girlfriend Elizabeth had stayed in the same hotel as the national team during the Gold Cup...the controversy overlapped with the news of lacklustre results at the Gold Cup, and became larger." ${ }^{209}$ The mainstream media generally interpreted this as a sign of immorality rather than cultural difference, and argued that it represented Hiddink's failure to conform to Korean expectations and conventions: for Korean society at the time, unmarried relationships at such an age were unusual at best, and romantic relationships were considered a strictly private affair that should not be allowed to interfere with public duties. ${ }^{210}$ In such ways, subtle commentary on Hiddink's foreignness underlined criticism of his performance, locating his foreignness as an inevitable weakness or flaw. In other words, the latent possibility for

\footnotetext{
207 ibid.

208 ibid. Also see: "kkumŭn iruŏjinda” (Dreams come true) (2002) p13. Also see: J. M. Kang (2006) p246.

209 "kkumŭn iruŏjinda" (Dreams come true) (2002) p17

210 "pukjungmi goldŭkŏp kyŏlsan / han'gukchukku tesŭtŭman hada nalsaenda" (North/Central America Gold Cup Summary / Korean football - experiments all day long). Chosun Ilbo, 04 February 2002. Sports section.
} 
unfavourable interpretation in Hiddink's persona and actions was now mobilised in the wake of a need for criticism and blame. Later events proved that these very characteristics that were criticised could just as easily be erased from media discourse, or even transformed into highly positive factors.

The transformation of Hiddink into a national hero happened quickly. As late as early 2002, the possibility of a new manager was discussed: but as the World Cup loomed closer the media criticism suddenly ebbed. In March 2002, Chosun Ilbo published a column that lambasted Hiddink for his excuses: only two weeks later, they were celebrating Korea's encouraging friendly results by suggesting Hiddink had been right all along. Then in May 2002, three matches provided the catalyst for a total transformation: the Korean team had given a markedly superior performance against Scotland, England and France, the latter two firmly recognised as 'football sŏnjin'guk'. It did not matter that only one of these matches was a victory, or that they were non-competitive matches: they performed the same role of the iconic catalyst that the 5-0 defeats had. Hiddink was suddenly becoming acclaimed as a genius, and the Korean team a success story.

"Guus Hiddink was nicknamed 'odaeyŏng' [five-nil] after losing to France 5-0 in last [2001] May's Confederations Cup... but through the friendlies against England and France, he has been reborn. His predictions came true, and the Korean team was reborn into a powerful team. Hiddink is now being marked out as the man who will turn the World Cup upside down... the criticisms of 'odaeyŏng' are now nowhere to be found. These days he is called 'He thinks', after the sound of 'Hiddink'."211

This article was published on the $28^{\text {th }}$ of May, three days before the start of the World Cup. Just before the tournament, the media had completed the reversal of its depiction of Guus Hiddink. The journalist's confident assertion that the nickname 'odaeyŏng' is "nowhere to be found" indicated that the negative image of Hiddink was not simply receding, but completely rejected. This rapid transformation was inspired by the Korean team's improved performances on the pitch: at the same time, it seemed likely that the media, independently, determined that criticism so close to the World Cup would likely be received as destructive and unpatriotic, and at odds with the general atmosphere of celebration they wished to promote. Finally, on the $4^{\text {th }}$ of June, Korea defeated Poland 2-0, completing this symbolic transformation. This victory was clear-cut and comfortable (rather than controversial), extremely prominent, and an event in which a great deal of importance and emotion had been invested. It was, after all, the first South Korean victory in

\footnotetext{
211 “tasi ttŭnŭn Hiddink - 'bijŏnŭi sanai'” (Hiddink rises again - ‘a man of vision'). Chosun Ilbo, 28 May 2002.
} Special section. 
the history of the World Cup, and came on the back of humiliating defeats in previous tournaments that had been interpreted as representing the nation's inability to compete on the world stage. It greatly amplified the optimism and respect surrounding Hiddink: through a series of prominent events functioning as catalyst, the media discourse first produced Hiddink the villain, then transformed him into Hiddink the national hero.

\section{The Hiddink Syndrome}

The 'Hiddink Syndrome' emerged in Korean society in late May 2002, and reigned as a dominant trend and news story until Hiddink's resignation in early July. Its primary characteristic was the production of Hiddink not only as an object of admiration, but an object who was admired through consumption. Firstly, Hiddink accrued an abnormally high level of social capital through both the success of his team and the media narrative of his beliefs and behaviour: negative interpretations of Hiddink, or denunciations of the positive interpretations, were nearly completely foreclosed from the public sphere. ${ }^{212}$ Secondly, consumption, whether of media texts or consumer products, was offered as a way to not only learn more about Hiddink, but identify oneself with him. In short, a Hiddink fandom had been born. Throughout June and July, the media invested their resources into every kind of coverage regarding Guus Hiddink:

"During the Poland match, he made 3 'uppercuts' after Hwang Sun-Hong's opener, but was checked by the assistant referee as he approached the field. Then there were two uppercuts after Yoo Sang-Chul's goal: I thought that was it, but when the final whistle blew he was at it again." 213

"If I stand on the sidelines, I can hear conversations between Hiddink and the players. 'Kihyŏni, what are you doing now? Move!' 'Mengbo, very good.' 'ppali ppali [hurry hurry].' Hiddink's orders

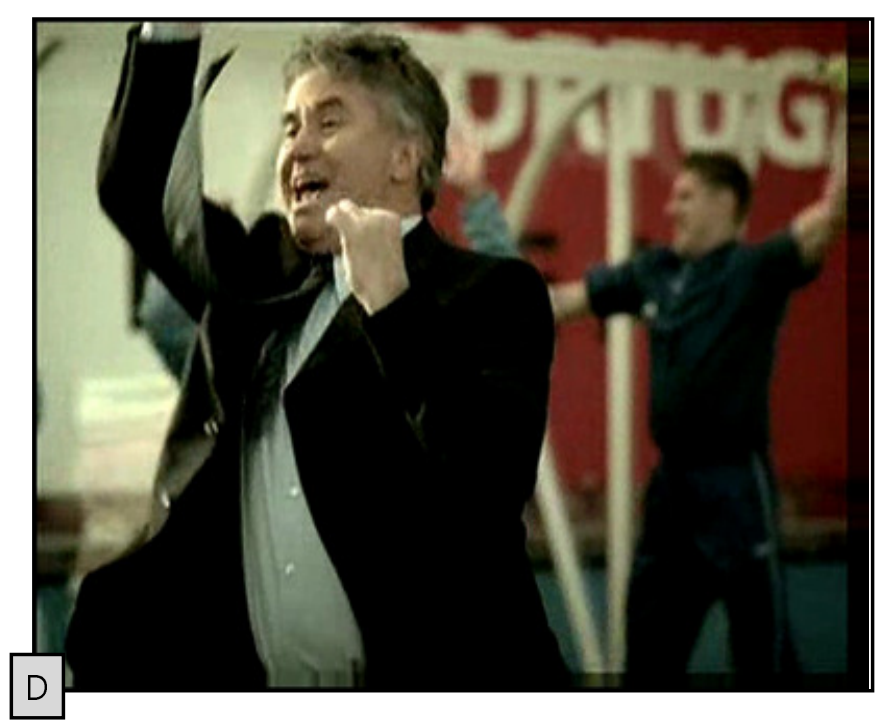

${ }^{212}$ S.H. Lee (2002) p8

213 “'hidingkŭŭi 90bun'” ('Hiddink's 90 Minutes'). Chosun Ilbo, 14 June 2002. Supplements section. 
switch seamlessly between harsh barks and warm praises."1214

His every action and gesture was tracked and reported by the press. Quirks such as his 'uppercut punch' goal ceremony, or his shortened nicknames for Korean players, were fondly reported by the media and extrapolated to form an image of a witty and passionate, as well as driven and diligent, character. ${ }^{215}$ Through both direct and indirect means, the media coverage was building a set of dispositions and signifiers assigned to and constitutive of Hiddink as a public figure. Hiddink's visual identity was, to a large extent, defined by these signs: the thoughtful frown, the firm and outstretched thumbs-up and the 'uppercut' goal celebration created a persona which encouraged respect as well as empathy. During and after the 2002 World Cup, Hiddink featured in several Korean corporate advertisements which made full use of these visual signifiers. One such advertisement opens with a close-up of Hiddink, with his hand on his chin and sporting his 'trademark' frown. The drum beat of the tae-han-min-guk chant and excited narration identifies the setting as a football match, and as the narration builds to a climactic scream to announce a goal, Hiddink is seen celebrating with his uppercut gesture (Photo $D)^{216}$. He calls over the goal scorer in excitement - and into his arms jumps a pizza delivery boy, sporting the company's pizza box. Though references are made to the context of football, it is in fact Hiddink's authentic performance of his own visual identity that provides the advertisement with its commodity value. The process of aestheticisation played a key part in mobilising Hiddink as a commodity situation, by producing him in terms of signifiers which were immediately identifiable, yet nonspecific in their ideological or philosophical disposition. These powerful yet 'emptied' signifiers could then be employed across a wide range of commodities.

This visual identity was supplemented by media narratives of his personal life and history, which mobilised the operative logics of celebrity culture to again maximise Hiddink's potential as a spectacular commodity. Hiddink's 'story' thus emerged through an intersection of familiar narrative models that drew on every available detail from his life:

"Hiddink likes to eat spaghetti. Salad and cheese are a must, as well. He's not especially fond of Korean food, but seems to like a few dishes, like kalbi [ribs]. Oh, and

\footnotetext{
214 “onŭlŭn 4gang kanŭn nal!" (Today we go to the semis!). Chosun Ilbo, 22 June 2002. Supplements.

${ }^{215}$ This blend of characteristics provided an air of sophistication that stood out in a milieu where the nation's heroes were often characterised by more 'rustic' values such as humility and modesty. It could be theorised that Hiddink offered a hero that was respectable as well as 'cool' - a rare blend for Korean media / audiences.

${ }^{216}$ Papa Johns Korea. Unnamed. Seoul: KBS, June 2006.
} 
he is a cappuccino maniac. I'm told he drinks one after every meal."217

"Hiddink's hometown is Doetinchem, a small country town two hours by car from Amsterdam. Though he is now a manager of international reputation, Hiddink was relatively unknown during his playing days. But in Doetinchem, he is a legendary figure. At the age of 21, he began his football career with the local club, De Graafschap." ${ }^{\prime 218}$

These texts identified and produced Hiddink according to the genres of celebrity culture, historical figures, football, nationality and more. Hiddink was being used as a site of a diverse range of discursive techniques which entertained their audience by presenting simultaneously compelling and familiar narratives. Hiddink had become spectacular, in the sense that his body was invested with a rich variety of commodifiable signs and narratives and a great level of cultural capital that granted a sense of legitimacy. Very quickly, other social fields within Korea, ranging from political parties to small businesses, recognised this commodity potential and began to appropriate Hiddink for every kind of product and cause (Photo E, F) ${ }^{219}$ :
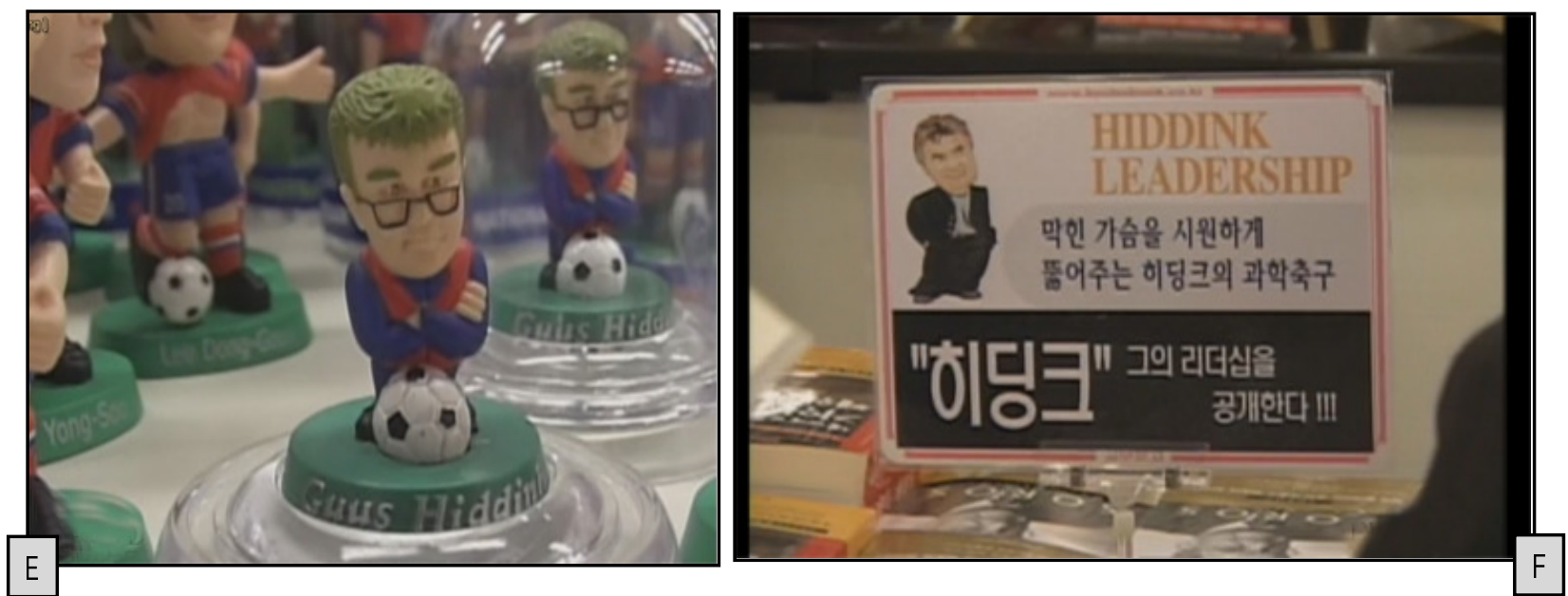

Narrator: $\quad$ "Hiddink Syndrome: this time, it's books. As Team Hiddink reached the semi-finals, men and women are busy reading up on Hiddink."

Interviewee: $\quad$ "This is called 'The Power of Hiddink', it's a Hiddink-related book."

Narrator: "Why are you reading it?"

Interviewee: "Because I'm a fan..." (*laughs*)

Narrator: "Another source of the Hiddink Syndrome is none other than a pub.

217 "kyŏngijang bakŭi hidingkŭ kamdok" (Hiddink off the field). Chosun Ilbo, 18 June 2002. Supplements section.

${ }_{218}^{21}$ "hidingkŭ sinhwanŭn sijaktwaetda" (The Hiddink Legend has begun). Seoul: MBC, June 2002.

219 “Aju tǔkpyŏrhan ach'im” (A very special breakfast). Seoul: MBC, June 2002. 
We are told that following the World Cup, a huge number of people are looking for beer from Hiddink's homeland, the Netherlands...everywhere we look, there's Dutch beer on the table. ${ }^{\prime 220}$

"Guus Hiddink may have left Korea, but he continues to have an impact even in the Financial Services Commission and the Financial Supervisory Service. On the $8^{\text {th }}$, Lee Gŭn-Yŏng, head of the FSS, opened the board meeting by commenting that 'Hiddinkstyle leadership has generated a lot of attention lately', and said that 'in the future, recruitment of FSS auditors will avoid discrimination by region and schools and focus on merit'."'221

The policies of the FSS echoed those of a number of corporate and government entities which all rushed to adapt Hiddink's policies and philosophies as best practice - at once a bid to leverage his cultural capital for their own ends and a possibility for social change. The Hiddink Syndrome had exceeded its original boundaries of sport and Hiddink as an individual. As Hiddink increasingly became an ensemble of discursively produced narratives and signifiers, he became more and more transposable to different fields and contexts. The discourse of Hiddink suggested that if he was a hero and visionary for Korean football, he could be the same for Korean business, politics, and more. The logic of the commodity had, through discursive production, organised Hiddink into modular and transposable narratives, signifiers and dispositions that could be widely disseminated, yet still draw their legitimacy from the social capital attributed to Hiddink as an individual. This was notable because it enabled the production of Hiddink as a champion of Korean nationality. Hiddink's significance was no longer confined to his individual popularity: his character, policies, principles and achievements were used to map out the potential and future of Korean nationality. This is, of course, typical of media-produced national heroes: Zidane and Maradona were also subject to the same techniques of aestheticisation and symbolic identification. ${ }^{222}$ The key difference was that Hiddink was not Korean, and this would need to be resolved somehow.

\section{The Discursive Reconstitution of Hiddink}

At a basic level, the discursive transformation of Hiddink into a national hero effectively inverted

\footnotetext{
220 ibid.

221 "igŭnyŏng hidinkŭshik insa doiphalgŏt" (Lee Geun-Young will adopt Hiddink-style recruitment policy), Donga Ilbo, 9 July 2002. Business section.

${ }^{222}$ See: H. Dauncey (2008) p302 and N. Salazar-Sutil (2008) pp444-8.
} 
the techniques that had been used to produce him as an Other and a villain. Yet this rendered Hiddink's foreignness highly problematic: how could a triumphant celebration of a 'Korean victory' take place while crediting the genius of a foreign manager? After all, as discussed above, the media had a vested interest - both as an explicit policy and following the internal logic of their business - in promoting the narrative of the World Cup as a triumph of Korean nationality. What emerged as a result of these imperatives was a discursive reconstitution of Hiddink. As the 2002 World Cup progressed, Hiddink's role as a public figure became a polyvalent vessel of two different and seemingly contradictory discourses. Hiddink represented the still prevailing superiority of Western scientific method and regimes of truth, while simultaneously affirming the validity of quintessentially 'Korean' virtues. Hiddink, and the particular ways in which the media produced him as a public figure, conflated and converged these two discourses so that far from appearing mutually exclusive, they were read as complementary. This allowed the affirmation of Korean nationality in the context of its relationship with the global, and specifically, the sŏnjin'guk.

In these two discourses, and in their conflation, media coverage of Hiddink positioned the audience in a very specific way. In Foucault's terms, there was a tactical exercise of power enacted through discourse whereby specific relations of power were imprinted on the subject, and the subject was in turn compelled to a perspective that re-affirms the truth value of that relation. ${ }^{223}$ Firstly, the Korean subject was made to acknowledge that the policies, philosophies and methods of sŏnjin'guk that Hiddink brought to the Korean team were valid, and by implication, superior to existing ones practiced before him. In this case, Hiddink performed the role of a benevolent external force, whose knowledge and ability was necessary for the success of the Korean team. During and after the World Cup, the Korean media produced a large number of texts that analysed the 'secret' behind Hiddink's success in such terms:

"Hiddink accurately identified the problems in Korean football that domestic experts could not work out for decades... Using 'sport scientists' who specialised in physiotherapy and sports physiology, he brought science to Korean football. So far, domestic coaches had relied on their eyes to work out how fit a player was."224

"Above all, his man management is a lesson not only for our sports but for our politics and society. Taking his post as the national team manager, he picked players strictly on merit. No player could be guaranteed a place. Players who showed off but couldn't

\footnotetext{
${ }^{223}$ See: M. Foucault (1975 [1979]) pp136-8 and M.Foucault (1975-6 [2003]) pp24-5

224 "hidingkŭ '500il yaksok' chikyŏtda" (Hiddink keeps his '500 days' promise). Donga Ilbo, 15 June 2002. Sports section.
} 
pull their weight were boldly removed... the favouritism by region and school that was so endemic in Korean football did not fly with Hiddink."225

A focus on the basics, a strict merit-based form of player management, scientific methods - all of these factors were described in a way that connected these individual techniques with perceived sŏnjin systems of thought and regimes of truth. These advanced technologies and ways of thinking were described as overcoming flaws seemingly inherent to the Korean way of things. ${ }^{226}$ As the 'Hiddink way' was transposed across various fields and presented as the solution to many of the problems in Korean society, so was this discursive relationship between Korean nationality and sŏnjin systems:

"And really, Hiddink has said that he is only a football coach, but when we see him, we think, if we had a leader like him in our society, then like our football team reached the semi-finals, we [Korean society] too could take a step up. ${ }^{\text {.227 }}$

This discursive transposition means Hiddink was seen not to have simply 'fixed' flaws inherent in the Korean team, but by extension showed the ways in which flaws inherent in Korean society could be resolved as well. For instance, Hiddink's decision to emphasise equality over seniority in the team espoused general ideals of scientific method, equality and meritocracy: in vulgar terms, the implication was that such 'advanced' discipline and logic successfully replaced pre-existing Korean corruption, backwardness and inefficiency. This was not necessarily a full admission of Korean inferiority, but a partially submissive discourse whereby sŏnjin tools were credited with resolving existing problems in Korean nationality. The Korean subject was thus prompted to recognise sŏnjin'guk regimes of truth and to internalise them.

Hiddink's role, however, was not confined to being the representative of 'advanced' technology and values. Even as the Korean subject was provided with the explanation that such tools have provided Korea with victory, he/she was assured that this success was a triumph of Korean virtues and qualities rather than foreign ones. This called to mind a familiar idea in Korea society - 'tongdo sŏgi-ron', or 'The Theory of Eastern Ways, Western Technology', wherein the adaptation of Western methods were justified as tools to be subordinated to an Eastern ideology. ${ }^{228}$ In this way,

\footnotetext{
225 “hidingkŭshik kyŏngyŏnglidŏship" (Hiddink-style management leadership). Chosun Ilbo, 06 June 2002. General section.

${ }^{226}$ Also see: K. K. Han (2003) pp15-7

227 “posŭtŭwŏldŭkŏp taehanmin'guk - hidingkŭnŭn uriege muŏtŭl namgyŏtna" (Post World Cup Dae-hanmin-guk: Hiddink's Legacy). Seoul: KBS, August 2002.

${ }^{228}$ S. Epstein (2000) p29
} 
fears of dependence on the West were assuaged and the viability of an autonomous sovereignty assured. This idea allowed the subject - already founded on a passionate attachment to the idea of Korean nationality and values - to understand the triumph of the World Cup as a wholly Korean achievement, rather than undeservedly granted by external and superior forces. Firstly, Hiddink was normalised and naturalised: previous accusations of his lack of knowledge and concern with Korean society were replaced by articulations of the affectionate relationship between Hiddink and the Korean people, and pejorative descriptions of his foreignness were now excised. ${ }^{229}$

"Uncle Hiddink, you helped the Korean team make the legend of the semi-finals: please stay in Korea until the next World Cup in Germany!

\section{Out of 1,700 children at Taegu's Uksu Elementary School, some 900 wrote letters} thanking Hiddink and sent them to the Korean Football Association by post. These letters were full of each child's thanks for the World Cup, their passion for football, and their love of Hiddink and the players." ${ }^{230}$

In another example, a television program aired a section titled 'I love Hiddink', where the journalists openly expressed their admiration of the Dutchman: the female interviewer boasted of being given a short hug from Hiddink, upon which the other presenters gasped and screamed in jealousy. ${ }^{231}$ In effect, a Hiddink fandom was in operation, whose discourses of admiration and familiarity, combined with exhaustive details of his personal life and characteristics, engineered an erasure of distance and located him as a Korean 'in spirit'. ${ }^{232}$ In addition, media attributed characteristics such as hard work, teamwork, self-sacrifice and bravery to the national team, and marked those qualities as quintessentially Korean. This allowed the Korean team's success to be understood as the success of Korean values and ideologies. Hiddink could then be positioned not as the sole architect of this victory, but a crucial element in a collaborative victory that emerged from Korea's inherent excellence.

"We will never forget today, the day when football told us that Korea is something to be proud of, that Koreans can be proud of their achievement. It was not by luck that

\footnotetext{
${ }^{229}$ S.H. Lee (2002) p8

230 "'hidingkŭ ajŏssi han'guke namajuseyo' uksuch'odŭng 900myŏng kamsap'yŏnji”' ('Uncle Hiddink, please stay in Korea' - letters of thanks from 900 at Uksu Primary School). Chosun Ilbo, 4 July 2002. Regional section.

231 "Aju tǔkpyŏrhan ach'im" (A very special breakfast). Seoul: MBC, July 2002.

${ }^{232}$ This same flexibility in nationalistic discourse would repeat itself two years later, when the German coach Otto Rehhagel was embraced as a hero of the Greeks - a man who "may not be a Greek, but proved to have Mediterranean temperament and ... acted like a Greek". See: Metrosport, 07 July 2004 in R. Tzanelli (2006) p492
} 
Korean football had pushed aside Europe's giants to reach the quarter-finals - it was ability. That's why we can be proud, why we can cheer our hearts out... Trained by Hiddink, the Korean team's fitness, fighting spirit and strategy had become world class... The players trusted in their manager, and the citizens [of Korea] trusted in their team." ${ }^{\prime 233}$

"Today, our players did us proud. In the eyes of the Portuguese players, they would have been small-time players from backwater leagues: but we were superior in not only ability, but organisation, and humiliated the Portuguese, who thought they were the best."234

\section{"Rather than saying that Hiddink has created something new, I think it's much more} important to note that he was able to bring out our unique qualities and strengths. We ourselves were not able to identify these and bring these out, but he could, from an outside point of view.

This kind of discourse anchored subjects in a familiar and reassuring ground that validated their own position as subjects and their passionate attachment to Korea. The media discourse asserted that Hiddink had not conferred on the Korean nation what it did not have or deserve, but merely enabled what was always not only possible but Korea's rightful place. Any potential contradiction between this assertion of superiority and celebration of Hiddink's sŏnjin methods was foreclosed: Hiddink as a foreigner and his foreign influences had been firmly integrated into the grand narrative of Korean national triumph. The discursive normalisation of Hiddink had allowed him to function both as a vessel for Eastern Ways and Western Technology. In that sense, at least, Hiddink was as much 'Korean' as he was 'European'.

Finally, it is worth noting how precarious Hiddink's status as hero was, and how fluid the discourses of Western superiority and Korean legitimacy were. The transformation of discourses involving two of Hiddink's policies over 2001 and 2002 demonstrate how the very factors which were mobilised to villify Hiddink were eventually used to praise him and Korean nationality. Before the 2002 World Cup, the media had focused on criticising two of Hiddink's policies - the prolonged period of experimentation and the refusal to announce a 'best 11' squad, and his insistence on physical fitness training.

\footnotetext{
233 "watnora, poatnora, igyŏtnora" (We came, we saw, we won). Chosun Ilbo, 19 June 2002. General section. 234 "chŏnsul-kyŏng'giunyŏng modu igyŏtda" (Tactics, gameflow - we won it all). Donga Ilbo, 15 June 2002. Sports section.

235 "hidinkŭga namgin'gŏtŭn" (What Hiddink has left for us). Seoul: MBC, July 2002.
} 
"It's pathetic... the hardest thing to understand is his training methods and use of players. It's hard to understand why he insists on physical training when tactical organisation is so badly required, and why he used players that had not been tested on the domestic stage... there's no more time to waste like this." 236

Throughout 2001, the Chosun Ilbo fielded headlines such as "Korean football - tests, tests all day long", and voiced expert opinion that fitness training was 'ruining' players. ${ }^{237}$ But when the national team began to win World Cup matches and perform well, the media was quick to applaud these policies, packaging them into elaborate terms, themselves connoting expertise and excellence:

"[The Korean team,] armed with their 'multi-player' tactic which allowed every player to move freely across the field, drove the opposition into chaos... The answer [to success] lies in their tireless running and bold movement. The flexible use of players and the strict 'power program' training [Hiddink] had employed since last year are now yielding fruit." ${ }^{238}$

This shows that the discourses of Western superiority and Korean legitimacy would perform their productive roles regardless of the rise and fall of Guus Hiddink as an individual. The power of these entrenched discourses was such that Hiddink could only be a facilitator, albeit an extraordinary one. Hiddink did not herald a new era of global community and multiculturalism, as some Korean commentators enthused at the time: rather, the events surrounding his success contributed to a gradual shift towards a more confident Korean mentality in the face of Western normativity, but one still firmly within the discursive contexts of tongdo sŏgi-ron and the underdog.

Both the public figure of Guus Hiddink and the concept of hospitality as a test of nationality were manifestations of the ways in which the Other, and perceptions of the Other, played an active role in determining how Korean nationality was articulated, defined and judged. Despite nationality's

\footnotetext{
236 “chŏnmungadŭl 'hidingkŭho sirhŏmŭn ije kŭman'” (Experts: 'No more experiments, Team Hiddink'). Donga Ilbo, 31 January 2002. Sports section.

237 "hidingkŭwa josŏnilbo, nuga malŭl bwakkwŏtna" (Hiddink and Chosun Ilbo, who did the U-turn?). ohmynews, http://www.ohmynews.com/NWS Web/view/at pg.aspx?CNTN CD=A0000070647\&PAGE CD= (Accessed 23 July 2010)

238 “hidingkŭshik 'p'ojishŏn p'agwe' pitnatda" (Hiddink-style 'position killing' shines). Donga Ilbo, 18 May 2002, Sports section.
} 
inevitable emphasis on its autonomous and sacred nature, it is the symbolic landscape of the global and globalisation that informs the frameworks and standards by which contemporary nationality is constructed and evaluated. In concert with the internal processes of affirmation exemplified by the Red Devils and the street supporters, the story of Hiddink shows that Korean nationality is just a part - if a central one - of a taxonomic system where standards of value, preference and normality are enacted and established through a public discourse that proclaims what Korea is and should become. 


\section{Towards Spectacular Nationality}

The Korean media coverage of the 2002 World Cup demonstrated the intimate relationship between media, spectacle and nationality in contemporary society, and the growing influence that commodity logic plays with regard to our understanding and experience of nationality. It is a relationship that continues to play out across other mega-events, such as the 2008 Beijing Olympics, and indeed on a daily basis in productive processes of banal nationalism. If nationality is a taxonomy of signifiers that continues to perform a normative, subjective function in society, then that taxonomy can be traced to the logic of commodity spectacle and the mechanisms of the mass media.

The case of the Red Devils illuminates the processes by which the media spectacle can discursively generate internal affirmations of nationality. Through a series of consumer products that leverage national subjects' passionate attachment to their nationality, the media appropriate and reproduce aspects of nationality in such a way that it reasserts nationality as a Foucaultian regime of truth and grid of intelligibility. This process calls on subjects to participate in a discursive production of their own nationality: in effect, it constitutes a large-scale, voluntary construction of a collective imaginary that provides the norms and values involved in subjection. At the same time, the media's prominent position in that process inflects these discourses with a spectacular turn. The logic of the spectacle precipitates a transformation of nationality, from an inchoate yet sacred element into a series of consumable objects through which a sense of the sacred may be imparted. Media spectacles, therefore, must now be considered a key context within which nationality is produced and consumed. This pattern has repeated itself in the 2010 World Cup: the vuvuzela, an instrument of indeterminate origin, was made into a symbol of South African culture and commodified as an exotic national souvenir; meanwhile, the attention given to the theatrical antics of Diego Maradona, the Argentinean coach, exemplified the way spectacle is inherently drawn towards the dramatic and aesthetic. We are witnessing an ever more dominant governance by the logic of the spectacle, both over the field of sport and nationality as a system of signs.

The case of Guus Hiddink and the Global demonstrated a double-sided gaze at work in the Korean media: it was a specific relationship between Korean nationality and the Global predicated on its antecedent positioning in a symbolic matrix of nationalities. While some aspects, such as the Korean idea of the sŏnjin'guk, are specific to Korean social conditions, the general relationship remains broadly applicable. Around the world, other nationalities act as linguistic and symbolic 
reference points through which norms can be established in a given society. This Other can be simultaneously an object of condemnation through which the Self is validated, and an ideal by which the Self is pulled towards a revered norm. In other words, every nationality operates within a normative matrix of nationalities. The case of Hiddink also demonstrates how the flexibility of such discourse allows a resilient and persistent exercise of power. The media discourse negotiates the gap between the normative values of nationality in their abstract form and their practical manifestations (even as media discourse itself is one such manifestation). This means that while media discourse can and does challenge existing power relations, this capacity is itself a part of the ways in which the symbolic order of nationality can maintain its authoritative position as the interpretive schema for events and stories.

In summary, the interaction between nationality and spectacle can be identified as a pseudosymbiotic relationship. On one hand, nationality derives social relevance by submitting itself to the spectacle: a familiar instance of this submission is the repackaging of traditional cultural forms, such as dance and painting, into popular entertainment in order to compete for prominence and cultural capital. ${ }^{239}$ In turn, media spectacle begets a sense of legitimacy and capital through its association with and apparent embodiment of 'quintessential' values and ideologies. This is a relationship which is transforming nationality's structures of signification and production. I suggest that over the coming decades, nationality will increasingly be defined, challenged, consumed and played out through the simulations of media spectacles. Following Baudrillard's law, these simulations are now in the process of becoming simulacra; ${ }^{240}$ in other words, they are transforming from a relationship in which media images refer to more traditional tropes and accounts of nationality and play on it, to a situation where one's subjection to a nationality and understanding of other nationalities will refer to and derive from media images themselves. This transformation challenges the continued viability of an 'authentic' national subjectivity, or a subject that is grounded in the idea of one's own nationality as a totality composed of one's lived experience. In its place, the current forms of spectacular nationality hint at the emergence of consumption (of media, or rather the image) as the preeminent method for one's constitution as a subject, the subject's satisfaction of his/her passionate attachment, and finally the attribution of identity. ${ }^{241}$ As processes of globalisation continue to transform our world, the relationship between spectacle and nationality will continue to develop. The economic conditions of the media as an industry, the aesthetic demands of the commodity market, the interplay between media and

\footnotetext{
${ }^{239}$ See: G. Debord (1988 [1990]) pp50-1

${ }^{240}$ See: J. Baudrillard (2001) p138, 142, 148-9

${ }^{241}$ This contrast mirrors the transition from Erfahrung to Erlebnis in industrialising / urbanising societies, as identified by sociologists. See: K. Hetherington (2007) pp96-7.
} 
consumer-subject at the level of discourse - these are the major factors that will determine the exact form of spectacular nationality and its social consequences in the years to come. 


\section{Bibliography}

1509irŭi taejangjŏng: A report on the 2002 FIFA World Cup Korea/Japan in Seoul (The long journey of 1509 days: A report on the 2002 FIFA World Cup Korea/Japan in Seoul). Seoul: Seoul Metropolitan Council, 2003.

Althusser, Louis. Essays on Ideology. London: Verso, 1971 [1984].

Anderson, Benedict. Imagined Communities. London: Verso, 1991.

Appadurai, Arjun. "Introduction: commodities and the politics of value" in The Social Life of Things: Commodities in Cultural Perspective, edited by Arjun Appadurai, 3-63. Cambridge: Cambridge University Press, 1986.

---. "Grassroots Globalisation and the Research Imaginaire" in Globalisation, edited by Arjun Appadurai, 1-22. Durham: Duke University Press

---. Modernity At Large. Minneapolis: University of Minnesota Press, 1996.

Baudrillard, Jean. The Consumer Society: Myths and Structures. London: SAGE, 1970 [1998].

---. Jean Baudrillard: Selected Writings, edited by Mark Poster. Cambridge: Polity Press, 2001.

Bell, Allan. The Language of News Media. Oxford: Blackwell, 2007.

Bhabha, Homi. The Location of Culture. New York: Routledge, 2004.

Bishop, H \& Jaworski, A. "We beat 'em': nationalism and hegemony of homogeneity in the British press reportage of Germany versus England during Euro 2000'. Discourse \& Society 14:3 (2003), 243-271.

Bourdieu, Pierre. Distinction: A Social Critique of the Judgment of Taste. Cambridge: Harvard University Press, 1979 [1984].

---. "Language and Symbolic Power" in The Discourse Reader, edited by Adam Jaworski \& Nikolas 
Coupland, 480-490. London: Routledge, 1999 [2006].

---. Pascalian Meditations. Palo Alto: Stanford University Press, 2000.

---. "Sport and Social Class" in Rethinking Popular Culture: Contemporary Perspectives in Cultural Studies, edited by Chandra Mukerji \& Michael Schudson, 357-372. Berkeley: University of California Press, 1991.

Boyle, Raymond \& Haynes, Richard. Power Play: Sport, the Media and Popular Culture. Harlow: Longman, 2000.

Brady, Anita \& Schirato, Tony. Understanding Judith Butler. London: SAGE, 2011.

Brookes, Rod. Representing Sport. London: Arnold, 2002.

Butler, Judith. The Psychic Life of Power. Stanford: Stanford University Press. 1997.

Cashman, Richard. Sport in the National Imagination. Sydney: Walla Walla Press, 2002.

Cho, Younghan. 'Unfolding sporting nationalism in South Korean media representations of the 1968, 1984 and 2000 Olympics'. Media, Culture \& Society 31:3 (2009), 347-364.

Choi, Yoon Sung. The Panoptic Gaze of Globalization: South Korea and the 2002 World Cup Tournaments. N.p:n.p., n.d.

Chosun-Ilbo World Cup Reporting Team. Kkumŭn iruŏjinda (Dreams come true). Seoul: Chosun-ilbo Publishing, 2002.

Chung, Hongik. 'Government involvement in football in Korea' in "Football Goes East: Business, Culture and the People's Game in East Asia", edited by J. Horne \& W. Manzenreiter, 117-130. New York: Routledge, 2004.

Coombes, Annie E. "The recalcitrant object: culture contact and the question of hybridity" in Colonial discourse / postcolonial theory, edited by Francis Barker, Peter Hulme \& Margaret Iversen, 89-104. Manchester, Manchester University Press, 1994. 
Crary, Jonathan. Techniques of the Observer: On Vision and Modernity in the Nineteenth Century. Cambridge: MIT Press, 1992.

Crawford, Garry. Consuming Sport: Fans, sport and culture. London: Routledge, 2004.

Dauncey, Hugh. 'Quiet contradictions of celebrity - Zinedine Zidane, image, sound, silence and fury'. International Journal of Cultural Studies 11:3 (2008), 301-320.

Dayan, Daniel \& Katz, Elihu. Media Events: The Live Broadcasting of History. Cambridge: Harvard University Press, 1992.

Debord, Guy. The Society of the Spectacle. New York: Zone Books, 1994.

---. Comments on the Society of the Spectacle. London: Verso, 1988 [1990].

Duffy, Enda. "As White As Ours": Africa, Ireland, Imperial Panic, and the Effects of British Race Discourse" in Empire and after: Englishness in postcolonial perspective, edited by Graham MacPhee \& Prem Poddar, 25-56. New York: Berghan Books, 2007.

Epstein, Stephen. "Distant Land, Neighbouring Land" in Complicated Currents: Media Flows, Soft Power and East Asia, edited by Daniel Black, Stephen Epstein \& Alison Tokita., 1-15. Clayton: Monash University ePress, 2010.

Etherington, Kevin. Capitalism's Eye. London: Routledge, 2007.

Fina, Anna De. "Group Identity, Narrative and Self-Representation" in Discourse and Identity, edited by Anna de Fina, Deborah Schiffrin and Michael Bamberg, 351-376. Cambridge: Cambridge University Press, 1966.

Fairclough, Norman. Language and Power. Harlow: Longman, 1989 [2001].

Foucault, Michel. The Care of the Self. New York: Random House, 1984 [1986].

---. Discipline and Punish. The Birth of the Prison. US: Vintage Books, 1975 [1979].

---. Power/Knowledge. Brighton: Harvester Press Ltd., 1972 [1980]. 
---. Psychiatric Power: Lectures at the Collége de France 1973-1974. New York: Palgrave Macmillan Ltd., 1973-1974 [2006].

---. Security, Territory, Population: Lectures at the Collége de France 1977-1978. New York: Palgrave Macmillan Ltd., 1977-1978 [2007].

---. Society Must Be Defended. New York: Picador, 1975, 1976 [2003].

---. The Will to Knowledge. London: Penguin Books, 1976 [1998].

Goffman, Erving. The Goffman Reader, ed. Charles Lemert \& Ann Branaman. Malden: Blackwell, 1997.

---. The Presentation of Self in Everyday Life. New York: Doubleday Anchor Books, 1959.

Giulianotti, Richard. Football: A sociology of the global game. Cambridge: Polity Press, 1999.

Ha, Yoon-Geum. Hanil World Cup Bangsong (Broadcasting the Korea-Japan World Cup). Seoul: Korean Broadcasting Institute, 2002.

Hahm, Chaibong. "Civilisation, Race, or Nation?" in Korea at the Center, edited by Charles K. Armstrong \& Gilbert Rozman et al, 35-50. New York: M.E. Sharpe, 2006.

Han, Kyung-Koo. "The Anthropology of the Discourse on the Koreanness of Koreans". Korea Journal 43:1 (2003), 1-31.

Hargreaves, John. "Constructing Media Sport" in The Sport Studies Reader, edited by Alan Tomlinson, 174-180. London: Routledge, 2007.

Hetherington, Kevin. Capitalism's Eye. London: Routledge, 2007.

"Hidingkŭwa chosŏnilbo, nuga malŭl bwakkwŏtna" (Hiddink and Chosun Ilbo, who did the U-turn?). 2002. Ohmynews.

http://www.ohmynews.com/NWS Web/view/at pg.aspx?CNTN CD=A0000070647\&PAGE CD= (accessed 23 July 2010) 
Horne, John, Manzenreiter, Wolfram. 'Accounting for Mega-Events: Forecast and Actual Impacts of the 2002 Football World Cup Finals on the Host Countries Japan/Korea'. International Review for the Sociology of Sport 39:2 (2004), 187-203.

---. "Global governance in world sport and the 2002 World Cup Korea/Japan" in Japan, Korea and the 2002 World Cup, edited by John Horne \& Wolfram Manzenreiter, 1-26. London: Routledge, 2002.

---. "The World Cup and television football" in Japan, Korea and the 2002 World Cup, edited by John Horne \& Wolfram Manzenreiter, 195-213. London: Routledge, 2002.

Horne, John. Sport in Consumer Culture. Palgrave Macmillan, 2006.

Inthorn, Sanna. 'The death of the Hun? National identity and German press coverage of the 1998 football world cup'. European Journal of Cultural Studies 5:1 (2002), 49-68.

Jong-Young, Lee. "The development of football in Korea" in Japan, Korea and the 2002 World Cup, edited by John Horne \& Wolfram Manzenreiter, 73-88. London: Routledge, 2002.

Joo, Kang-Hyun. Red syndromegwa Hiddink shinhwa (The Red Syndrome and the Legend of Hiddink). Seoul: Joongang M\&B, 2002.

Kang, Chun-Man. Chukgunŏn hangugida (Korea is Soccer). Seoul: Inmulgwa Sasang, 2006.

Kellner, Douglas. Media Spectacle. London: Routledge, 2003.

Kim, Samuel S. "Korea and Globalisation (Segyehwa): A Framework for Analysis" in Korea's Globalisation, edited by Samuel S. Kim, 1-28. Cambridge: Cambridge University Press, 2000.

---. "Korea's Segyehwa drive: Promise versus Performance" in Korea's Globalisation, edited by Samuel S. Kim, 242-281. Cambridge: Cambridge University Press, 2000.

"ko be'in gŏn pulgŭnangmainga kukmininga" (Whose nose has been cut off - the people, or the Red Devils?) 2008. Ohmynews.

http://www.ohmynews.com/NWS Web/view/at pg.aspx?CNTN CD=A0000315075\&PAGE CD= 
(accessed 18 August 2010)

Koh, Eunha. "South Korea and the Asian Games: The First Step to the World" in Sport, Nationalism and Orientalism, edited by Fan Hong, 64-73. London: Routledge, 2007.

Larson, James F and Park, Heung-Soo. Global Television and the Politics of the Seoul Olympics. Boulder: Westview Press, 1993

Lee, Chae-Jin. "South Korean Foreign Relations Face the Globalisation Challenges" in Korea's Globalisation, edited by Samuel S. Kim, 170-195. Cambridge: Cambridge University Press, 2000.

Lee, Hyun-Jung, Cho, Young-Han. "Performing Nation-ness in South Korea During the 2002 KoreaJapan World Cup". Korea Journal 49:3 (2009), 1-28.

Lee, Sung-Hwan. The analets of Hiddink. Seoul: nBook, 2002.

“Lemerre praises Koreans", 2002. BBC.

http://news.bbc.co.uk/sport3/worldcup2002/hi/matches wallchart/friendlies/south korea $v$ fran ce/newsid 2010000/2010505.stm (Accessed 8 July 2010).

MacAloon, John J. "The Theory of Spectacle: Reviewing Olympic Ethnography" in National identity and global sports event, edited by Alan Tomlinson \& Christopher Young, 15-40. New York: State University of New York Press, 2006.

MacPhee, Graham \& Poddar, Prem. "Introduction: Nationalism Beyond the Nation-State" in Empire and after: Englishness in postcolonial perspective, edited by Graham MacPhee \& Prem Poddar, 1-24. New York: Berghan Books, 2007.

Nam Jae-Woo, 17 June 2002, "kŭnalŭi kwanghwamun 2" (Kwanghwamun on that day, Part 2), Dr. Spark's Columns. http://sparkbbs.dreamwiz.com/cgi-

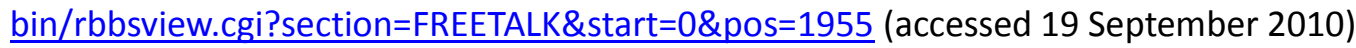

Papa Johns Korea. Unnamed. Seoul: KBS, June 2006.

Park, Hye-Jin. "Understanding Celebrity Endorsers in Cross-cultural Contexts: A Content Analysis of South Korean and US Newspaper Advertising". Asian Journal of Communication 15:2 (2005), 133- 
153.

Perera, Suvendrini. "'Cricket, with a Plot': Nationalism, Cricket, and Diasporic Identities" in $A$ Companion to Cultural Studies, edited by Toby Miller, 509-524. Malden: Blackwell, 2001.

"Potal, yŏnghyangnyŏg/silloedo 'chosŏn' apjirŭda" (Portal races past Chosun [llbo] in influence / reader trust), 2009, Naver.com.

http://news.naver.com/main/read.nhn?mode=LSD\&mid=sec\&sid1=001\&oid=006\&aid $=000003064$ 5\& (accessed 3 June 2010)

Red Devils. "Introduction". http://www.reddevil.or.kr/reddevil/introduction.asp (accessed 16 August 2010).

Redhead, Steve, 'Bourdieu, "Amérique", and the Hyperreal World Cup" in Sport and Postmodern Times, edited by Geneviéve Rail, 221-238. New York: State University of New York Press, 1988.

Roche, Maurice. Mega-events and Modernity. London: SAGE, 2000.

Said, Edward W. "Foucault and the Imagination of Power" in Foucault: A Critical Reader, edited by David Couzens Hoy, 149-155. Oxford: Blackwell, 1986.

Said, Edward W. "Orientalism" in The post-colonial studies reader, edited by Bill Ashcroft, Gareth Griffiths \& Helen Tiffin, 24-27. Oxford: Routledge, 2006.

Salazar-Sutil, Nicolás. 'Maradona Inc: performance politics off the pitch'. International Journal of Cultural Studies 11:4 (2008), 441-458.

Sasaki, Masamichi. "Globalisation and National Identity in Contemporary Society" in Social Change in the Age of Globalisation, edited by Jing Tiankui, Masamichi Sasaki \& Li Peilin, 271-281. Leiden: Koninklijke Brill NV, 2006.

Schirato, Tony. 'Sport, Spectacle and Spectatorship'. New Zealand Journal of Media Studies 10:1 (2007) http://www.nzmediastudies.org.nz/issues.php?issue=3\&title=Volume+10+No.1 
Schlenker, Barry. "Identity and Self-Identification" in The Self and Social Life, edited by Barry R. Schlenker, 65-100. United States: McGraw-Hill. 1985.

Shin, Gi-Wook. Ethnic Nationalism in Korea. Palo Alto: Stanford University Press, 2006.

"Sinmun hogamdo chosŏnilbo irwi--- yŏnghyangnyŏgdo apdojŏk" (Chosun Ilbo most favoured newspaper--- dominant in influence as well), 2009. Chosun-Ilbo.

http://news.chosun.com/site/data/html dir/2009/03/04/2009030402212.html?Dep0=chosunnews \&Dep1=related\&Dep2=related all (accessed 3 June 2010)

SK Telecom. "pulgŭnangma paksup’yŏn" (Red Devils, Clapping Episode). Seoul: KBS, May 2002.

Smart, Barry. The Sport Star: Modern Sport and the Cultural Economy of Sporting Celebrity. London: SAGE, 2006.

"sŭpochŭ mak'et'in sarye yŏngu - KTFwa SKTŭi wŏldŭkŏp mak'et'ingŭl jungsimŭro" (Sports Marketing Study - KTF and SKT's World Cup Marketing). 2008. DC Korea. http://dckorea.co.kr/tt/171 (accessed 22 June 2010).

Sugden, John \& Tomlinson, Alan. "Sport, Politics and Identities: Football Cultures in Comparative Perspectives", edited by Maurice Roche, 169-188. Aachen: Meyer \& Meyer Verlag, 1998.

" 'Sŭponsŏ ŭngwŏndan' pulgunangma, twoejang bak'ŭinŭn dabi upda" (A 'Sponsor Supporters' Group' - the only solution is to send off the Red Devils). 2010. Pressian. https://member.pressian.com/article/article.asp?article num $=40100609090032 \&$ Section $=08$ (accessed 1 September 2010)

Tzanelli, Rodanthi. "Impossible is a fact': Greek nationalism and international recognition in Euro 2004. Media Culture Society 28:4 (2006), 483-503.

Turnbull, James. "Korean Advertising: Just Beautiful Women Holding Bottles?". 2009. The Grand Narrative. http://thegrandnarrative.com/2009/12/07/korea-gendered-advertising/ (accessed 1 September 2010)

van Dijk, Teun A. News Analysis: Case Studies of International and National News in the Press. Hillsdale: LEA, 1988. 
---. "Critical Discourse Analysis" in The Handbook of Discourse Analysis, edited by Deborah Schiffrin, Deborah Tannen \& Heidi Hamilton, 352-366. Malden: Blackwell, 2001.

Wilson, John, "Leisure and Nationalism" in The Sport Studies Reader, edited by Alan Tomlinson, 136-142. London: Routledge, 2007.

Whang, Soon-Hee. "Korea and Japan 2002: Public Space and Popular Celebration", in National identity and global sports event, edited by Alan Tomlinson \& Christopher Young, 214-231. New York: State University of New York Press, 2006.

Whannel, Garry. Fields in Vision. Television sport and cultural transformation. London: Routledge, 1992.

---. "Individual Stars and Collective Identities in Media Sport" in Sport, Popular Culture and Identity, edited by Maurice Roche, 23-38. Aachen: Meyer \& Meyer Verlag, 1998.

"'wŏldŭkŏp ŭngwon chanmul' pulgŭnangma ŭngwon nollan" ('A damper on World Cup support': Controversy over Red Devils' supporting). 2010. Edaily News.

http://www.edaily.co.kr/news/NewsRead.edy?DCD=A00107\&SCD=DA35\&newsid=0215168659300 3032 (accessed 22 June 2010).

Xavier Inda, Jonathan, Rosaldo, Renato. "A World in Motion" in The Anthropology of Globalisation: A Reader, edited by Jonathan Xavier Inda \& Renato Rosaldo, 1-34. Malden: Blackwell Publishing, 2002.

Yi, Soon-Hyung. The Red Devil and Worldcup. Seoul: Seoul National University Press, 2004.

Yoon, Sang-Chul, Ahn, Min-Suk. Sociology of Worldcup. Seoul: Hanul Publishing, 2002.

"Zidane's injury mars gutsy win for France", 2002. The Independent.

http://www.independent.co.uk/sport/football/world-cup/zidanes-injury-mars-gutsy-win-forfrance-652414.html (accessed 8 July 2010).

Zizek, Slavoj. The Plague of Fantasies. London: Verso, 1997. 
In addition to the following, a total of 931 selected articles from the 24 May 2002-15 July 2002 issues of daily newspapers Chosun-Ilbo and Donga-Ilbo, and 32 selected television programs from broadcasters KBS and MBC, 2001-2, were also referenced in this thesis. 